\begin{tabular}{|c|c|c|}
\hline (ATINER) & $\begin{array}{l}\text { The Athens Journal of } \\
\text { Business \& Economics }\end{array}$ & (ATINER) \\
\hline \multicolumn{3}{|c|}{ Volume 5, Issue 4, October 2019} \\
\hline $\begin{array}{l}\text { Front Page } \\
\text { PETER JOI } \\
\text { Stories and }\end{array}$ & $\begin{array}{l}\text { DAPHNE COMFORT } \\
\text { telling in UK Banking }\end{array}$ & \\
\hline $\begin{array}{l}\text { STEPHAN } \\
\text { The Effect } \\
\text { Implicatior }\end{array}$ & $\begin{array}{l}E R \\
\text { ocative Efficiency of Free Markets on } \\
\text { Taxes }\end{array}$ & py and its \\
\hline $\begin{array}{l}\text { EKATERIN } \\
\text { Greek Wor } \\
\text { of Print Im }\end{array}$ & $\begin{array}{l}\text { Mentality towards Fashion Brands at } \\
\text { a }\end{array}$ & Influence \\
\hline $\begin{array}{l}\text { MÁRIA BÁ } \\
\text { Climate Fi } \\
\text { Special At }\end{array}$ & $\begin{array}{l}\text { K } \\
\text { by Multinational Development Bar } \\
\text { n to Europe }\end{array}$ & vith \\
\hline
\end{tabular}




\section{Mission}

ATINER is a World Non-Profit Association of Academics and Researchers based in Athens. ATINER is an independent Association with a Mission to become a forum where Academics and Researchers from all over the world can meet in Athens, exchange ideas on their research and discuss future developments in their disciplines, as well as engage with professionals from other fields. Athens was chosen because of its long history of academic gatherings, which go back thousands of years to Plato's Academy and Aristotle's Lyceum. Both these historic places are within walking distance from ATINER's downtown offices. Since antiquity, Athens was an open city. In the words of Pericles, Athens"... is open to the world, we never expel a foreigner from learning or seeing". ("Pericles' Funeral Oration", in Thucydides, The History of the Peloponnesian War). It is ATINER's mission to revive the glory of Ancient Athens by inviting the World Academic Community to the city, to learn from each other in an environment of freedom and respect for other people's opinions and beliefs. After all, the free expression of one's opinion formed the basis for the development of democracy, and Athens was its cradle. As it turned out, the Golden Age of Athens was in fact, the Golden Age of the Western Civilization. Education and (Re)searching for the 'truth' are the pillars of any free (democratic) society. This is the reason why Education and Research are the two core words in ATINER's name. 
The Athens Journal of Business \& Economics

ISSN NUMBER: 2241-794X- DOI: 10.30958/ajbe

Volume 5, Issue 4, October 2019

Download the entire issue $(\underline{\mathrm{PDF}})$

Front Pages

Stories and Storytelling in UK Banking

Peter Jones \& Daphne Comfort

The Effect of Allocative Efficiency of Free Markets on 287 Entropy and its Implications on Taxes

Stephan Unger

Greek Womens' Mentality towards Fashion Brands and 301 the Influence of Print Images

Ekaterini Drosou

Climate Finance by Multinational Development Banks 329 - with Special Attention to Europe

Mária Bábosik 


\section{Athens Journal of Business \& Economics Editorial and Reviewers' Board}

\section{Editors}

- Dr. Christos Sakellariou, Associate Professor of Economics, Nanyang Technological University, Singapore \& Vice President of Administration and Finance, Athens Institute for Education and Research (ATINER).

- Dr. Gregory T. Papanikos, Honorary Professor, University of Stirling, UK \& President of ATINER.

- Dr. Peter Yannopoulos, Professor, Brock University, Canada \& Vice President of Global Communications, ATINER.

- Dr. Julia Underwood, Professor, Azusa Pacific University, USA \& Academic Member, ATINER.

- Dr. Nektarios Tzempelikos, Senior Lecturer in Marketing, Anglia Ruskin University, UK.

\section{Editorial Board}

- Dr. Panagiotis Petratos, Vice President of ICT, ATINER \& Professor, Department of Computer Information Systems, California State University (Stanislaus), USA.

- Dr. Michael P. Malloy, Director, Business \& Law Research Division, ATINER \& Distinguished Professor of Law, University of the Pacific, USA.

- Dr. Peter Koveos, Head, Accounting \& Finance Research Unit, ATINER \& Professor of Finance, Syracuse University, USA.

- Dr. Sharon Claire Bolton, Head, Management Research Unit, ATINER \& Professor, The Management School, University of Stirling, Scotland.

- Dr. Cleopatra Veloutsou, Head, Marketing Research Unit, ATINER \& Professor of Brand Management, University of Glasgow.

- Dr. John Thanopoulos, Professor of International Business (IB), and Dean, Business and Economics, IST

College \& Emeritus Professor, University of Piraeus, Greece.

- Dr. Elyas Elyasiani, Professor Finance and Economics, Fox School of Business and Management, Temple University, USA.

- Dr. Eduardo Segarra, Academic Member, ATINER \& Professor, Department of Agricultural \& Applied Economics, Texas Tech University, USA.

- Dr. Samuel Seaman, Academic Member, ATINER \& Professor of Decision Sciences, Graziadio School of Business and Management, Pepperdine University, USA.

- Dr. Hercules Haralambides, Academic Member, ATINER \& Professor of Maritime Economics and Logistics, Department of Econometrics, Erasmus University Rotterdam, The Netherlands.

- Dr. Steven Dellaportas, Academic Member, ATINER \& Professor of Accounting, RMIT (Royal Melbourne Institute of Technology) University, Australia.

- Dr. George V. Priovolos, Professor, Iona College, USA.

- Dr. George Saridakis, Director of Doctoral Programmes, Kingston Business School, Kingston University \&

Professor of Small Business and Entrepreneurship, Kingston Hill, Kingston Upon Thames, UK.

- Dr. Liliana Costa, Tutor, Department of Communication and Art, University of Aveiro, Portugal.

- Dr. Gilles Chemla, Academic Member, ATINER \& Professor, Imperial College Business School, UK.

- Dr. Nathalie Homlong, Associate Professor, University College Volda, Norway.

- Dr. Tatyana Boikova, Associate Professor, Business Administration Department, Baltic International Academy, Latvia.

- Dr. Zubin Sethna, Associate Professor of Entrepreneurial Marketing, Regent's University London, UK.

- General Managing Editor of all ATINER's Publications: Ms. Afrodete Papanikou

- ICT Managing Editor of all ATINER's Publications: Mr. Kostas Spyropoulos

- Managing Editor of this Journal: Ms Fani Balaska (bio)

\section{Reviewers' Board}

Click Here 


\section{President's Message}

All ATINER's publications including the e-journals are open access without any costs (submission, processing, publishing, open access paid by authors, open access paid by readers etc) and are independent of the presentations made at any of the many small events (conferences, symposiums, forums, colloquiums, courses, roundtable discussions) organized by ATINER throughout the year. The intellectual property rights of the submitted papers remain with the author.

Before you submit, please make sure your paper meets some basic academic standards, which include proper English. Some articles will be selected from the numerous papers that have been presented at the various annual international academic conferences organized by the different divisions and units of the Athens Institute for Education and Research.

The plethora of papers presented every year will enable the editorial board of each journal to select the best ones, and in so doing, to produce a quality academic journal. In addition to papers presented, ATINER encourages the independent submission of papers to be evaluated for publication.

The current issue of the Athens Journal of Business and Economics (AJBE) is the fourth issue of the fifth volume (2019). The reader will notice some changes compared with the previous issues, which I hope is an improvement. An effort has been made to include papers which fall within in one of the subfields of business and economics.

Gregory T. Papanikos, President

Athens Institute for Education and Research 


\section{Athens Institute for Education and Research}

\section{A World Association of Academics and Researchers}

\section{5 ${ }^{\text {th }}$ Annual International Symposium on Economic Theory, Policy and Applications 29-30 June \& 1-2 July 2020, Athens, Greece}

The Economics Unit of ATINER, will hold its $14^{\text {th }}$ Annual International Symposium on Economic Theory, Policy and Applications, 29-30 June \& 1-2 July 2020, Athens, Greece sponsored by the Athens Journal of Business \& Economics. The aim of the conference is to bring together academics and researchers of all areas of economics and other related disciplines. You may participate as panel organizer, presenter of one paper, chair a session or observer. Please submit a proposal using the form available (https:// www.atiner.gr/2020/FORM-ECO.doc).

\section{Academic Members Responsible for the Conference}

- Dr. Gregory T. Papanikos, President, ATINER \& Honorary Professor, University of Stirling, UK.

- Dr. Chris Sakellariou, Head, Economics Unit \& Associate Professor of Economics, Nanvang Technological University, Singapore.

\begin{tabular}{|l||}
\multicolumn{1}{c|}{ Important Dates } \\
\hline \hline - Abstract Submission: 25 November 2019 \\
- Acceptance of Abstract: 4 Weeks after Submission \\
- Submission of Paper: 1 June 2020
\end{tabular}

\section{Social and Educational Program}

The Social Program Emphasizes the Educational Aspect of the Academic Meetings of Atiner.

- Greek Night Entertainment (This is the official dinner of the conference)

- Athens Sightseeing: Old and New-An Educational Urban Walk

- Social Dinner

- Mycenae Visit

- Exploration of the Aegean Islands

- Delphi Visit

- Ancient Corinth and Cape Sounion

\section{Conference Fees}

Conference fees vary from $400 €$ to $2000 €$

Details can be found at: https://www.atiner.gr/2019fees 


\section{Athens Institute for Education and Research}

A World Association of Academics and Researchers

\section{$7^{\text {th }}$ Annual International Conference on Business, Law \& Economics 4-7 May 2020, Athens, Greece}

The Business, Economics and Law Division (BLRD) of ATINER is organizing its $7^{\text {th }}$ Annual International Conference on Business, Law \& Economics, 4-7 May 2020, Athens, Greece, sponsored by the Athens Journal of Business \& Economics and the Athens Journal of Law. In the past, the six units of BLRD have organized more than 45 annual international conferences on accounting, finance, management, marketing, law and economics. This annual international conference offers an opportunity for cross disciplinary presentations on all aspects of business, law and economics. This annual international conference offers an opportunity for cross disciplinary presentations on all aspects of business, law and economics. Please submit an abstract (email only) to: atiner@atiner.gr, using the abstract submission form (https://www.atiner.gr/2020/FORM-BLE.doc)

\section{Important Dates}

- Abstract Submission: 1 October 2019

- Acceptance of Abstract: 4 Weeks after Submission

- Submission of Paper: 6 April 2020

\section{Academic Member Responsible for the Conference}

- Dr. Gregory T. Papanikos, President, ATINER.

- Dr. Michael P. Malloy, Director, Business, Economics and Law Division, ATINER \& Distinguished Professor \& Scholar, University of the Pacific, USA.

- Dr. David A. Frenkel, LL.D., Head, Law Research Unit, ATINER \& Emeritus Professor, Law Area, Guilford Glazer Faculty of Business and Management, Ben-Gurion University of the Negev, Beer-Sheva, Israel.

\section{Social and Educational Program}

The Social Program Emphasizes the Educational Aspect of the Academic Meetings of Atiner.

- Greek Night Entertainment (This is the official dinner of the conference)

- Athens Sightseeing: Old and New-An Educational Urban Walk

- Social Dinner

- Mycenae Visit

- Exploration of the Aegean Islands

- Delphi Visit

- Ancient Corinth and Cape Sounion

More information can be found here: https://www.atiner.gr/social-program

\section{Conference Fees}

Conference fees vary from $400 €$ to $2000 €$

Details can be found at: https://www.atiner.gr/2019fees 



\title{
Stories and Storytelling in UK Banking
}

\author{
By Peter Jones ${ }^{*}$ and Daphne Comfort ${ }^{*}$
}

The twenty first century has witnessed wide-ranging changes in the banking industry and these changes have brought a number of challenges for customers and employees. Many banks have looked to employ storytelling as one way of trying to help both customers and employees to accommodate these changes and challenges. This exploratory paper looks provide a range of illustrations of the ways in which the UK's leading banks have publicly employed stories on the Internet as part of their external and internal communication programmes and offers some reflections on the role of stories within such programmes. The paper reveals that the UK's five leading banks all publicly employ stories, which address a number of issues including business successes and achievements, customers' experiences, environmental and social commitments, career development, employees' work experiences and the history of banks and their branches. The authors suggest that these themes collectively looked to reinforce the banks' fundamental emphasis on trust, confidence, and customer relationships. At the same time, while the findings of the paper revealed that the stories are exclusively positive and are essentially scripted to cast banks in a favourable light, the authors counsel caution in that there is a danger that such stories may not always be fully representative of a bank's relationships with its customers and employees.

Keywords: UK Banks, Stories, Trust, Confidence, Opportunity, Customer Relationships.

\section{Introduction}

The twenty first century has witnessed wide-ranging changes in the banking industry. World Finance (2018), for example, argued 'the banking industry is undergoing a transformation - an ongoing evolution that is seeing change at every level and in every corner of the planet. It first started some 15 to 20 years ago, with the arrival of the internet. Things have moved on considerably since then: nowadays, cutting-edge technologies and innovative business models, such as artificial intelligence, blockchain, crowdfunding and cloud computing, are among the most important disruptive forces in existence. This burgeoning entrepreneurial ecosystem has helped these new technologies to thrive across a multitude of sectors.' This in turn, has meant that the way banks think about building and maintaining relationships with customers have been changing rapidly and dramatically. Lacerte (2016), for example, suggested that 'as customer demand for new and better digital experiences reaches a fever pitch, the way banks think about building and maintaining relationships with customers is changing - fast. Once the cornerstone of the banking experience, face-to-face

\footnotetext{
*Professor, School of Business and Technology, University of Gloucestershire, UK.

${ }^{\dagger}$ Research Associate, School of Business and Technology, University of Gloucestershire, UK.
} 
interactions with customers are no longer a given. Increasingly, banks are interacting with customers through mobile and online banking transactions.'

At the same time, working practices within banks have changed dramatically. Developments in ICT have brought many changes. On the one hand, they have reduced the need for bank branches and between 2011 and 2014, for example, there was an $11 \%$ decline in the number of jobs within banks in Britain (BBA 2015). Such job losses generate an uncertainty amongst employees and can in turn lead to a lack of commitment and engagement. On the other hand, developments in ICT have demanded new working regimes and practices, and skill sets soon become outdated. Regulatory changes, many attendant on the banking crisis, have brought changes in organisational structures and accountability and in working practices and have led to the need for an empowered and inclusive workplace culture.

Plumbaum (2017) suggested 'banks are under pressure. Fewer and fewer people frequent bank branches to seek advice or use local services. This increasingly eliminates the opportunity to convince customers of one's own offer in direct contact, to establish a basis of trust and to bind them emotionally to their own bank in the long run.' Further Plumbaum (2017) argued 'banks must be able to approach customers emotionally without personal contact and make abstract products and services understandable, tangible and, ultimately, desirable. One means of achieving just this is called storytelling.' More generally, Ryder (2017), writing under the American Marketing Association banner, argued that business leaders must exhibit the interpersonal and business communication skills that allow them to form positive relationships with others' and that 'when it comes to establishing and maintaining those relationships', then 'one communication technique really shines - storytelling.' With these thoughts in mind, this exploratory paper has two objectives, firstly to provide a range of illustrations of the ways in which the five leading banks within the UK have publicly employed stories on their corporate websites as part of their external and internal communication programmes and secondly to offer some reflections on the themes underlying these stories. As such, the paper's contribution is to shine some light on the role of stories in business communications within the UK banking industry. The main body of the paper begins with a short review of the emerging literature on the role of stories in business communication and with a description of the frame of reference and the method of enquiry, which underpins the study. This is followed by illustrations of the range of stories posted on their corporate websites by the selected UK banks, which prompts some critical reflections on the role of storytelling in internal and external business communications of the UK banking industry.

\section{Literature Review: The Role of Stories in Business Communications}

Storytelling - simply defined as the cultural activity of sharing and interpreting experiences - is as old as the human race and has traditionally been used to share, and pass on, knowledge, values, myths, legends, fables and religious 
beliefs, from one generation to another and across geographical space. Initially, storytelling was conducted though drawings and word of mouth communication, though over time the written, and then the printed, word became an increasingly important storytelling medium. Osman (2014), for example, argued 'transcending barriers of language and culture, storytelling is one of the oldest art forms in history, utilised to transmit cultural, moral and complex information in a simple, engaging and meaningful manner.' More recently, the Internet, digital technology and social media have all facilitated and enhanced storytelling and the Internet has been described by the author Neil Gaiman as 'a new version of oral storytelling' (Buzzfeed 2015).

In many ways, stories inform and illuminate all walks of life, and in recent years, there has been increasing recognition of the role of storytelling in the business world. Gill (2015) defined 'corporate storytelling' as 'the process of developing and delivering an organisation's message by using narration about people, the organisation, the past, visions for the future, social bonding and work itself, in order to create new point-of-view or reinforce an opinion or behaviour.' PricewaterhouseCoopers (2017) suggested that 'storytelling is one of the most powerful tools available to effective communicators' and Reissner and Pagan (2013) suggested that 'storytelling in management practices has evidently enjoyed increasing popularity in recent years, as managers have sought to organise both business processes and professional relationships through more symbolic means.'

Within the business world, the role of storytelling has been employed both within companies and organisations and as part of the external communication process. Internally, stories as used, for example, as method of communication with employees, in business leadership, in developing and strengthening employee loyalty, in promoting career progression and staff development opportunities, and in business process management. Gill (2011a), for example, claimed that 'the use of corporate stories by management is an engaging means to building employee loyalty during change through strengthening support and connection with employees for the organisation's culture, policies and leadership.' Gill (2011b) also suggested that 'corporate storytelling can be an engaging and effective means of internal public relations.' At the same time, Career Builder (2016), the international public relations consultancy, argued 'storytelling has become a new tool in recruitment because it makes corporate culture, values and traditions tangible to outsiders' and that 'stories offer companies an original way of communicating information and reaching target groups they otherwise wouldn't reach.'

Externally, companies are increasingly listening to customers' stories, and they use stories in recruiting new employees, in communications about their corporate sustainability commitments and achievements, more generally in raising the reputation and awareness of an organisation among external stakeholders and in branding. Dowling (2006), for example, argued that 'by creating and telling an engaging corporate story, corporate reputation can become a more valuable strategic asset.' In emphasising the virtues of 'learning from customer stories', Gorry and Westbrook (2011) suggested that 'few managers and even fewer 
executives hear customers speak, in their own words and ways' and they counselled 'senior executives to lead by example, to listen to customer stories, to learn from them and to share them with others in the executive suite.' Stories have also become an increasingly important element in branding, and more specifically in conveying what a brand stands for and the provenance of that brand. Singh and Sonnenburg (2012) suggested 'the branding literature has long recognized the power of storytelling to provide meaning to the brand and practitioners have used storytelling to enhance consumers' connections with brands.'

While this literature review is brief, it is identifies the key ways in which stories are seen to be contributing to both internal and external business communication. More specifically, the authors cited a number of quotations in order to illustrate the importance a number of academic researchers attached to the role of stories and storytelling in various arenas of business communication. As such, this review provides a loose structure that is used both to report the findings of the paper and also to inform the discussion. That said, some of the themes raised in the discussion span storytelling for both internal and external audiences and thus there is no direct mapping of the themes from the findings into the discussion.

\section{Frame of Reference and Method of Enquiry}

Banks provide some of the core services of a financial system, including holding deposits, providing payment services and lending to households and companies. The UK banking system is large compared to other developed countries and particularly international in nature: both in terms of the scale of foreign bank activity in the United Kingdom and the scale of the international operations of UK-owned banks. The banking system within the UK is often described as concentrated, Burrows and Low (2015), for example, working out of the Bank of England emphasised 'the banking system in the United Kingdom is particularly concentrated.' That said, Barty and Rickets (2014), writing on behalf of the British Bankers Association argued 'the UK banking system is not just one market' but 'a collection of product markets' and taking these various product markets into account reinforces 'the UK's position as one of the least concentrated sectors in Europe.'

However, for the vast majority of bank customers a small number of large banks represent the public face of British banking. The retail and commercial banking market in Britain is dominated by just five banks. HSBC, Barclays, Lloyds Banking Group, Royal Bank of Scotland Group, and Santander, who account, for example, for over $85 \%$ of all current accounts, though some of the five companies operate more than one banking brand in the UK. The Lloyds Banking Group, for example, includes Lloyds, Bank of Scotland and the Halifax, while the Royal Bank of Scotland Group includes National Westminster and Ulster Bank. A summary of the size and characteristics of the five leading banks is provided in Table 1 . The table reveals some variations amongst the leading banks 
in that while HSBC, the world's seventh largest business, has the largest operating income and total assets of all the five banks, it hadsfewer branches than Barclays and the Lloyds Banking Group. Lloyds Banking Group has the largest share of both current accounts and gross lending while Barclays has the largest number of branches. That said, the numbers of branches and employees of all the five major banks have been declining for some years, and this decline reflects mergers within the industry, cost cutting measures, competition from new entrants, changes in the nature of banking transactions and the growth of alternative means of accessing bank service (Edmonds 2018).

Table 1. The Five Leading Banks in the UK (2017)

\begin{tabular}{|l|c|c|c|c|c|c|}
\hline & $\begin{array}{c}\text { Operating } \\
\text { Income } \\
\text { (£billion) }\end{array}$ & $\begin{array}{c}\text { Total } \\
\text { Assets } \\
\text { (£billion) }\end{array}$ & $\begin{array}{c}\text { Number } \\
\text { of } \\
\text { Employees }\end{array}$ & $\begin{array}{c}\text { Number } \\
\text { of } \\
\text { Branches }\end{array}$ & $\begin{array}{c}\text { Share of } \\
\text { Current } \\
\text { Accounts } \\
(\%)\end{array}$ & $\begin{array}{c}\text { Share of } \\
\text { Gross } \\
\text { Lending } \\
(\%)\end{array}$ \\
\hline HSBC & 11,493 & 1,958 & 225,000 & 1,073 & 12 & 7.1 \\
\hline Barclays & 3,541 & 1,113 & 80,000 & 1,464 & 18 & 9.0 \\
\hline $\begin{array}{l}\text { Lloyds } \\
\text { Banking } \\
\text { Group }\end{array}$ & 3,547 & 812 & 75,000 & 1,210 & 27 & 16.0 \\
\hline $\begin{array}{l}\text { Royal } \\
\text { Bank of } \\
\text { Scotland }\end{array}$ & 2,289 & 738 & 80,000 & 587 & 18 & 12.0 \\
\hline Santander & 1,984 & 1,270 & 190,000 & 945 & 10 & 9.8 \\
\hline
\end{tabular}

Source: Statista 2019a, Statista 2019b, Statista 2019c.

In an attempt to undertake an exploratory review of the ways in which banks were employing stories and storytelling in their public corporate messages, the five banks named above, namely HSBC, Barclays, Lloyds Banking Group, Royal Bank of Scotland Group, and Santander, were chosen for study. The authors conducted an Internet search for information, using the key phrase 'stories and storytelling' and the name of each of the five selected banks. This search, conducted in October 2018, using Google as the search engine, revealed all five selected banks posted what they explicitly labelled as stories but that the number of stories varied, in that HSBC posted 15 stories, while the corresponding figures for Barclays, Lloyds Banking Group, Royal Bank of Scotland Group and Santander were 69, 23, 21 and 44. These stories were listed under different banners including 'Your Stories', 'Success Stories', 'Our History', 'Client Stories' and 'Branch Stories.'

A selection of these stories provided the source material for this paper. In selecting the stories, the authors pursued a simple interpretivist, rather than a systematic approach, which might, for example, have employed content analysis. The authors believe their impressionistic approach is appropriate in an exploratory paper, which looks to illustrate the ways the leading banks employed stories as part of their internal and external communication programmes. Further, the authors included a large number of verbatim quotations in an attempt to capture the details and emotions of the stories as vividly as possible. All quotations are 
numbered in the main body of the paper and listed under Bank Web Sites at the end of the paper. The specific examples and selected quotations drawn from the stories were used for illustrative purposes, with the principal aim being on reviewing how the selected banks employed storytelling in their corporate messages and not on providing a comparative evaluation of the storytelling process. The paper is based on information that was posted on the Internet, and thus in the public domain, and the authors took the view that they did not need to contact the selected banks to obtain formal permission prior to conducting their research. At the same time the authors recognise that their study has its limitations not least that it is based exclusively on bank stories posted on the Internet and on authors' interpretation of these stories.

\section{Findings}

The Internet search revealed that all five of the UK's leading banks publicly posted a range of stories on their corporate websites to address a number of themes. Stories about employees' work experiences, career opportunities and development and employees' work experiences were told principally, bur perhaps not exclusively, for internal audiences. Externally, stories focused on business successes and achievements, the history of banks and their branches, customers' experiences, and social and environmental commitments. Under the banner, 'Our Stories', Barclays (2018a) for example, invited readers to 'discover life at Barclays, from amazing career journeys, big projects and brilliant programmes, to our charity initiatives and community work.' In a similar vein, Lloyds Banking Group listed 'Stories About Businesses' (Lloyds Banking Group 2018a), 'Branch Stories' (Lloyds Banking Group 2018b) and 'Stories About People' (Lloyds Banking Group 2018c) and 'Our Colleague Story' (Lloyds Banking Group 2018d) on its corporate websites and Santander (2018a) posted a number of 'Client Stories.' Messages, photographs, video clips and cameo case studies were widely used in the storytelling process.

Some of the selected banks use stories to promote career development. Under the banner 'Career Development Day Stories: The Big Success' Royal Bank of Scotland (2018a), for example, Marian Kamara, a Senior Project Analyst in Mandatory and Regulation Change with the Royal Bank of Scotland, described working with subject matter experts and business leaders to drive through compulsory change projects. Marian claimed it's a really interesting role because you're always looking at new things. For example, one of my last projects was on Open Banking, which is one of the hottest topics in the banking sector right now' (Royal Bank of Scotland 2018a). Marian argued that the two careers day she had attended had helped her first, to change direction in the bank, and then a year later, to win promotion. In a similar vein, Narinder Kudhail, now a Performance Consultant in Royal Bank's Internal Audit team, previously worked at branch level, and told the story of how her participation in a career development day helped her to progress her career. 
Under the banner 'Our Colleague Story' Lloyds Banking Group (2018d), claimed 'together we make it all possible' and that 'we have a proud heritage of leading the way and that doesn't stop here - through simplification, digitisation and innovation we enable our colleagues to better serve our customers. We are working together to help shape the financial services of the future.' Further, Lloyds Banking Group (2018d) argued 'we have a diverse and inclusive workforce and encourage all colleagues to thrive - whoever you are.' his general message was illustrated with five specific stories, including that of Anthony Francis, a recent graduate, who is 'already helping Britain prosper by working on a range of multimillion IT projects. By making the most of the diverse opportunities available at Lloyds Banking Group, he's built trust, gained confidence and delivered success beyond expectations' (Lloyds Banking Group 2018e). The story continues 'Anthony sees his role as part of a bigger picture, and that's inspired him to achieve and explore more. He's found the support he needed to deliver real change - such as creating agile and flexible systems to help firsttime homebuyers' (Lloyds Banking Group 2018e) Anthony himself commented 'It's good to I know I can continue on this career path and make a success of it. But I know there are loads of alternative options across the business, and that's pretty exciting' (Lloyds Banking Group 2018e).

The banks also used stories to illustrate other features of their working practices and operations. The Royal Bank of Scotland (2018b), for example, offered advice on ways to handle conflict at work. This advice was rooted in the recognition that 'an office is a diverse place', and that 'during your working life you're likely to come into contact with people with all kinds of backgrounds, beliefs and perspectives.' Further, the story suggested 'it shouldn't be a surprise that you'll inevitably run into some disagreements' which 'might be over something as simple as a misunderstanding, or it could be something more substantial, like the direction a project is taking' (Royal Bank of Scotland 2018b). The bank then outlined a number of 'tips for how to handle disagreements at work' (Royal Bank of Scotland 2018b) including addressing disagreements openly rather than ignoring them, putting emotions to one side, listening closely to a colleague's argument, looking to find common ground and concentrating on the facts rather than the person.

Externally, all five of the banks featured business success stories. Santander, for example, posted over forty stories outlining its work with a wide range of clients. One story told how Santander provided tailored cash flow support for Coultons Bread Limited. This wholesale and distribution bakery company, which operates in the North of England, has an annual turnover of $£ 20$ million and cash flow is important because the business is effectively based on large numbers of small quick transactions. Santander took time to get to know the business and its owner, and then proposed tailored solutions that helped to free up cash. The solution was to set up competitive invoice discounting at all the company's sites and to arrange for all the company's drivers to deposit cash, using chip and pin cards, at Post Offices on a daily basis, rather than relying on depositing cash with banks once a week. Coultons' owner, Howard Hunter, argued 'At Coultons, our business is built on relationships, and we have to talk 
to each other on a daily basis to make sure we can deliver to our customers. The relationship we have with our banking partner is just as important' (Santander 2018b). Further, Howard Hunter emphasised 'If something goes wrong, I need to be able to get on the phone and speak to someone who can smooth things over while I sort it out. With Santander, I know that when I do have to ask for something, they are always there' (Santander 2018b).

A number of the stories of Santander's business relationships have a strong international dimension. 'Cornish Sea Salt Grows its global footprint' (Santander 2018c), subtitled 'Cornwall is a land steeped in legend but this salty business story is no myth', for example, uses a three-minute video clip, to demonstrate how Santander helped the company to expand and develop a new product range. The video clip, included pictures of the rugged Cornish coast, pictures of the product and meetings between company executives and senior managers within the bank. In the clip, Mark Sullivan, the company chairman claimed that 'Cornish Sea Salt is now a global brand and our vision had always been to take the product out internationally and to take the brand out to people in a way they can really understand what we have in Cornwall' (Santander 2018c). Paul Julian, a Relationship Director at Santander then explained that once he had recognised the potential of Cornish Sea Salt, it was a case of sharing my enthusiasm with others within the bank and bringing in the right people to assist' (Santander 2018c).

Mark Sullivan further argued 'the great thing about Santander is they're hugely international and their mind set aligns to ours, in terms of walking the talk around the world' (Santander 2018c). Julie Ounsworth, the bank's International Director for the South West, suggested that 'Santander's global presence gave us a deep understanding of local markets all around the world and that enables us to give our customers great opportunities' (Santander 2018c). The company is now exporting to 33 countries and Peter Abel, the bank's Director of Capital Growth outlined how Santander provided the company with a flexible funding structure, which allowed the business to reinvest its profits back into expansion opportunities rather than repaying its debt capital. This in turn, he explained, has facilitated investment in the company's sales and marketing programme, in new production facilities and a new product range for sea therapy. In summary, Paul Sullivan asserted that Santander 'were bringing to bear a hands on perspective of companies around the world and how to work with them' and that they were 'creative, dynamic and proactive and have really been there for us in crucial times' (Santander 2018c).

HSBC (2018a) also relayed a number of 'Success Stories' drawn from its international operations. The story entitled 'Making connections with emerging markets' (HSBC 2018b), for example, told of a client in Europe who had won a contract with a major mobile 'phone business in Latin America, giving exclusive rights for buying, storing, packing and distributing some 50 million mobile phones, and who required major financing. HSBC outlined its solution, namely, 'with our infrastructure and resources in Latin America we were able to support a deal of this scale. We used long-standing connections in this emerging market, working with our Madrid-based HSBC Commercial Banking team, who have strong links with the telecommunications industry' (HSBC 2018b). HSBC 
also reported that the bank was able to secure the necessary funding for the client and gave the client access to cash management, foreign exchange and local banking services. In 'Creating a Dynasty', HSBC (2018c) told the story of how the bank successfully worked with 'one of Asia's wealthiest tycoons who was looking to secure his legacy and create a dynasty' in the face of 'extremely complex succession and family governance issues, with different branches of the family involved in different parts of a business empire that spanned the globe.'

Lloyds Banking Group (2018a) listed 50 'Stories about Businesses'. Under the banner 'Making Dreams Come True' (Lloyds Banking Group 2018f), for example, the bank told the story of Karen Marlow, a customer or 30 years, who took a loan from Lloyds Bank to buy an established business in Lowestoft, along with commercial premises, to 'pursue her dream of owning a hairdressing salon.' The story describes how James Burraway, the bank's local business development manager, took Karen through the application process and provided business advice and support 'on her journey to becoming a business owner (Lloyds Banking Group 2018f). Karen endorsed the support she had received with the following statement 'I've banked with Lloyds for a good few years now and they have been the security behind me when I've needed it. So for my next journey as a business owner, here I am again, with the confidence and support that they have given me to enable me to buy my own business' (Lloyds Banking Group 2018f). James Burraway commented, 'it's incredibly rewarding to be able help people like Karen achieve their dreams' (Lloyds Banking Group 2018f).

HSBC (2018d) posted 'Our Story', a 34-page document illustrated with a large number of images, which outlined the origins and development of the bank. The first half of the document outlines the first century of the bank's activities, from its establishment in Hong Kong in 1865 and its expansion into Japan, India and the Philippines. Moving into more modern times, HSBC described how Hong Kong 'established itself as one of the world's most important centres from the 1960 's onwards' (HSBC 2018d) and how in 1982 HSBC 'closed a deal with the UK's Midland Bank that would finally deliver the European piece of the global jigsaw.' General themes throughout the story are the role of the HSBC (2018d) is 'connecting customers to opportunities' and supporting growth'.

Under the banner, 'Branch Stories' Lloyd's Banking Group (2018a) outlined how it had 'been supporting households, businesses and communities in Britain since its foundation in 1765.' This message was illustrated with stories, accompanied by a photograph, of eight of the bank's longstanding branches including Newcastle, Canterbury, Cambridge, Truro and Stafford. The building, which houses the Grey Street branch in Newcastle, for example, originally dates back to the sixteenth century and first became a bank in 1788, originally to finance the coal mining industry. The story of the Cambridge branch first opened in 1894, and accompanied by a photograph of the interior of the bank, was described, as ' $a$ fine example of neo-gothic architecture' (Lloyds Banking Group 2018g) and was designed by Alfred Waterhouse, who also designed the Natural History museum in London. Lloyds took over the branch in 1904.

Stories about banks' social and environmental contributions and achievements were also prominent. In endorsing Barclay's (2018b) story of Green growth' 
associated with an onshore wind farm in mid Wales, Neil Fleming, the bank's Director of the Infrastructure and Project Finance Team, claimed 'with Barclays' strong track record in supporting renewables projects, we saw our part in this key venture through the provision of debt finance as a natural fit' (Barclays $2018 \mathrm{~b})$. This story concerned the refinancing of a 12-turbine wind farm at Tirgwynt in Powys, North Wales. The wind farm, which has a 25-year life span, will provide renewable energy to power over 20,000 homes, following the agreement of a long-term power purchase agreement with an energy services company. Barclays (Barclays 2017) also told the story of how it is 'unleashing the green economy in Asia. Here, the focus is on Barclay's work with the Unreasonable Group, which looks to serve as a catalyst in helping to support entrepreneurs to create new employment opportunities while also addressing key environmental issues.

Barclay's (2018c) story about developing its 'LifeSkills' programme designed to help young people reach their potential, featured Baroness Karen Brady, a prominent business personality in the UK and Chair of the LifeSkills Advisory Council. Barclays set up the LifeSkills in 2013 to help to address high levels of youth employment, the needs of contemporary businesses and the perceived lack of quality career guidance and work experience in schools. In the following three years, some three million young people took part in the programme. In supporting the programme, Baroness Brady, suggested 'before this programme, there was such a lack of quality work experience for young people and it's a catch-22 because they need to gain the skills for the world of work to be able to get into the world of work. A lot of businesses worry what they'll do with a teenager. But I think they are underestimating young people. There's something hugely rewarding about helping a young person on the path and giving them advice and inspiration to go and find their way' (Barclays 2018c).

Under the headline 'Stories about People', Lloyds Banking Group (2018c) told the story of how the bank is 'Building Britain's Digital Skills' (Lloyds Banking Group 2018h). Here the bank describes how in 2017, 'we've helped more than 708,000 people, small businesses and charities improve their digital skills. They include those who visited one of our Bank of Scotland Digizones, where our colleagues are helping people improve their digital skills' (Lloyds Banking Group 2018h). The Digizones are dedicated spaces located within branches, where our colleagues can speak with and help customers to get online, to use $\mathrm{Wi}-\mathrm{Fi}$, and to outline the benefits of digital, banking online. This story was illustrated with details of how a Bank of Scotland customer, Betty, is 'now banking online for the first time thanks to the free training that was provided in one of our Digizones. Branch colleague, Counter Support, Jamie Kelly helped Betty to get online with regular sessions in the branch using Betty's tablet' (Lloyds Banking Group 2018h). Another of the 'Stories About People' (Lloyds Banking Group 2018c) told the story of Louise Harper, from Lloyds Banking Group's Retail Learning Team, who volunteered to organise digital awareness sessions for people over 50 years of age in a community centre in Swindon. 


\section{Discussion}

All the selected banks employ stories on their corporate websites, as part of their external and internal communication programmes. These stories address a wide variety of specific themes as outlined above, but two sets of issues merit discussion and reflection. Firstly, the ways in which storytelling can help to develop trust and confidence, foster opportunity, forge and enhance relationships and might also be seen to contribute to the selected banks' brands, and secondly the ways in which stories are used by the five leading UK banks

Firstly, many of the stories address the themes of trust and confidence, which are central to banks' relationships with their customers. Skvarciany and Iljins (2015), for example, argued 'trust in commercial banks is considered to be one of the vital factors affecting the success of commercial banks' activities' but suggested 'however the level of trust in banks has decreased during last years and is quite low at present.' The factors underpinning this loss of customer trust and confidence were summarised by Llewellyn (2014) 'the scandals surrounding British banking are well known, the banking crisis, several examples of banks misselling financial products to vulnerable customers, attempts to rig LIBOR and to manipulate the foreign exchange market and mis-treatment of SMEs.'

The stories cited in this paper look to emphasise trust and confidence within the banks' business in a variety of ways locally and the internationally. At the local level, for example, in the story Santander's support for a local bakery company in the North of England, trust and confidence are conveyed in the company's owner's message that 'with Santander, I know that when I to have to ask for something they are always there' (Santander 2018b). In a similar vein, in the Lloyds Banking Group's story about the hairdressing business in Lowestoft, Karen Marlow, argued 'for my next journey as a business owner, here I am again, with the confidence and support that they (the bank) have given me to enable me to buy my own business' (Lloyds Banking Group 2018f). At the international level, trust and confidence in Santander's commitment to Cornish Sea Salt was evidenced by the company Chairman's endorsement that the bank had really been there for us in crucial times' (Santander 2018c). Trust and confidence can also be seen to be reflected in stories about the history of banks and their branches. Here, the stories and the photographs that accompany them were told to emphasise a bank's solidity, its continuity and long standing trading tradition.

Another underlying message within a number of the stories is that of opportunity. This was reflected in both external and internal communications programmes. Externally, the banks were keen to emphasise how they can open up, and extend, a wide range of opportunities for individual and corporate businesses and enable them to rise to the challenges of the changing business environment and of new markets. The theme of opportunity was also clearly reflected in the story of Barclays support for the LifeSkills programme that, offers career guidance and work experience for substantial numbers of unemployed young people. Perhaps more parochially, there are opportunities for retail banking customers to learn new skills, that facilitate easier routine banking transactions while also help to reduce digital exclusion within some parts of society. Internally, 
a number of the stories look to demonstrate the variety of career development and progression opportunities for existing employees within the banks. Here the accent can be seen to be reassuring and motivating employees at times of, often dramatic, change in the working environment within the banking industry.

The selected banks also look to use stories to forge and enhance relationships with existing and potential customers and as such, storytelling can create emotional connections that can strengthen both personal and commercial financial relationships. Credibility and authenticity can be vitally important in developing successful business relationships and the selected banks consistently cited and named specific employees and company owners and executives to emphasise the authenticity and authenticity of their stories. Howard Hunter, the owner of Coultons Bread, for example, claimed 'our business is built on relationships', and argued 'the relationship we have with our banking partner is just as important' (Santander 2018b). More specifically, the banks employed stories that have a strong human dimension and strike a potentially powerful emotive chord. This was reflected, for example, at a personal rather in Karen Marlow's story of the establishment of her new hairdressing business and in the story of Lloyds Banking Group helping Betty to bank online and to develop her digital skills. In this latter case a photograph of Betty holding her I-Pad and smiling, that accompanied the story, looked to emphasise the emotional content of the story and of the relationship between the customer and the bank.

Employing video clips in storytelling can be a valuable way of producing engaging and interesting content, creating an emotional connection between a company and its customers and in developing relationships. Pera and Viglia (2016), for example, argued video storytelling has tremendous power compared to written storytelling as it favours the occurrence of the emotional dimension of consumer relationship experiences transforming individual consumption experiences into collective ones. Further Pera and Viglia (2016) suggested by building relationships among members, customers are building a relationship with the brand.' The Cornish Sea Salt video clip, gives a live voice to the engagement and to the development of the ways of working and business relationship between the company's chairman and senior executives at Santander and allows both parties to give their endorsement to the relationship.

The stories outlined in this paper might be seen as fashionable methods of communication, and as such to mirror the more general interest in storytelling in the business world. At the same time, they can also be seen to contribute to the bank's corporate brands. On the one hand, for example, many of the stories portrayed the banks' success in building relationships, rooted in trust and confidence, with generations of customers and demonstrated how the banks were responding to the needs of their customers. On the other hand, a number of the stories about employees, which were focussed, for example, upon inclusion and staff development opportunities, look to cast the banks in a progressive light. While many of the stories have a strong emotive appeal, they have a clear corporate stamp, and they were designed to enhance the banks' brands and were choreographed to that end by the banks. However, there is an issue of differentiation here, in that branding is widely seen to offer important 
opportunities for companies to differentiate themselves from their competitors and to enable consumers to know what to expect. While the specific details of the stories posted by the UK banks vary, as illustrated earlier in this paper, in many cases some of the underlying messages, for example about the bank's role in fostering business success and in providing career opportunities for employees, are very similar. On the one hand, the underlying similarities between many, but not all, of the banks' stories might be seem, in part at least, to undermine the role of storytelling in branding. On the other hand, such similarities might be seen to be characteristic of the activities and ethos of large banks and, as such, to be a hallmark of their identity.

Secondly, while the findings reveal that the selected banks employ stories that are exclusively positive and were scripted to emphasise their commitments to trust and confidence and to the ways they look to forge successful business relationships and to contribute to social and environmental wellbeing, there are issues surrounding the way storytelling is employed. On the one hand, for example, concerns might be seen to arise when both customers and employees are approached to contribute to, and feature in, bank stories. On the one hand, employees might feel that a refusal to contribute and provide a positive endorsement could prejudice future career progression. Here Maagard (2014), for example, argued that employees must 'not merely be a mouthpiece for the management' and concluded that employees' messages 'put into relief not only the difficult balance between authenticity and promotional force in corporate communication, but also the entanglement of participant roles, in organizations' co-construction of employee stories to serve strategic purposes.' In a similar vein while commercial and corporate customers who have received financial support from a bank may understandably be keen to provide positive messages, they too may be reluctant to comment on any testing episodes in their relationships with their bank. On the other hand, there may be times when both employees and customers are flattered to be asked to contribute their stories for publication on corporate websites. That said, in such circumstances, they might look to enhance and embellish their stories to highlight their personal or business success stories.

There are also issues surrounding the relationship between the 'particular' and the 'general', in that the stories cited in this paper have been chosen and choreographed by the banks to show their business operations in a favourable light. While these stories can be seen to have a strong human interest and powerful emotive appeal, they cannot necessarily be seen to be representative of all the selected banks' dealings and relationships with its customers and employees or of its approach to social and environmental issues. As such, the selected banks can be seen to be building storytelling into their corporate communications with small successful episodes in an attempt to counter the often very critical media coverage of more fundamental and large-scale problems the banking industry has faced in recent years. This is not to call into question the authenticity of the stories cited in this paper, per se, but rather to suggest they should be seen against the wider picture not only of the relationships between banks and their customers but also of the role of banking industry within society. 
More generally, there are concerns about the dominant contemporary approach to storytelling in the business world. Gearin (2018), for example, suggested that 'storytelling has become a loaded term' and that when corporate writers 'engage in storytelling it suggests they are operating at a higher level, following in the grand traditions of Homer, Rowling and Spielberg. Hammond (2017) argued "not only is the term "story" overused in the world of communication, it is also widely misused.' Hammond (2017) argues that in the 'classical oral storytelling tradition' stores 'were never set in stone but forever changing as they were told, influenced by audience reaction and then re-told.' Looking to the future, Hammond (2017) suggested that digital environments not only offer 'accelerated interactivity' but 'still echoes the ancient tradition of storytelling by mirroring the importance of the audience in the process. In both instances and across centuries, the audience and consumers are there to listen, to develop and to share. 'More speculatively, the paper begs the question, to whom are the stories addressed. On the one hand, a number of the stories illustrated in this paper are targeted at the banks' employees and, as such, they form part of staff development and career development reference materials. The banks may also use stories about customers' successful business ventures when promoting their business services and in prospecting for new business clients. However, the level of customers' interest in stories about the banks' social and environmental achievements, let alone in stories about their employees, business successes and histories, remains very much to be seen.

\section{Conclusions}

Many commentators claim that storytelling has grown in importance within the world of business and it is now widely employed in corporate communication. This exploratory paper illustrates some of the ways the leading banks within the UK have used stories as part of their external and internal communication programmes. More specifically, the paper outlines how the banks' stories address a range of themes including business successes, both corporate and individual customers' experiences, career development, employees' work experiences, environmental and social commitments and the history of banks and their branches. The authors suggested that these themes collectively looked to reinforce the banks' more fundamental emphasis on trust, confidence, opportunity and customer relationships. At the same time, while the findings of the paper revealed that the stories are exclusively positive and are essentially scripted to cast banks in a favourable light, the authors counsel caution in that there is a danger that such stories may not always be fully representative of a bank's relationships with its customers and employees.

The authors recognise that the paper has its limitations, as outlined earlier, but they believe that it provides an initial commentary on the ways the leading banks within the UK use storytelling in corporate communications and that, as such, it provides a platform for future research. Looking to the future, such academic research might profitably look, for example, to explore how banks 
identify and develop stories, of if, and how, such stories are effective in building trust, confidence and in forging customer relationships and if, and how, customers' perceptions of, and responses to, such stories influences bank patronage behaviour. Researchers might also explore how banks in other parts of the world, and more widely financial services companies, employ storytelling as part of their external and internal communication strategies.

\section{References}

Barclays (2017) Unleashing the Green Economy in Asia. Retrieved from https://bit.ly/ 2UpYsnf. [Accessed 12 October 2018].

Barclays (2018a) Our Stories. Retrieved from https://bit.ly/2WFyFov. [Accessed 12 October 2018].

Barclays (2018b), Green Growth. Retrieved from https://bit.ly/2UfUTkn. [Accessed 12 October 2018].

Barclays, Karen Brady (2018c) LifeSkills and Inspiring Young People. Retrieved from https://bit.ly/2TSZXpM. [Accessed 12 October 2018].

Barty J, Ricketts T (2014) Promoting Competition in the UK Banking Industry, Retrieved from https://bit.ly/1M8Ny5b. [Accessed 21 October 2018].

BBA (2015) Banking on British Jobs. Retrieved from https://bit.ly/2JXtbUC. [Accessed 30 October 2018].

Burrows O, Low K (2015) Mapping the UK Financial System. Retrieved from https://bit. ly/2WCP3pG. [Accessed 21 October 2018].

Buzzfeed (2015) Neil Gaiman on Storytelling in the Age of the Internet and Other Oddities. Retrieved from https://bzfd.it/2WER5pq. [Accessed 29 June 2018].

Career Builder (2016) The Changing Face of HR: Storytelling in Recruitment. Retrieved from https://bit.ly/2IdRXgC. [Accessed 13 October 2018].

Dowling GR (2006) Communicating corporate reputation through stories. California Management Review 49(1): 82-101.

Edmonds T (2018) Bank Branch Closures, House of Commons Library, Briefing Paper 385. Retrieved from https://bit.ly/2MpM7v6. [Accessed 22 October 2018].

Gearin P (2018) The Storytelling Myth and how Brands Get it so Wrong. Retrieved from https://bit.ly/2CTGFuO. [Accessed 4 January 2019].

Gill R (2011a) Using storytelling to maintain employee loyalty during change. International Journal of Business and Social Science 2(15): 23-32.

Gill R (2011b) Corporate storytelling as an effective internal public relations strategy. International Business and Management 3(1):17-25.

Gill (2015) Why the PR strategy of storytelling improves employee engagement and add value to CSR: An integrated literature Review. Public Relations Review 41(2015): 662-674.

Gorry GA, Westbrook RA (2011) Can you hear me now? Learning from customer stories. Business Horizons 54(6): 575-584.

Hammond N (2017) The Myth of Storytelling in Marketing and why Brands should encourage Story Sharing. Retrieved from https://bit.ly/2FL9oT2. [Accessed 4 January 2019].

HSBC (2018a) Success Stories. Retrieved from https://bit.ly/2Uc0VCp. [Accessed 12 October 2018].

HSBC (2018b) Making Connections with Emerging Markets. Retrieved from https://bit. ly/2I4YwCg. [Accessed 12 October 2018]. 
HSBC (2018c), Creating a Dynasty. Retrieved from https://bit.ly/2WCQAMs. [Accessed 12 October 2018).

HSBC (2018d) Our Story. Retrieved from https://bit.ly/2HWhETY. [Accessed 12 October 2018].

Lacerte R (2016) How Customers Are Rethinking Engagement in the Digital Era. Retrieved from https://bit.ly/2Uq3Bf3. [Accessed 18 October 2018].

Llewellyn DT (2014) Reforming the culture of banking: restoring trust and confidence in banking. Journal of Financial Management, Markets and Institutions 2(2):221-235.

Lloyds Banking Group (2018a) Stories about Businesses. Retrieved from https://bit.ly/ 2CLLXZd. [Accessed 12 October 2018].

Lloyds Banking Group (2018b) Branch Stories. Retrieved from https://bit.ly/2FJBhuD. [Accessed 12 October 2018].

Lloyds Banking Group (2018c) Stories about People. Retrieved from https://bit.ly/2YLa Ld9. [Accessed 12 October 2018].

Lloyds Banking Group (2018d) Our Colleague Story. Retrieved from https://bit.ly/2TR PUkJ. [Accessed 12 October 2018].

Lloyds Banking Group (2018e) Meet Anthony Francis. Retrieved from https://bit.ly/ 2HWlqN1. [Accessed 12 October 2018].

Lloyds Banking Group (2018f) Helping Businesses Start Up and Grow. Retrieved from https://bit.ly/2FSAtVy. [Accessed 12 October 2018].

Lloyds Banking Group (2018g) Cambridge. Retrieved from https://bit.ly/2FKWG6R. [Accessed 12 October 2018].

Lloyds Banking Group (2018h) Building Britain's Digital Skills. Retrieved from https:// bit.ly/2I8b6R9. [Accessed 12 October 2018].

Maagaard C (2014) Employee testimonials: Animating corporate messages through employees' stories. Discourse, Context and Media 6(2104): 22-32.

Osman K (2014) Telling Tales - Storytelling as a Marketing Technique for the Travel, Tourism and Hospitality Industry. Retrieved from https://bit.ly/2WC6NSa. [Accessed 6 April 2018].

Pera R, Viglia G (2016) Exploring how video digital storytelling builds relationship experiences. Psychology and Marketing 33(12): 1142-1150.

Plumbaum F (2017) Storytelling in Finance. Retrieved from https://bit.ly/2u9pykh. [Accessed 18 October 2018].

PricewaterhouseCoopers (2017) Storytelling in Business. Retrieved from https://bit.ly/2F 7e9pq. [Accessed 24 October 2017].

Reissner S, Pagan V (2013) Storytelling in Management Practice: Dynamics and Implications. Abingdon: Routledge.

Royal Bank of Scotland (2018a) Career Development Day Stories: The Big Success. Retrieved from https://bit.ly/2Vembnv. [Accessed 12 October 2018].

Royal Bank of Scotland (2018b) 6 Tips for Handling Conflict at Work. Retrieved from https://bit.ly/2HWlqN1. [Accessed 12 October 2018].

Ryder S (2017) Storytelling as a Business Communication Skill Retrieved from https://bit. 1y/2TTY2RX. [Accessed 20 October 2018].

Santander (2018a) Client Stories. Retrieved from https://bit.ly/2JYW6aZ. [Accessed 12 October 2018].

Santander (2018b) A Helping Hand: Santander Supports Bakery Wholesaler with Tailored Cash Flow Solutions. Retrieved from https://bit.ly/2HWMlbi. [Accessed 12 October 2018].

Santander (2018c) Cornish Sea Salt Grows Its Global Footprint. Retrieved from https:// bit. ly/2TREAVF. [Accessed 2018]. 
Singh S, Sonnenburg S (2012) Brand performance in social media. Journal of Interactive Marketing 12(2012): 189-197.

Skvarciany V, Iljins J (2015) The role of change management in trust formation in commercial banks. Verslas Teorija Ir Practika 16(4): 373-378.

Statista (2019a) Number of branches of leading UK banks as of 2017. Retrieved from https://bit.ly/2CWO0dD. [Accessed 12 February 2019].

Statista (2019b) Market Share of Current Accounts of Leading UK banks in 2014. Retrieved from https://bit.ly/2eJWg59. [Accessed 12 February 2019].

Statista (2019c) Leading UK Banks from 2014 to 2017, By Market Share of Gross Lending. Retrieved from https://bit.ly/2WH3pWe. [Accessed 12 February 2019].

World Finance (2018) How Leading Banks Are Adapting to a Constantly Changing Financial Sector. Retrieved from https://bit.ly/2DAN1hO. [Accessed 11 October 2018]. 



\title{
The Effect of Allocative Efficiency of Free Markets on Entropy and its Implications on Taxes
}

\author{
By Stephan Unger*
}

This article shows that the entropy in a free market is maximized under the allocative efficiency condition. In contrast to that, it is shown that any pre-determined allocation, as it is the case with the collection and distribution of taxes, exhibits a higher probability of minimizing the entropy in the system, where the loss in entropy corresponds to the deadweight loss caused by the excess burden of taxation. The implications are that any chaotic system, or exchange economy, converges to an optimal structure of wealth distribution which maximizes social welfare, in contrast to a randomly, pre-determined distribution of wealth.

Keywords: Entropy, Social Welfare, Deadweight Loss, Perfect Competition, Allocative Efficiency, Taxes.

\section{Introduction}

Adam Smith argued in his seminal work, "The Wealth of Nations" (1776), that the invisible hand of free markets, also known as the first welfare theorem, channels an economic system to reach the correctly required level of production. This required level of production would lead to a system where all resources are optimal allocated.

Arrow and Debreu showed mathematically that free markets reach an equilibrium that is Pareto efficient in allocation (Frank 2003). In the state of a Pareto efficient allocation the entropy of the system is at its maximum.

The notion of entropy was first defined by Carnot in 1803 (see Oliveira 2014) but got adapted by Boltzmann (1866), Gibbs (1878) and Maxwell (1871). The domain of entropy is widely spread among thermodynamics, statistical mechanics, communications and information theory.

Technically, entropy is an extensive state variable that is definable for any material substance or any system. The term "extensive" means that it is proportional to the "size" of the system (like volume or mass) in contrast to an "intensive" variable (like temperature, pressure or density). The term, along with the underlying concept, was introduced by Rudolph Clausius, in the $19^{\text {th }}$ century, to help explain the tendency of temperature, pressure, density and chemical gradients (in fact, all sorts of gradients) to flatten out and gradually disappear over time. The physical law behind the concept is deceptively simple to state: If the system is isolated and closed, so that it does not exchange matter or energy with any other system, its entropy increases with every physical action or transformation that occurs inside the system.

*Assistant Professor, Saint Anselm College, USA. 
Entropy can never decrease in an isolated system or in the universe as a whole. When the isolated system reaches a state of internal equilibrium its entropy is maximized. When two systems interact with each other, their total combined entropy also tends to increase over time. This non-decreasing property, roughly speaking, is known as the Second Law of Thermodynamics, or just the "entropy law". (Ayres 1996)

In information theory, entropy defines the average amount of information produced by a system. In terms of an exchange economy, entropy encompasses all information about all transactions taking place. Considering that any kind of wealth distribution among all agents in this system is based on this information, a state of maximum entropy is desirable. Jaynes (1965) established the principle of maximum entropy which states that "the probability distribution which best represents the current state of knowledge is the one with largest entropy".

The distribution of wealth in a system in which entropy is not maximized means that the distribution does not consider all information embedded in the system, meaning all economic data and variables. Therefore the realized distribution can also not be optimal. According to the second law of thermodynamics, every natural system tends to maximize entropy by increasing its complexity. By adding information to the system, the complexity of the system increases. By sufficient addition of information it can be shown that the system converges to an equilibrium which is optimal.

Such collective mechanisms are e.g. given in a free market environment where each unrestricted transaction taking place serves as an additional input of information, thus optimizing the distribution of wealth in an economy.

There are two ways to determine the collection and distribution of wealth in an economy: Through a social market economy or a free market. The existence of a centralized entity in a social market economy is sufficient but not necessary as it might administer the actual distribution of wealth. Concurrently it is highly inefficient to have the centralized entity decide about the shape of wealth distribution as the probability that this determination is optimal converges to zero with increasing amounts of trials to realize an optimal distribution of wealth.

In contrast to that, a determination of wealth by a free market is based on the system's agent's learning progress through trial and error by the implicit generation of information in every iteration. Robinson (1969) suggests that the seller may be conceived to equate marginal revenue to marginal cost "either by estimating the demand price and the cost of various outputs, or by a process of trial and error".

Therefore learning outcome is evaluated at each distribution step in terms of realized entropy. The probability that the system reaches an optimal status, with respect to its maximum entropy, increases as the number of trials increases as information $N \rightarrow \infty$. This paper shows how the maximization of entropy leads to an optimal distribution of wealth.

I will first give an overview of wealth distribution in a social market environment vs. a free market environment. Then we take a look at the starting conditions necessary to determine the evolution of a tax collection regime with subsequent redistribution of wealth vs. the consolidation of a wealth distribution in a free market. 
After explaining the difference of wealth distribution evolution in both systems, I will explain the concept of entropy maximization in an exchange economy, showing that the quality of a certain realized wealth distribution can be measured by the Kullback-Leibler divergence, even if the optimal distribution is unknown.

Finally, I will analyze centralized taxation and its implications on the deadweight loss, as well as its meaning to entropy in an exchange system. Additionally I will briefly explain the effect of entropy on monopolies.

\section{Wealth Distribution in a Social Market vs. Free Market}

"Prior to the passage of the $16^{\text {th }}$ Amendment in 1913, the United States government funded its operations mainly through excise taxes, tariffs, customs duties and public land sales. The federal government had relatively few expenses compared to today and did not have as much need to raise large amounts of money. The U.S. government was capable of paying for its expenses without an income tax prior to 1913 largely because it had fewer responsibilities. Thomas Eddlem noted in "The New American" that the federal government's responsibilities were limited to basic operational matters and did not include such modern expenses as social insurance programs, welfare programs or agricultural subsidies." (Gabriel 2018)

Article I, Section 9 of the U.S. Constitution states, "No Capitation, or other direct, Tax shall be laid, unless in Proportion to the Census or enumeration herein before directed to be taken." A federal income tax had been enacted in 1861, but was struck down as unconstitutional by the Supreme Court in 1895 because it was found to be a direct tax outside the constitutional constraints. Congress removed these limits in 1913 with the passage of the 16th Amendment, which allows it to impose income taxes specifically, "without regard to any census or enumeration."

The history shows that a social system is able to function without the imposition of personal income taxes. Raising taxes on income lowers purchasing power and the allocation ability. If no taxes were imposed, an agent could determine his own allocation and spending amount towards system relevant factors such as energy, health, social security or pensions.

On the supply side, every agent would observe the realized spending distribution and prices would be set according to the willingness of providing the services requested. The probability that both agents don't equilibrate is initially very high, thus information entropy is very low in this system, because none of the agents knows the other agents adjustment capability.

Negotiation among both agents might lead to a market clearing price. This price might be an exchange price for two commodities, but might also be the exchange between one unit of labor and a commodity. For the system, information entropy would increase. Considering many agents, entropy is very small at this stage with just two agents contributing towards an n-agent's system entropy with just one cleared market price. 
The process of finding a market equilibrium in which some services clear will accelerate as soon as more and more information is revealed on the supply as well as on the demand side, thus entropy increases as the complexity increases, because more and more transaction information has to be considered. As entropy increases, resources are allocated more and more efficient towards relevant and market clearing sectors. All sectors start getting priced fairly which means that wealth starts getting distributed optimally. Moreover, economies of scale will lead to fair pricing, e.g. electricity provider will be able to produce at rates which consumers will be willing to accept.

For a market clearing system with maximum entropy, the probability that the wealth is distributed optimally converges to 1 . Therefore, a system which predetermines the shape of the distribution of the resources just realizes one possible outcome of an N-trial entropy-maximizing system. The probability that this outcome is optimal vanishes with increasing number of trials.

\section{Prerequisites}

\section{Social Market System}

First we need to define the starting conditions for the two systems subject to comparison: The social market exchange economy and the free market economy. In order to run an $\mathrm{N}$-trial exchange system the starting values are set randomly in both systems.

For the social market economy we can assume that a central entity chooses with a certain probability the distribution of wealth $\mathrm{W}$, conditional on the tax collection distribution $\mathrm{T}$, based on available market information such that

$$
P(W \mid T)=\frac{P(T \mid W) P(W)}{P(T)},
$$

provided that $P(W), P(T)>0 . P(T \mid W)$ is hard to evaluate since in a social market environment, the distribution collection of taxes given a certain wealth distribution is exposed and subject to political debate and choice. Therefore we can interpret $P(W \mid T)$ as measure for redistribution of wealth. $P(W)$ is the probability of realization of a certain wealth distribution and $P(T)$ is the probability of a certain tax collection choice.

The tax brackets are subject to change, based on constant updates. The problem a social market system faces is that with increasing number of updates (or iterations), the complexity of the system increases too. This makes it impossible for a central entity, besides political pressure, to update its distribution conditional on all information.

Moreover, the social market system faces this problem in two ways: First, in the determination of the tax collection brackets, and second in the choice of redistribution of the wealth. As we will see, the problem of system complexity turns out to be crucial when it comes to the determination of a socially optimal distribution of wealth. 


\section{Free Market System}

A fundamental requirement for a free market to exist is pure competition. There is general agreement upon concrete circumstances which are prerequisite to the functioning of pure competition. Professor Chamberlin asks: (1) that the number of buyers and sellers be large "so that the influence of any one or several in combination is negligible"; (2) and that an identical good be offered by all the sellers. (Triffin 1947c)

Perfection of the market is identified with the identity of the product. In a free market environment the starting condition is set by buyers and sellers who negotiate about a transaction price. Their negotiation may also be based on given market information, e.g. cost of resource, cost of labor, comparable goods, etc. By realization of transaction prices $A$, the distribution $\mathrm{W}$ is formed successively, where each new transaction price, displays new information, serving as input for the generation of subsequent transaction prices. Thus, the distribution of wealth in a free market environment is based on realized transaction prices:

$$
P(W \mid A(n))=\frac{P(A \mid W) P(W)}{P(A)},
$$

provided that $P(W), P(A)>0, P(A \mid W)$ is generated successively, simply by realization of transaction prices based on the given distribution of wealth, where the starting distribution of wealth might not be equal among the agents due to different endowments of resources, etc.

Since $\mathrm{T}$ and $\mathrm{A}$ are functions of $\mathrm{N}$ iteration steps, both systems might face the same starting conditions, but as we will see, will develop in a different way over time, due to different complexity accumulation.

\section{Entropy Maximization in an Exchange Economy}

Assuming that we denote the unknown optimal distribution of wealth by $\mathrm{X}$ and the approximating distribution, either set by a government, as $Y_{G}$ or determined by the free market, as $Y_{F}$. To determine which distribution approximates better $\mathrm{X}$, we can measure the Kullback-Leibler (KL) divergence. Since the distribution with the least distance to the real distribution is the preferable one, we need to minimize the KL-divergence. By minimizing the KL-divergence between $\mathrm{X}$ and $Y_{G}$, respectively $\mathrm{X}$ and $Y_{F}$ we automatically maximize the entropy of the system as

$$
\begin{aligned}
& \tilde{g}(x)_{N} \rightarrow p(x) \Rightarrow D\left(X \| Y_{G}\right)=-\sum_{x=1}^{n} p(x) \log \left(\frac{g(x)}{p(x)}\right) \rightarrow 0 \text { as } N \rightarrow \infty, \\
& \tilde{f}(x)_{N} \rightarrow p(x) \Rightarrow D\left(X \| Y_{F}\right)=-\sum_{x=1}^{n} p(x) \log \left(\frac{f(x)}{p(x)}\right) \rightarrow 0 \text { as } N \rightarrow \infty,
\end{aligned}
$$


where $\mathrm{X}$ is distributed as $p(x), Y_{G}$ as $\mathrm{g}(\mathrm{x})$ and $Y_{F}$ as $\mathrm{f}(\mathrm{x})$. For large $\mathrm{N}$ we can find the best parameters, which minimize the KL-divergence for both approximating distributions:

$D\left(X \| Y_{G}\right)=-\sum_{x=1}^{M} p(x) \log \left(\frac{g(x ; w)}{p(x)}\right)=-\sum_{x=1}^{M} p(x) \log (\mathrm{p}(\mathrm{x}))$

$-\sum_{x=1}^{M} p(x) \log (\mathrm{g}(\mathrm{x} ; \mathrm{w}))$,

$D\left(X \| Y_{F}\right)=-\sum_{x=1}^{M} p(x) \log \left(\frac{f(x ; w)}{p(x)}\right)=-\sum_{x=1}^{M} p(x) \log (\mathrm{p}(\mathrm{x}))$

$-\sum_{x=1}^{M} p(x) \log (\mathrm{f}(\mathrm{x} ; \mathrm{w}))$,

where $-\sum_{x=1}^{M} p(x) \log (\mathrm{p}(\mathrm{x}))$ is constant.

Therefore the KL-divergence gets minimal if the terms $-\sum_{x=1}^{M} p(x) \log (\mathrm{g}(\mathrm{x} ; \mathrm{w}))$ and $-\sum_{x=1}^{M} p(x) \log (\mathrm{f}(\mathrm{x} ; \mathrm{w}))$, defining the entropy, get maximized. That means that with increasing number of $\mathrm{N}$ transaction prices, the KL-divergence converges to its min.

Thus, a free market environment can always generate and encompass more information than any fixed chosen distribution. This leads to the conclusion that a free market framework approximates more accurate any optimal distribution of wealth than a chosen distribution. The reason lies in the fact that any central entity which chooses a certain distribution can only consider a certain amount of complexity of the system, and is thus limited in gathering all market information. Of course this condition holds just if the rate at which the complexity of the system increases is below the rate at which information is generated.

\section{Efficient Allocation}

To prevent a system without tax payments from a collapse due to social unrest the agents will have to self-organize by efficient allocation of their resources. Since the system consists of learning agents, the system will yield for an equilibrium $i^{*}$ with probability $p_{i^{*}}$, which is Pareto-optimal for all system entities.

For production to happen at marginal cost and equalizing marginal benefit of the consumers, all information has to be known (meaning that the system complexity is at its maximum), thus entropy has to be maximized.

In order to ensure that the system is allocating its resources efficiently by maximizing its entropy it has to satisfy following Shore and Johnson axioms:

- The maximum $p_{i^{*}}$ has to be unique.

- Predictions about the resource allocation should be coordinate invariant.

- Subset independence: If the probability or realization of a resource allocation path $p_{k^{*}}$ is increased and the probability or realization of another resource allocation path $p_{j^{*}}$ is decreased then no other realizations $p_{n^{*}}$ are affected. 
- System independence: The predicted joint probability of realizing two resource allocations must be the product of the predicted marginal probabilities.

Efficient allocation prevails when the marginal cost equal marginal revenue, thus when the quantities $Q^{*}$ are exchanged at an efficient price $P^{*}$. Both functions, $\mathrm{g}(\mathrm{x})$ and $\mathrm{f}(\mathrm{x})$, try to approximate these efficient quantities and prices.

In order to measure if $\mathrm{g}(\mathrm{x})$ or $\mathrm{f}(\mathrm{x})$ better approximates $\mathrm{X}$, we have to take the model which maximizes the likelihood function $\log (L)=\sum_{x=1}^{M} \tilde{p}(x) \log (\mathrm{p}(\mathrm{x} ; \mathrm{w}))$. By using the Bayesian Information Criterion (BIC) we can determine which distribution approximates better the optimal distribution:

$$
B I C=-2 \log (L)+K * \log (n) .
$$

A small BIC is preferred, therefore we are interested in evaluating the performance of $\mathrm{g}(\mathrm{x})$ and $\mathrm{f}(\mathrm{x})$ when $N \rightarrow \infty$ and how the BIC changes:

$$
\begin{gathered}
\frac{d B I C}{d n}=K * \frac{d}{d n}(\log (n)) * \frac{d}{d n} \log (n), \\
\frac{d B I C}{d n}=\frac{K}{n}
\end{gathered}
$$

We can see that the rate at which the BIC information criterion gets minimal is when $N \rightarrow \infty$. Since $\mathrm{g}(\mathrm{x})$ is fixed, $N<\infty$ whereas $\mathrm{f}(\mathrm{x})$ is not fixed, thus allows $N \rightarrow \infty$.

The rate at which the BIC approximately changes is:

$$
\begin{gathered}
P_{1}+\left(\frac{K}{n}\right)\left(Q^{*}-\widehat{Q}\right)=P_{2}+\left(\frac{K}{n}\right)\left(Q^{*}-\widehat{Q}\right), \\
\left(P_{2}-P_{1}\right)=2 * \frac{K}{n}\left(Q^{*}-\widehat{Q}\right), \\
\frac{K}{n}=\frac{1}{2} * \frac{\left(P_{2}-P_{1}\right)}{\left(Q^{*}-\hat{Q}\right)}, \\
d\left(P^{*}, \hat{P}\right) \wedge\left(Q^{*}-\hat{Q}\right)=\left\|\frac{K}{n}\right\|=\left\|-\frac{1}{2} *\left[\log \left(P_{2}-P_{1}\right)+\log \left(Q^{*}-\hat{Q}\right)\right]\right\| .
\end{gathered}
$$

A system without a central entity determining how many resources are levied and subsequently allocated is automatically not able to maximize its entropy.

In such a system, the entropy $H(X)$ is the average information available to all entities which are part of the system:

$$
H(X)=-\sum_{p_{i}} p_{i} \log _{2}\left(p_{i}\right) .
$$


In a system where a central entity determines the resource allocation, the resource allocation is a deterministic function, or in other words, the probability for a random allocation to a certain project to be optimal is zero:

If $p_{i}=0$, then $p_{i} \log _{2}\left(p_{i}\right)=0$ since

$$
\lim _{p \rightarrow 0} p_{i} \log _{2}\left(p_{i}\right)=0 \text {. }
$$

The result implies that the probability for an infinite set of trials to minimize the entropy of the exchange system is higher than for just one pre-determined distribution of allocable resources.

This implies that resource allocation is only efficient in free markets.

Any pre-determined resource allocation is just one possible outcome of any randomly generated resource allocation. Equipping a central agency with the power to impose and levy taxes means adding constraints to the system. If every entity in the system is free to choose its optimal resource allocation with respect to its individual risk preference and utility function, then the aggregate utility is Pareto-optimal. This implies also that such a system would be socially sustainable.

\section{Deadweight Loss}

The deadweight loss (DWL) is defined as the loss in welfare by realization of an equilibrium in an exchange economy under imposed taxes. The socially optimal equilibrium should prevail where marginal cost of production equal the marginal cost of benefit, or when supply meets demand. By the imposition of taxes, the market is just able to realize quantities less than it could produce in the optimum and faces a reduction in the marginal benefit as realized prices for demand side are higher and on the supply side are lower than in the social optimum. The implications of this loss in welfare are well known (Hausman 1981, Case 1999, Hines 1999, Lind and Granqvist 2010). What is interesting is how the rate of complexity reduction, and thus the loss in entropy in a system with a fixed choice of wealth distribution, can explain the size of the deadweight loss:

$$
\begin{gathered}
D W L=\frac{1}{2}\left(P_{2}-P^{*}\right)\left(Q^{*}-\hat{Q}\right)+\frac{1}{2}\left(P^{*}-P_{2}\right)\left(Q^{*}-\hat{Q}\right) \\
=\frac{1}{2}\left(Q^{*}-\hat{Q}\right)\left[\left(P_{2}-P^{*}\right)+\left(P^{*}-P_{1}\right)\right]=\frac{1}{2}\left(Q^{*}-\hat{Q}\right)\left(P_{2}-P_{1}\right), \\
D W L=d\left(P^{*}, \hat{P}\right) \wedge\left(Q^{*}-\hat{Q}\right)=\left\|\frac{K}{n}\right\| \\
=\left\|\frac{1}{2} *\left[\log \left(P_{2}-P_{1}\right)+\log \left(Q^{*}-\hat{Q}\right)\right]\right\|, \\
\Rightarrow D W L=\frac{d(B I C)}{d n} .
\end{gathered}
$$

The welfare loss caused by taxation can therefore be explained by the rate at which information cannot further contribute towards the complexity of the system 
caused by a determined tax brackets and wealth distribution. The difference between a social market entropy and a free market entropy could be interpreted as the opportunity costs of information.

An increase in information, as given in a free markets setup, maximizes the complexity, thus the entropy of the system, and yields to an optimal wealth distribution. But since the complexity of the system increases not to the power of $n$ (the number of information bits), the BIC information criterion tends to get minimal as $N \rightarrow \infty$, where the BIC information criterion measures the KullbackLeibler (KL) divergence between an unknown social optimal wealth distribution and a realized wealth distribution. The reason for the superiority of free markets vs. a pre-determined wealth distribution can be explained by the phenomenon that the increase in information entropy of the system leads to allocative efficiency in the market, which minimizes the KL-divergence, as can be shown and measured by the BIC.

The rate at which the optimal wealth distribution is approximated, respectively the pre-determined wealth distribution is outperformed, corresponds to the rate at which information is added to the system, namely

$$
H(X)=-\sum_{i} p_{i} \sum_{x=1}^{n} p(x) \log (x) \propto \frac{d B I C}{d n},
$$

where $\mathrm{i}$ is a welfare-state and $p_{i}(x)$ is the probability of $\mathrm{x}$ given $\mathrm{i}$ as the previous welfare-state with a given wealth distribution.

\section{Allocation under a Monopoly}

One of the critics of free markets is that they tend to form monopolies that allocate resources non-optimally. Monopoly exists for Mises (1963) when "...the whole supply of the commodity is controlled by a single seller or a group of sellers acting in concert". He further states that if monopoly prices do exist, then they are an "infringement of the supremacy of the consumers and the democracy of the market". Mises also argues that although most monopolies and monopoly prices are made possible by government intervention in the free market (tariffs, licenses, etc.), there are certain instances in which monopoly (and monopoly prices) arise in the unhampered market. He specifically mentions natural resource monopoly, geographic monopoly, limited-space monopoly, and monopoly that might arise because consumers place a "special confidence...on the individual or firm concerned on account of previous experience," as with certain trademarked drugs.

But for Rothbard (1962) there is no social "problem" associated with monopoly in a free market. Monopoly prices cannot be defined logically, let alone established in a free market. According to Kirzner (1973), if markets are always competitive so long as there is freedom to buy and sell, then in a free market there is always competition and never any monopoly.

Paretian analysis defines competition as incomplete when marginal costs are increasing and as complete when they are decreasing. When costs are decreasing the rules of profit maximization induce the firm, not to limit its production at a 
certain level, but to expand it indefinitely. In the opposite case, when increasing marginal costs limit the size of the profit maximizing output, Pareto considers that competition is "incomplete": Each producer finds it advantageous to limit his supply. (Triffin 1947a)

In the case of $N \rightarrow \infty$, under independent trials, we can assume that provided information leads to an efficient usage of resources and therefore to cost reduction in a long term. Relating the existence of monopolies to the reduction of entropy in a system we can measure the loss of entropy again at the same rate as the loss of entropy in the case of the dead weight loss.

An interesting point arises when we consider interdependence in a free market environment: Especially the interdependence of buyers and sellers. When a commodity is sold, sellers and buyers are linked in an immediate way since the price received by the first is disbursed by the latter. (Triffin 1947b) Interdependence between buyers and sellers might arise a bilateral monopoly, which in turn would imply that free markets automatically cause monopolies, which would mean that even in a free markets environment, entropy could not be maximized.

But according to Mises (1963) "monopoly prices emerge as differentiated from competitive prices" could only evolve if the demand for the product is inelastic. Hence, it is not "monopoly" as such that is catallactically relevant for Mises, but only the "configuration" of the demand function and the emergence of monopoly prices. (Mises.org 2005)

Thus, it is important to take a look on the demand side, meaning, if demand stays elastic, entropy can still be maximized even under monopolistic market conditions.

Monopolies don't tend to exist for a long time if exposed to a free market environment, even if entry-levels are high. Events like technology disruptions or evolutionary change in society and methods always threaten monopoly powers as they evolve out of nowhere and might be able to satisfy demand which was not even there before. Furthermore, it is important to remark that industries which have a higher rate of monopoly formation and longer persistence of monopoly power are those industries in which government has a large hand in regulation.

One may argue that monopolies don't even exist if there is no intervention into the market over a certain period of time, as there always exists a competitor in the market. It may only look like a monopoly only under myopically static analysis. Any broader definition of an industry exhibits an increased level of competition. Just narrow enough definitions of brand name products appear to have monopoly characteristics. In a competitive environment and without any governmental intervention, a company would not be able to set a price at a higher level and maintain it for a long period of time since consumers would create demand for products with prices well below the monopoly price. Thus, any realized dead weight loss by a monopoly set price would not prevail and increase entropy over time at the rate (17).

The same holds for subsidized monopolies. Since subsidies are a realization of a conditional probability of attaining a certain distribution, based on available market data at a time $t$, they realize and maintain the dead weight loss by not 
allowing entropy to increase. Due to the limitation of incorporated market information, entropy is capped at a certain level.

In a free market, subsidized monopolies would not exists since there would not exist any kind of subsidy. The subsidy is nothing else than the realization of the dead weight loss, caused by conditional redistribution. It is interesting to note that even subsidized monopolies are challenged by competition. A good example is given by the digital revolution which challenges even subsidized monopolies such as the electricity sector, e.g. by the evolvement of the blockchain technology and the shift towards de-centralized payment systems and residential prosumers. By jumps in technology, surge in innovation and changes in the social mindset it gets hard for subsidized monopolies to justify their subsidy. This shows again that, even if a company appears to be a monopoly, it won't be able to maintain its status as such over a longer period of time without governmental intervention. Exposure to a free market will have a disruptive effect to any monopoly as entropy maximization is the natural process, which breaks up any monopoly structures over time.

\section{Conclusion}

This article stresses the effect of wealth collection and distribution of allocable resources in a social market economy setting in contrast to a free market system. If no constraints are imposed on a system such as a free market economy, it will converge to an equilibrium at which all resources are optimally allocated. This equilibrium can only be realized if the entropy of the system is maximized, meaning that all offered and asked prices as well as transaction prices and quantities subject to the exchange are known and therefore contribute to a maximum complexity of the system.

The maximization of the entropy of a system leads to a convergence of all possible allocation distributions to an optimal distribution which is allocative fully efficient. The convergence process is characterized by an information increase of size $\mathrm{N}$, as well as an $\mathrm{N}$-trial learning process of the system. By identification of the level of entropy, the agents in the system learn in an iterative process how to allocate all available resources such that the entropy of the system is maximized. By maximizing the entropy, the agents automatically maximize the allocative efficiency of the system, which is Pareto-optimal.

In contrast to a free markets setup, any pre-determination of resource allocation, as done in a social market economy, restricts the information generation to let $N \rightarrow \infty$, and thus to maximize the system's entropy. The probability that this specific choice of distribution is maximizing the entropy of the system converges to zero when compared to the multiple adaption process of a free market system which converges to an optimal distribution with certainty.

The Kullback-Leibler divergence allows to measure the distance of a predetermined allocation from its optimal one, even if the optimal distribution is unknown. The relative distance to its optimum is compared to the relative distance of free market setup. The goal is to minimize the BIC information criterion, thus 
minimizing the KL-divergence. Minimizing the KL-divergence means maximizing the systems entropy in terms of its complexity. This can only be achieved by increasing information, which in turn leads to the maximization of entropy.

The probability that imposed taxes on resources for allocating them according to a pre-determined distribution is optimal, converges to zero, compared to the free market setup where information is generated and used to minimize the entropy.

Further, it is shown that the rate of social welfare loss from mis-allocated resources, caused by imposed taxes, equals the rate of accumulating the deadweight loss which occurs in a distorted economy.

The result implies that levying taxes reduces social welfare. This means that the realization of an inefficient allocation of resources leads to a lower level of living standard.

\section{References}

Ayres RU (1996) Eco-Thermodynamics: Economics and the Second Law: 2-3, Fontainebleau, France: NSEAD's Centre for the Management of Environmental Resources.

Boltzmann L (1866) Über die Mechanische Bedeutung des Zweiten Hauptsatzes der Wärmetheorie. [On the mechanic importance of the Second Fundamental Law of thermal theory]. Wiener Berichte, 53, 195-220, Volume I, paper 2, Reissued. New York: Chelsea 1969.

Case KE, Fair RC (1999) Principles of Economics (5th ed). Prentice Hall; Subsequent edition. ISBN 0-13-961905-4.

Frank RH (2003) Microeconomics and Behaviour ( $5^{\text {th }}$ ed). NY: MacGraw Hill.

Gabriel B (2018) How Was the United States Government Funded Prior to Income Tax? Retrieved from DOI=https://pocketsense.com/united-states-government-funded-pri or-income-tax-12769.html.

Gibbs JW (1878) On the Equilibrium of Heterogeneous Substances. Transactions F, The Connecticut Academy Of Arts And Sciences, Vol. 3. New Haven: Tuttle, Morehouse $\&$ Taylor, Printers.

Hausman J (1981) Exact consumer's surplus and deadweight Loss. American Economic Review 71(4): 662-76.

Hines JR (1999) Three sides of harberger triangles. Journal of Economic Perspectives 13(2): 167-188.

Jaynes ET (1965) Gibbs vs Boltzmann entropies. American Journal of Physics 33(5): 391398.

Kirzner IM (1973) Competition and Entrepreneurship. Chicago: University of Chicago Press, 20.

Lind H, Granqvist R (2010) A note on the concept of excess burden. Economic Analysis and Policy, 40(1): 63-73.

Maxwell JC (1871) Theory of Heat (reprinted 2001), ISBN 0-486-41735-2. New York: Dover.

Mises LV (1963) Human Action, USA: Yale University Press, 358-375. 
Mises.org (2005) A Critique of Neoclassical and Austrian Monopoly Theory. Mises Daily Articles. Retrieved from https://mises.org/library/critique-neoclassical-and-austrianmonopoly-theory.

Oliveira ARE (2014) 'The Fundamental Principles of Equilibrium and Motion' of Lazare Carnot. In: A History of the Work Concept. History of Mechanism and Machine Science, Vol 24. Springer, Dordrecht.

Robinson J (1969) Monopoly Equilibrium. The Economics of Imperfect Competition. London: Palgrave Macmillan. ISBN 978-1-349-15320-6.

Rothbard MN (1962) Man, Economy, and State with Power and Market. Ludwig von Mises Institute, Volume II. ISBN: 978-1-933550-27-5, 564.

Smith A (1776) The Wealth of Nations. Modern Library, Sixth Printing edition, Cannan E (January 25, 1994). ISBN-10: 0679424733.

Triffin R (1947a) Monopolistic Competition and General Equilibrium Theory, 58. UK: Cambridge Harvard University Press.

Triffin R (1947b) Monopolistic Competition and General Equilibrium Theory, 124. UK: Cambridge Harvard University Press.

Triffin R (1947c) Monopolistic Competition and General Equilibrium Theory, 133. UK: Cambridge Harvard University Press. 



\title{
Greek Womens' Mentality towards Fashion Brands and the Influence of Print Images
}

\begin{abstract}
By Ekaterini Drosou*
This paper presents the findings on Greek women's viewpoints and opinions in regards to foreign fashion brands and the symbolic meanings they attach to them. Further, a greater and wider knowledge was desired on the effects of fashion magazine brand advertising in the formation to the views and symbolisms formed, through the adoption of a symbolic interactionist framework. Additionally, a greater understanding on the communication process between Greek women and fashion brands advertised in fashion magazines was also of interest, assisting in comprehending Greek women's interpretation of print images and how these images influence fashion brand symbolism. This research provides an understanding towards the general mentality of Greek women towards foreign fashion brands, how they attach meanings to those brands and what influences this process.
\end{abstract}

Keywords: Greek, Foreign Fashion Brands, Symbolism, Meaning.

\section{Introduction}

The Greek market appears to be neglected in consumer identity studies compared to other markets such as the American and British (Karanika and Hogg 2010). The Greek female consumer is an underexplored social group, resulting in a great lack of knowledge in regards to the symbolisms and meanings foreign fashion brands have for them.

This presented a need to achieve a greater understanding on the socially shared meanings and interpretations Greek women give to fashion brands, while adding to an understanding of symbolic consumption as a socially rooted process. Additionally, the discovery of those meanings being socially shaped, shared and created was intended. Exploration of visual social semiotics i.e.: fashion brands in fashion magazine advertisements and how they are 'read', was seen to offer ground for exploring how such images effect the symbolisms, opinions and meanings formed.

Although relatively small, the Greek market was found to have the 'highest proportion of luxury branded items worldwide (Nielsen 2008 as cited in Perry and Kyriakaki 2014) even after the economic crisis. Influenced by the UK and USA (Hatzithomas et al. 2009) through great media exposure, Greek consumers have been found to prefer expensive foreign fashion brands over Greek ones as they are considered to be better in quality (Kamenidoy et al. 2007).

\footnotetext{
*Independent Researcher, Sweden.
} 


\section{Literature Review}

\section{Brand Symbolism and Advertising}

Brands have symbolic meanings (Elliot and Leonard 2004), acting as 'codes' (McCraken and Roth 1989) and 'labels', publicly displayed (Feinberg et al. 1992) to create messages (Auty and Elliot 1998) in order to make presences distinguishable (Piamphongsant and Mandhachitara 2008). Through semiotics an understanding of brand symbolism can be accomplished. Valentine (2003) for instance supports the notion of 'brand mirrors', where expressing self-image is possible is encoded in various semiotic 'languages'.

Through 'fashionable' items consumers fulfil social needs (Waide 1987) and consumers signal their status (Dion and Boraz 2017) as visibility of fashion clothing acts as a form of expression (Petrenko 2015). Brands, such as luxury ones, are purchased to intentionally display brand ownership (Husic and Cicic 2009) and 'show off' (Elliot and Leonard 2004) due to their perceived symbolic value (Tynan et al. 2009). 'Louis Vuitton' for instance enables buyers to differentiate themselves (Hume and Mills 2013) as brand status affects purchasing attitudes (Thanh 2012) with brand differentiation affecting the way brands are perceived, i.e.: suitable for different individuals (Jiang 2004). This displays how the unique brand identity and meaning serves fulfilment of social needs.

Brand personality serves a symbolic function (Klink and Athaide 2012) as its characteristics directly influence its relationship with its owner (Fennis and Pruyn 2007) attempted commonly in 'matching' brands to consumers (Cianfrone et al. 2006) and increase brand awareness (Heckler et al. 2014) through advertising images (Meenaghan 1995).

\section{Social Interaction and the 'Self'}

Greater knowledge in marketing research has been found to benefit from symbolic interactionist theory, as it contributes to a greater understanding of the meanings consumers attach (Rahman 2013) to fashion brands. The theory can be applied to marketing research regarding consumer perceptions on fashion brand meaning, achieved through its understanding and approach to social groups and the meanings attached to objects and individuals (Zhang and Kim 2013). Blumer's principle of individuals acting towards items based on their meaning (Oliver 2012), can be related to fashion brand symbolism and the meanings that brands have for individuals. Further, since fashion is an continuing process (Dean et al. 2016) symbolic interactionism was found to be a beneficial approach since via empirical discovery through social interaction, individuals come to realise the real world (Handberg et al. 2015).

The 'self' is believed to be prominent in relation to literature concerning symbolic consumption (Millan and Reynolds 2014), as self-perception is achieved through social interaction with self-values primarily taken from one's family while growing up and being socialised. Meaning is influenced through social interaction (Handberg et al. 2015) and Mead's (1934) ideas can offer a useful basis to gain 
greater insight into how visibility of products is used by individuals in order to communicate something about themselves to others in a symbolic manner (Lee 1990). The 'self' is seen as 'a reflexive process of social interaction' (Callero 2003), considered to play a big role, as images in the media are studied and their effects upon individuals, who often appear to compare themselves to the models in the media (Martin and Peters 2005).

\section{Conceptual Framework}

Figure 1 presents the conceptual thinking, identifying the determinants perceived to shape the meanings, viewpoints and opinions of fashion magazine advertising via a process of consumer interpretation. Magazines provided the opportunity to show participants luxury brands, which are not so commonly seen in other media such as Instagram. The framework derived from advertising and brand research literature.

Figure 1. The Process of Consumer Interpretation of Fashion Brand Magazine Advertising

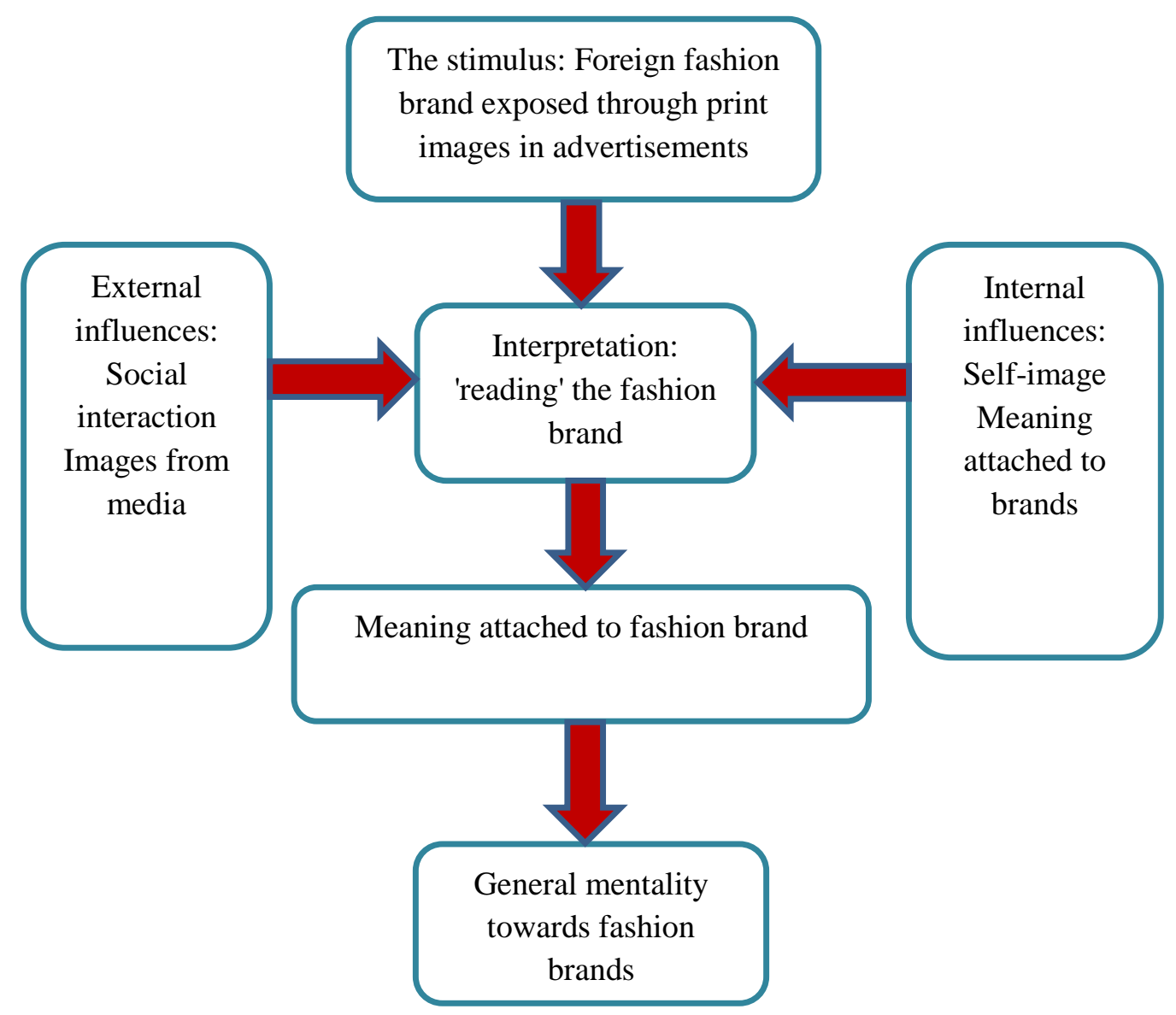




\section{Methodology}

In order to discover in-depth the perceptions, opinions and process involved when 'reading' print magazine advertisements, a qualitative research method was seen as more appropriate. Providing participants with space was crucial in order for them to analyse and go into detail regarding their experiences and relationship to foreign fashion brands and the symbolic meanings they attach to them.

In order to discover how print images are 'read' elaboration was necessary in order to discover print image influences in the attachment of brand meaning. The lack of presupposition adopted in symbolic interactionism assisted the study in terms of the method used, as it was of interest to discover rather than test hypothesis. According to Benzies and Allen (2001),the roots of social interaction in psychology and the approach to truth as 'fluid' by pragmatists, offers the understanding that participants need to be provided with room and comfort to do so, both literally and metaphorically such as the time available and privacy.

The view of individuals experiencing constant adaptation to a social world (Jeon 2004) made it a suitable lens for comprehending and expanding knowledge on Greek women in relation to foreign fashion brands. The approach contributes to the greater understanding of meaning attachment (Rahman 2013) to fashion and the 'world' (Fine 1993) constructed through interaction (Jussim 1991).

\section{Methods}

The research included two phases, interviewing Greek women living in Athens (who came from various cities), different in each phase. A purposive sample was used, of women which the researcher had access to, using a snowball technique when more participants were needed. The Thomas (2006) framework was used to analyse the data, as it assists the 'thick description' in qualitative research while 'making sense' of excessive amounts of data without losing the rich and valuable content. Through close reading and evaluation of text, descriptions of meanings, links and categories can be identified (Thomas 2006).

1) Phase One: 20 semi-structured interviews of 20-40 year old women. The wide age gap was used in order to identify any patterns related to age.

The phase focused on participant views regarding fashion brands and the symbolic meanings they attach to them and their wearers. They were asked to talk about their relationship with fashion brands and fashion magazines. In the last part of the interview, 20 foreign fashion brands were randomly picked from various Vogue issues (Greek edition). Participants were asked to describe the brands and the women wearing those fashion brands.

Although a plethora of significant findings emerged, it was considered further data would provide an opportunity to illuminate on the influences fashion advertising images within magazines have towards the meanings, views and 
opinions held towards fashion brands. Therefore a Phase Two was seen as appropriate.

2) Phase Two: 10 open-ended interviews, $30-35$ years old. As age in Phase One did not appear to be a determinant in influencing brand perception, meaning or views held by the participants, the mean age from Phase One sample was chosen.

Firstly, participants were given the opportunity to talk about their relationship and views towards fashion brands, the brands they wear and what influences their dress choice.

Secondly, in order to discover more on how print images in advertisements are 'read', and affect brand meaning and symbolism, six advertisements were chosen randomly from Greek editions of Vogue, Elle and Glamour, also randomly picked. The brand name was hidden and participants were asked to talk about the advertisement, how they felt looking at it, guess the brand and item may be advertised and how they would describe it. When participants felt they had nothing more to say about the image, the brand name was revealed and participants had a chance to talk about their views on the advertisements and whether they had changed after knowing the brand.

\section{Findings}

The close study of the transcripts demonstrated patterns forming in a quite 'vivid' manner where the frequency of common responses resulted in the identification of key themes and their association to self, meaning and interaction.

Self, meaning and interaction, important principles in symbolic interactionism (Mead 1934) were found highly relevant to the research, acting as 'pillars', accommodating the key themes identified. Table 3 presents the pillars and key themes relevant to them, all interrelated to each other.

Table 3. Key Themes and the Three Pillars

\begin{tabular}{|l|c|c|c|}
\hline \multirow{2}{*}{ Key theme } & \multicolumn{3}{|c|}{ Pillars } \\
\cline { 2 - 4 } & Self & Meaning & Social interaction \\
\hline $\begin{array}{l}\text { Brands as symbols of self and } \\
\text { socioeconomic status }\end{array}$ & $\mathrm{X}$ & $\mathrm{X}$ & $\mathrm{X}$ \\
\hline Body image and weight & $\mathrm{X}$ & $\mathrm{X}$ & $\mathrm{X}$ \\
\hline $\begin{array}{l}\text { Understanding of the term 'brand' and its } \\
\text { role in projection }\end{array}$ & $\mathrm{X}$ & $\mathrm{X}$ & $\mathrm{X}$ \\
\hline $\begin{array}{l}\text { Shared brand symbolism and brand } \\
\text { copies }\end{array}$ & & $\mathrm{X}$ & $\mathrm{X}$ \\
\hline Shared viewpoints & $\mathrm{X}$ & $\mathrm{X}$ \\
\hline $\begin{array}{l}\text { Advertising as a means of brand } \\
\text { communication and its influences }\end{array}$ & $\mathrm{X}$ & $\mathrm{X}$ & $\mathrm{X}$ \\
\hline $\begin{array}{l}\text { Shared brand meaning, categorisation } \\
\text { and coding }\end{array}$ & & & $\mathrm{X}$ \\
\hline Style influences & & & \\
\hline
\end{tabular}




\section{The Three Pillars}

\section{'Self'}

'Self' was found to be important as self-image plays a big part in the way fashion brands and their advertisements are understood and evaluated. The 'self' is important in how Greek women understand and position themselves and others within their social group. The 'self' can be associated to how fashion advertisements are 'read', related to studies on the 'accepted' or 'ideal', promoted by advertising. Participants tended to compare themselves to what they thought they should look like in order to be able to wear fashionable clothes like the models in the advertisements, expressing weight to be a key determinant in their dress style.

Symbolic interactionist ideas on the social construction of reality are related in regards to how participants perceived their own and other women's bodies, influenced by fashion advertising images.

\section{Meaning}

A shared understanding was displayed in the definition of 'brand', interpreted to mean expensive, known and/or luxury, with certain brands attached to specific symbolic meanings, overall linked to higher socio-economic class. Brand meaning also differs according to the brand, with brand symbolism appearing an important determinant when shopping, as brands are linked to certain symbolic meanings, overall linked to higher socioeconomic status.

\section{$\underline{\text { Interaction }}$}

Shared viewpoints are born through social interaction, interaction with print images in advertisements and interaction with fashion brands. A rich amount of data emerged in regards to the role of interaction in sharing a 'reality' related to brand meanings, categorisation and coding of fashion brands and their wearers.

Advertising acts as a means of communication influencing style equally significant to the influence of social 'norms', concepts of the 'accepted' and 'appropriateness'. A command of social conduct and social standards exist in terms of the 'acceptable' or 'appropriate' way to dress according to the occasion.

\section{The Key Themes}

\section{Brands as Symbols of Self and Socioeconomic Status}

A sense of social fulfilment is gained through fashion brands, suggesting brands act as social tools, offering or inferring social status. Specific symbolic meanings are attached to specific fashion brands commonly associating specific brands to certain individuals. Brands are considered to reflect the socioeconomic status or profession, e.g.: 'X' brand for a doctor, lawyer and 'upper class' supporting 
the notion of consumption being a result of status or means to portray status (O'Cass and Frost 2002).

Luxury or expensive brands were expressed to display 'good taste' or 'superiority' in comparison to cheaper clothes like 'Zara' as 'you get what you pay for' with a tendency in believing such brands influence employment prospects:

'Instantly the other person looks and says 'he has money' and it influences them a lot'.

'Brands' were commonly seen as attractive or tasteful, while non-branded items were not. Foreign fashion brands were considered to have better quality than Greek ones with an apparent shared view of certain fashion brands. 'Louis Vuitton' for instance was frequently mentioned to refer to an expensive, quality brand and 'Chanel' thought to be worn by elegant women.

Shared and common viewpoints suggest social interaction influences meaning creation and attachment to brands, displayed in the common references of how others see brands and how society has taught them to understand fashion brands. Although women wearing fashion brands were seen as 'show-offs', participants acknowledged they do so in order to project a certain image and gain status.

Dress style for different occasions might hold implications for 'acceptable' spending on fashion items as certain brands were perceived suitable for specific social situations:

'I try to dress youthfully on the one hand but appropriately for each occasion I attend, where I am, with whom'.

Although no specific brands were mentioned to be associated with lower socio-economic classes, cheaper fashion brands were not mentioned when talking about 'brands' and socio-economic status:

'You can't always follow fashion and when you aren't in that upper, higher class, and are lower to middle, you step back'.

Specific language and words were used to attach meanings to brands and connotations of words emerged as a way of sharing meaning in relation to fashion. A tendency to speak as outsiders was apparent when commenting on fashion trends, excluding themselves as being affected.

\section{Body Image and Weight}

Weight appeared to be a big issue for Greek women, determining dress choice, style and self-value in terms of size, rather than health:

'when I lose weight it (dress style) does change. I feel more comfortable, wear more colours, I may buy a dress, a skirt, that I think may suit me, while when I'm heavier, I don't feel like shopping'. 
'A piece of clothing cannot be worn by someone who's $50 \mathrm{~kg}$ and another whose 90kg' [Interviewer]: Why? 'It loses its beauty'.

Advertising was expressed to promote 'role models' where Greek women try to look like the models and overall views were overwhelmingly negative. Occasionally, the wider social impacts were mentioned, supporting shops sell clothes for slimmer women, of an 'accepted' style promoted by the fashion industry. The fashion industry and advertisements were seen to have negative effects as:

'It doesn't take into account the average Greek woman because the average Greek woman isn't $1.90 \mathrm{~cm}$ and $45 \mathrm{~kg}$ - no way!

A 'Replay' advertisement (Phase Two) displayed how weight was expressed in many different ways but all related to the model's figure comparing it to theirs. It is demonstrated at this point, how fashion advertisement images can make women feel self-conscious as models appeared to prompt participants' selfreflection.

Participants raised the issue of women dwelling on the possible negative aspects of her figure, weight or size if her perception of her body shape fails to resemble the models.

Participants believed the advertisement attempted to create links between the product and the image of the wearer:

'Put on these jeans and look like that'.

suggesting the intended message aimed at creating a desire to try to look like the model linking fashion items and female identity (concept of 'femininity'):

'because the jeans are skinny, they bring out femininity' (Participant10).

\section{'Brand' and Its Role in Projection}

Language plays an important part, displayed in how 'brand' has a specific, shared meaning, referring to 'eponyma' clothes, (known, expensive or luxury brands) with only 2 participants asking for clarification of what is meant by brand when asked. The findings support the relevance of symbolic interactionism by the similar and common use of the term, displaying the importance of language and how it is shared. It has been displayed that language is important in effective communication within social groups and references to certain brands reinforced the meaning of the term. Brands were seen to act as social tools used to 'show off' and 'project' with 'Louis Vuitton' frequently mentioned as a brand purchased with the intention to stand out within the social group. Brand ownership in general was identified to infer status or success in responses such as: 
'Inside me, I know it doesn't mean anything, but we all want to have a known brand in our wardrobe'.

Such responses suggest internal psychological conflicts within the participant as although admitting 'inside' her the item does not mean anything, at the same time she desires a known brand in her collection, a view clashing with a previous response of brands bought only with a purpose to 'get noticed'.

Brands act as social tools purely for social or psychological reasons, perceived to be purchased for social projection. The importance of brand symbolism was highlighted frequently, relating to the brand's utility and functional value. Greek women understand others based on their brand choices as fashion brands act as markers of the wearer's socioeconomic status. A tendency exists in perceiving higher socioeconomic status positive and aspirational with fashion brands acting as an assessment tool in the 'reading' of the wearer's socioeconomic status.

A fashion brand can be a force, strong enough, to create conflict between personal feelings and consumption patterns and wearing brands was expressed to be a result of being:

'placed in our minds that we'll look better, be better'.

Branded items were implied to have meanings to others if they generate positive or admirable attention with similar sentiments associating fashion brands and status and brands being status symbols. Women purchasing brands they could not afford, were perceived 'pretentious', aiming at displaying a certain economic status unreflective of their current status.

\section{$\underline{\text { Shared Brand Symbolism }}$}

Meanings and symbolism are attached to fashion brands with the belief the brand rather than the actual product sells, displayed particularly when referring to handbags. Brand visibility was considered important as brands act as markers of status, holding specific, strong, symbolic meaning.

\section{'If there was no label on the bag they would never buy it'.}

This was most vividly displayed in the shared understanding of brand meaning and symbolism of brand copies were very strong views were expressed on what fake brands represent to them, commonly using negative terms and attitudes towards their wearers. Even in cases the copy was identical or unnoticeable to the original brand, it was perceived to relate to lower status and taste, contrary to what original brands displayed. Wearing a 'fake' was seen unacceptable even if the wearer belonged to the socioeconomic group initially thought to wear the original.

Wearing fakes was partly objected to as it confused 'reading' the wearer's social status. A copy was seen incapable of living up to the associations of genuine brands ('quality' and 'good'). Wearing them was seen as an 'illegitimate' way 
through which wearers place themselves on specific social categories they did not belong to, a pretentious attitude and attempt to appear something unreflective of reality. Wearers were perceived as 'fake', even 'impostors', creating misconceptions and projecting inauthentic images of their socioeconomic status (associated to Ryan, Eisend and Schuchert-Guler 2006).

Complex views on the relationship between fashion style and brands appeared as participants expressed individuals do not need to spend a lot of money to dress smartly (and were indifferent to spending a lot of money to wear brands) but would not buy a copy. Copies and their wearers were attached to negative terms such as 'fake' and genuine fashion brands were attached to positive symbolic meanings and chosen to wear on special occasions. Participants often expressed how they would be 'afraid' to be discovered to wear fakes by others, more than the bad quality of the copy clearly displaying the importance of projection in social:

'It would bother me if they told me. Of course, if I had bought it, I would be aware of it, but still I would mind... so I avoid doing so'.

The participant was more worried of 'getting caught' wearing copies rather than wearing them displaying the importance of interaction regarding fashion brands.

Overall, social interaction was discovered to be important for the 'self' and the way Greek women understand themselves through it:

'A copy it will show'... visually and ...ok...in my mind.

Even if it doesn't show I will know it's a copy'.

Even when others could not tell, in her mind, copies represented something quite negative, suggesting deeper issues to those of quality. Such issues appeared to originate from the participants' environment with certain views as a result of social interaction, which might reflect how beliefs have been shaped by others:

'If I decide to buy something, e.g.: 'Louis Vuitton', I'll buy the original.

Yes, I'll spend half my salary on it but, if not, I'm not going to buy something fake! I don't want to show off something that isn't authentic'.

Issues around authenticity and the 'self' were discovered by the frequent use of 'show off' proposing an intentional attempt of status display, implying a conscious process of self-projection. Although 'show off' was used in a negative tone when speaking of others, a tendency was apparent in using the same term to explain the reasons behind purchasing fashion brands themselves, displaying double standards. 'Showing off', displayed high relevance in relation to projection, even though participants often denied their desire to 'show off' themselves. This was contradictory to their apparent consumption and views towards fashion brands, linked to beliefs of fashion brands able to make statements. Genuine brands are important in projecting status with purchasing motivated solely in displaying possessions to others. 
Although copies were seen as an attempt to appear something unreflective, participants failed to realise (or acknowledge) spending money they did not have on a item, does indeed display the same behaviour they criticise, as the item is not truly 'affordable' to them. They therefore act in a similar manner to the one they criticise as 'fake', attempting to appear something unreflective. When the participant above was probed, she admitted she was doing so, expanding:

'But the person seeing you doesn't know you have spent half your salary'.

suggesting a greater interest in how Greek women project themselves to others than being true to their personal values (e.g.: being a fake is negative).

\section{$\underline{\text { Shared Viewpoints }}$}

Shared viewpoints and understanding of 'reality' exist, regarding fashion brands and their worth with a general mentality concerning brands and their wearers. The frequency of similar, identical or synonymous terms in responses revealed a specific mentality towards fashion brands and a shared interpretation system used in 'filtering' brands. This was apparent when describing women who might wear different brands (Phase One). 'Gucci' and 'Armani' for example, displayed high levels of consensus in the descriptors attached to them, suggesting shared thinking, language and strength in brand association and meaning.

Media appeared to have a strong influence although perceived by participants to have only a general one. They failed to realise (or admit) the level to which they were affected, suggesting they could be affected subconsciously, failing to realise they belong to the group they criticise. Meanings are attached to advertisements through the use of the same language often using specific vocabulary, displayed in 'good' or 'nice' used in a similar manner when referring to brands. These terms were interpreted in the same way, displaying common attitudes e.g.: frequently using 'psonio' (similar to a show-off).

Common language supports the idea of language being a form of communication in social interaction, responsible for creating definitions and understanding the 'self', others and objects. This was apparent by the descriptors used and attached to fashion brands and the vivid similarities identified in views relating to brand wearers.

Socially-shared symbolisms of fashion brands and the use of 'fashionable' items in order to fulfil social needs were discovered as brands and wearers were labelled and categorised in a specific manner. They expressed to do this on a conscious level as wearing ' $\mathrm{X}$ ' fashion brand is intentionally chosen to project something to others. Brands were perceived to act as symbols, providing hints on the wearer's socioeconomic status, associating fashion brands to wealth.

\section{$\underline{\text { Advertising as a Means of Brand Communication and Its Influences }}$}

Fashion advertising influences brand choice and the models within them, were seen to make individuals crave the clothes they wear and promote certain 
lifestyles and body shapes. Participants acknowledged that advertising has negative effects as it brainwashes, but at the same time expressed fashion brands are important to Greek women, although they themselves were not keen on fashion brands.

Participants expressed the Greek culture and society to be filled with individuals obsessed with fashion brands as it is an important part in a Greek woman's life. Contradictions were highly noticeable throughout, as the importance of brands in the participants' life displayed in their attitudes, appeared to be the same as those they criticised. This was commonly displayed in the participants' references to women wearing brands as: 'psonia' and perceiving brands negatively, but when a participant was asked about 'Burberry' (Phase One) for instance, she smiled, softened the tone of her voice replying: 'my favourite'. This suggests ability to distinguish and differentiate between brands and could be argued that brand knowledge is required in order to have a favourite brand.

Phase Two offered a deeper understanding on the 'reading' of fashion brands, revealing the common use of words when describing advertisements. Even when there was a lack of overall consensus, there was a visible level of agreement in connotations. In a 'Monsoon' advertisement used, participants overall failed to understanding what brand was being advertised (even those who had purchased it in the past), an issue regarding effectiveness levels in the communication between brands and consumers. The shared views expressed towards the brands and advertisement, were commonly negative for similar reasons, with the advertisement commonly seen unsuitable. This displayed a faulty communication process between the brand and the consumer:

'Don't think it is a brand for the Greek audience...,

... 'the colours are not bright'.

Participants failed to match the advertisement to the fashion brand image with confusion towards what was being advertised.

A 'Miss Sixty' advertisement, also displayed shared perceptions quite vividly, with high levels of positive feedback. The brand was commonly described as: 'youthful' with high levels of awareness and the advertisement appeared to effectively communicate with the consumer through the apparent shared views of participants when guessing correctly what was being advertised.

Other advertisements, such as 'UGG' displayed a difficulty in guessing the price range of the item advertised, commonly expressed price could range from very cheap to very expensive. Only upon seeing the brand name participants were able to make a guess on the price displaying how an item or image alone do not have a symbolic meaning and only when the brand is known an attempt in attaching a price can be made. A tendency was displayed in how shared views regarding pricing cannot be effectively provided by the advertisement alone, proposing brands in advertisements are 'read' in combination to participants processing brand names, symbolism and meaning, and their own experiences together. All of these factors serve different purposes but work together when 'reading' the brand, resulting in the formation of brand perceptions which 
influence the level of effectiveness in brand communication regarding consumption choice.

A 'Replay' jeans advertisement, also displayed a failure or mismatch of brands as participants failed to identify the brand correctly. All of the participants replied instinctively, almost reflex-like 'Diesel' as soon as the advertisement was presented. This displayed that participants associate the image to 'Diesel' without offering any reason as to why. Upon revealing the brand, participants expressed that all jeans' brands are the same, without clarifying their immediate response. This raises issues of brand differentiation and level of difficulty in distinguishing between brands of certain fashion items.

Participants commonly stated they did not particularly purchase brands although they appeared to have exceptional high levels of brand awareness considering brands they knew to be of greater quality to those they did not. Specific advertisement images were linked to specific lifestyles and views towards wearers projecting status through brands, seemed to influence advertisement interpretation. A 'Louis Vuitton' advertisement displayed how views appeared to exclusively reflect the 'reading' of fashion brands as tools for projecting socioeconomic status. This was due to the essence of luxury and wealth expressed to be experienced and the relevance of self in interpreting the advertisement:

it refers to the type of kind of rich women the type...

rich more high society...

...refers to a really specific audience, a classic rich woman

from the suburbs'.

The advertisement was perceived to belong to a 'good' brand (clarifying 'good' as expensive and of high quality). When guessing the brand, cases such as 'Chanel' were mentioned displaying a categorisation process where brands are grouped together into similar categories. 'Ralph Lauren' for example, was also described and discussed in the same manner and context and categorized similarly to 'Louis Vuitton' seen as: 'classy', 'elegant' and 'sophisticated'. This displayed shared views and opinions towards the symbolic meanings of certain brands and their advertisements as even when failing to guess correctly, the 'Ralph Lauren' advertisement was expressed to not belong to a brand like 'Replay' but to a fashion house.

Although advertisements were perceived to 'brainwash', the images within them were taken seriously and while fashion media exposes images of thin women, participants did not seem to relate how they could be influenced. Instead, they distanced themselves and spoke of other women being affected although compared themselves to the models.

Overall exposure to advertisements of consumable and disposable goods had a bigger influence, e.g.: make-up, as it was seen more easily accessible compared to clothes (in effort and affordability). Power of advertising over purchasing decisions was displayed as Greek women are open to persuasion from print advertising as it is perceived to be more persuasive in making them go and see the product advertised, as it often offers more product information. Participants 
admitted to purchasing or going to see an item after exposed to its advertisement at some point:

'I see a new foundation 'L'Oréal' has brought out, and I'll say, oh, this according to its presentation and projection covers my needs so let's go and buy it'....

Media influences fashion brand recognition, subconsciously in some instances, as it was clearly reported that brand advertising influences consumers:

'placing it in my head as a known brand, so I recognise it when...

not all brands but some I can recognise, let's say, with my eyes closed by seeing an item or logo or just a shape...or a colour, so it refers me to the brand..'

References of: 'good' and 'bad' in advertising, brings forward issues on perceptions regarding the acceptability or appropriateness of products which are perceived through advertising.

\section{Shared Brand Meaning, Categorisation and Coding}

Attachment of symbolic meaning to brands and brand coding are inter-linked. 'Coding' is a system, resulting from the shared views held towards the meanings of the term 'brand' and the common meanings attached to fashion brands. Codes are 'labels' placed upon brands and wearers, e.g.: 'elegant'. Through coding, effective communication is possible in interaction providing a clear, shared understanding and use of terminology deriving from the language and context used when referring to brands.

The shared views, perceptions, understanding and identification Greek women have of others when wearing specific fashion brands, reflect how the coding system functions and emerges. This system is used to differentiate between the symbolic meanings of fashion brands and their wearers, and effectively communicate when interacting as effective interaction is an outcome of shared language associated with fashion brand meaning.

The 'codes' serve various purposes such as facilitate the effective communication and inform why Greek women use a categorisation process. This became clear in how 'age' slightly affects brand awareness (a couple of cases) and does not appear to have any specific influence on perception towards brands or the descriptors attached to them. Identical or synonymous terms were used to describe specific fashion brands and the fashion industry, commonly linking high price to quality. Once again, participants contradicted themselves:

'by wearing them women have self-confidence to approach someone or could be pretentious'...

'....the older I get, the more I want to buy something good if I can' ('good' meaning expensive). 
Strong views and obvious knowledge of fashion brands were displayed further, as participants (Phase One) were instantly able to articulate opinions about them, with few exceptions. Although the 20 brands used were foreign, brand awareness levels were so high, some were commonly thought to be Greek. Voicing perceptions was effortless, displayed in the attachment of symbolic meaning to fashion brands and the 'coding process' shared which leads to brands and wearers being categorised.

Coding portrays a shared 'reality' through which mutual understanding is developed and acts as a means of communication in brand and wearer categorisation, facilitated by the 'codes' created. Wearers were categorised into different typologies and there was a tendency to categorize brands by various criteria, as references to specific brands (without being asked) were offered as examples of specific situations.

Certain social situations and surroundings were considered factors in certain brands being the 'norm' for everyday use, as environment in upbringing or work was seen to influence individuals. Reasons for wearing brands were connected to different types of women, age groups and socio-economic status:

'in high class it is compulsory (to wear foreign brands), in middle class they may like them

and in the lower class because they want to project'.

Women wearing brands were perceived to have 'economic flexibility', placed in a different group to non-brand wearers with specific symbolisms attached to individuals wearing specific brands, e.g.: 'Burberry' for instance was commonly seen as: 'elegant'.

Brands tended to be grouped in relation to: their target groups, prestige and socioeconomic status, sex appeal and femininity versus 'conservative' and masculine. Description of different brands in a similar manner, suggested participants placed them under the same category e.g.: ' $X$ ' brand is like ' $Y^{\prime}$ brand, 'they are in the same category'.

\section{$\underline{\text { Style Influences }}$}

Style was talked about in two ways: as a creation and projection of a personalised style and the way they dressed. Style was expressed to be the wearing of clothes which suited them and felt comfortable in, physically and mentally. Although friends, family and work were expressed to not influence clothing choice, participants acknowledged they could not dress as they wished at work or special events when asked. Appropriateness of time and a place act as determinants in dress style, with an apparent understanding in what is commonly 'appropriate' and acceptable in certain situations. This is an indicator of how although Greek women support to not be influenced, their dress style is highly influenced by society and social conventions, peer groups, and advertising which did indeed appear to influence dress style did not solely depend on personal taste or personality. 
Weight and body image was also displayed to influence dress style but could not be explored in depth due to acknowledged potential sensitive ethical issues. Clothes were through to look better on thin bodies and weight 'ideals' and 'norms' appeared to be important when dressing. Weight determined most of the participants' purchasing choices which depended on what 'suits' them, failing to define the criteria in deciding this:

'I have been influenced by pregnancy, it changed my body a lot and can't yet control it. I can't find the rhythms I once had of my body and this annoys me a little and because of that I don't want to see it in the mirror and therefore I wear longer clothes, more baggy top'.

\section{Discussion}

As a lens, symbolic interactionism assisted rather than 'shaped' the findings. The research can be seen to build on Kamenidou et al. (2007) and towards Greek women's understanding of foreign fashion brands and the value they place on them while gaining a more in-depth knowledge of opinions held and the effectiveness of fashion advertising towards those views.

The findings can be seen to be highly relevant to Goffman's (1959) notions of 'acceptable' and 'norm' in dressing appropriately to according social situations. The 'coding' and categorising process emerging through the labelling of brands and wearers in regards to how Greek women 'presented' themselves in different social situations can be seen of relevance and built upon Goffman's notions.

A greater and more detailed understanding was gained regarding the process consumers go through in order to interpret images exposed to in print advertisements within fashion magazines e.g.: the image and brand name is needed to guess the price of the item. The interviews provided clues to the existence of a process far more complex and socially-defined than a simple sense-making of brands initially considered. Figure 2 presents the proposed process individuals go through emerging from the findings.

\section{An Explanation of Figure 2}

Figure 2 suggests the influences and the process Greek women go through to form the mind-sets, views, meanings and opinions towards foreign fashion brands. Each 'stage' is explained next. 
Figure 2. The Process of Consumer Interpretation of Fashion Brand Magazine Adverting

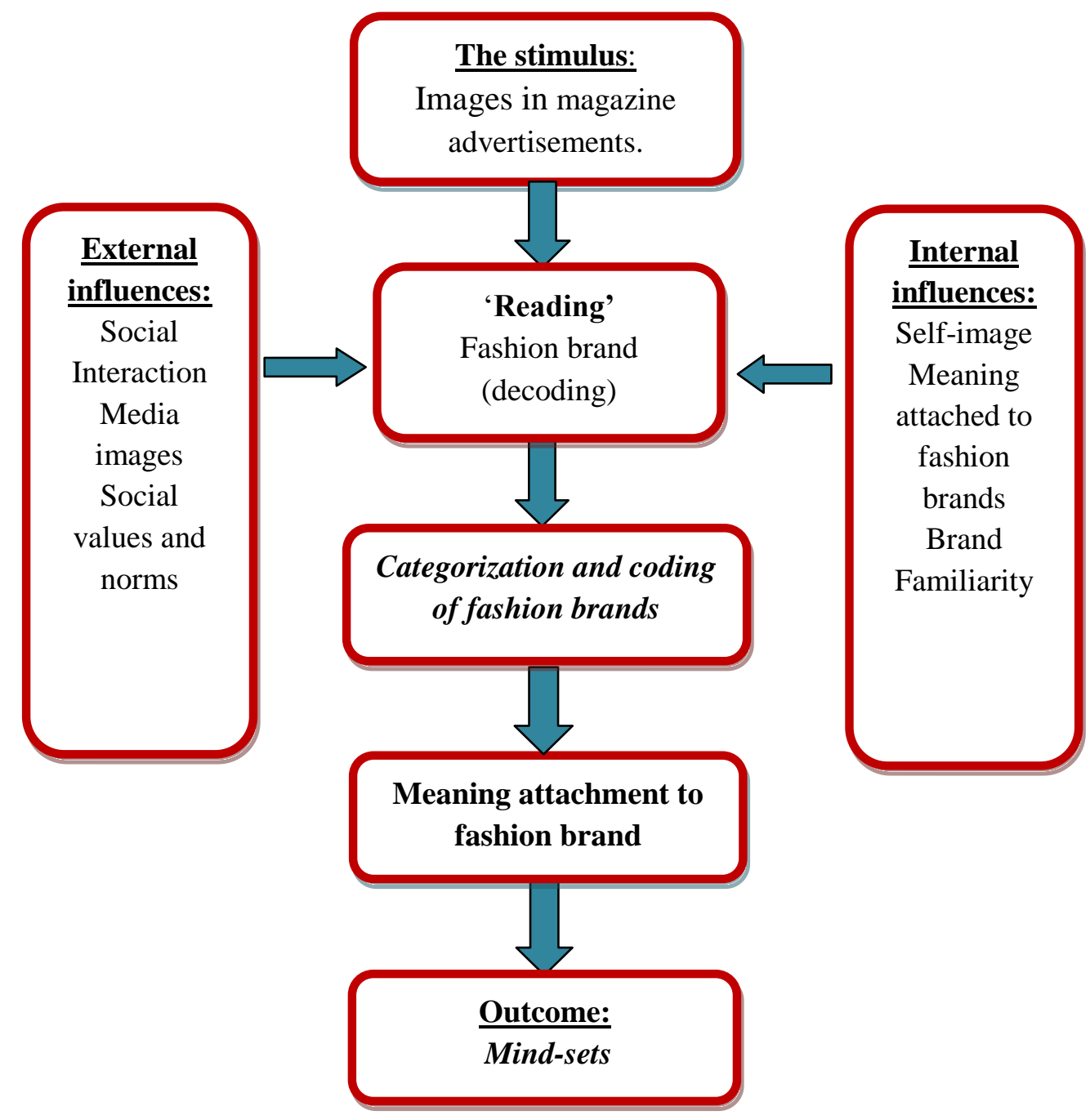

The stimulus does not simply create brand awareness or acts as a means of information. It is linked to the reader's familiarity levels with an advertisement of specific, named brands and brands categorised as 'similar' within a choice set of brands.

Additionally, it influences individuals through the images it projects, acting as a 'code' transmitter. Images act in various ways through which brands are communicated offering information such as brand identity. The stimulus influences at a similar level to 'internal' and 'external' influences but is placed separately, as it follows marketing strategies and is part of a communication process planned between the product and the consumer. It attempts effective communication regardless or independent of the external and internal influences being a separate type of influence as it is not socially or individually-controlled. Although the stimulus could be debated to be an external influence, it is not 
socially created, as the outcome is, and in the context of the research, the stimulus is perceived to be a means of communication Greek women are exposed to.

\section{The Influences}

The influences are considered instrumental in how fashion brands are 'read', acting as the first stage participants go through/ face. They inform individuals by exposing them to images where messages within fashion brands and media are received. Both sets of influences have an impact, following initial exposure to fashion brands, shaping the 'reading' of the stimulus. The influences are the starting point, where all of the information is achieved. Whether this is created through the social group, self-perception or experience, they are all influential in their own unique way and combined, affect the way fashion brands are 'read' or understood.

\section{External Influences}

Social interaction and interaction with print images influence how fashion brands are understood and 'read' through advertising practices. Through social interaction, individuals achieve a sense of acceptability of style and fashion brands as well as concepts of 'norm', 'ideal'. Shared reality in general is discovered regarding fashion brands, shaping shared understanding.

Understanding such social norms impacts fashion brand perception while the stimulus shapes norms and ideals, in the same way those are created through interaction. The social 'norms' created through interaction and the 'stimulus' are equally important, and although the processes differ, their effects are equally significant as the stimulus has a relatively strong influence. This is displayed particularly in weight and body shape issues, revealed by the thin 'ideal' in female body shape, considered to be promoted by fashion advertising which significantly impacts what is considered attractive or beautiful, in relation to this medium.

\section{Internal Influences}

Internal influences displayed to be determinants in self-image, meaning and familiarity. They were considered internal influences as they emerged from selfperception, as Greek women evaluate themselves by comparing what they look like to what they 'should' look like. They value themselves in terms of their selfimage and its 'acceptability' within their social group (e.g.: weight, size and body image). Although acceptability of the social group is considered an external influence, self-image was perceived in relation to how Greek women see themselves and how that influences a shared 'reality' in their society.

Participants distanced themselves from their social group supporting their self-image not being influenced by external factors, although shown they were indeed influenced and not subjective in how they 'see' themselves and their selfimage. Internal factors influence Greek women when attaching meanings to fashion brands but are less significant than external influences in regards to the 
aim of the research. Weight and body image play a great role in influencing views in terms of dressing up and media influences which stem from fashion advertisements in magazines.

The way their body looks is of greater importance to Greek women than the suitability of an item in regards to their age, as weight and body image affects dress style and purchasing decisions. They wear certain clothes only when slimmer, as certain types of clothes were thought to look better on 'thin' bodies with a common understanding of clothes looking better and being more suitable for thin rather than fit bodies. This can be related to symbolic interactionism and the shared meanings and symbolism which are created through social interaction while constructing concepts of the accepted, 'ideal' and attractive body type. Also, self-description can be related to how the stimulus and social interaction affects individuals. Self-image is linked to projection and reflection displayed in the notion Greek women have, that in order to be accepted or desired within their social group, a certain body type or image is mandatory, including societal acceptance.

Advertising alone displayed to be more influential in reinforcing existing brand knowledge rather than create knowledge for inexperienced brands, apparent when participants openly compared and contrasted advertisements (Phase Two) to their experiences and familiarity with the named brands, with a tendency to 'reject' advertisements when 'mismatching' them to the actual brand.

\section{'Reading' the Fashion Brand}

Individuals 'read' fashion brands and this stage acts as a way of decoding information offered in the stimulus. The influences and images contribute to how individuals make sense of brands and decode the information exposed to, in order to form views, opinions and meanings. Readers interpret information about fashion brands which can be seen relevant to literature on advertising creating 'values' (e.g.: Meenaghan 1995). This is seen 'in action' in the reactions to the advertisements (Phase Two) as participants offered the clues they used when attempting to guess the advertised brand, its projected message and suitability to them, revealing how cultural meanings stem from the individual's world (Elliot and Wattanasuwan 1998) and how consumers 'socialisation' (Petit and Zakon 1962) through this.

\section{Meaning Attachment}

The stimulus and influences contribute in creating meanings, developed in the process of understanding fashion brands and the ways social meaning is attached to them. The influences affect the process in various ways and through meaning attachment, Greek women understand a brand's social status, power and social utility. This can be linked to symbolic interactionism and studies on the symbolic meanings of brands and the fulfilment of symbolic needs (Bhat and Reddy 1998). Creation of brand identity is not carried out here, but is completed in the stimulus, shaping brand identity and the external influences affecting identity. Interaction 
creates shared understanding of foreign fashion brands and their meaning. Consistency in shared meanings exists in the general meaning of fashion brands and in very specific ideas and mentality of specific brands (linked to Piamphongsant and Mandhachitara 2008). Brands act as a non-verbal language, through which individuals can be understood and feel part of a society while fulfilling social needs (Waide 1987).

With respect to the specific symbolic meanings of foreign fashion brands, consumers go through a stage creating 'codes' in order to categorise fashion brands according to their meaning.

\section{Categorisation and Coding}

Fashion brands are categorised in relation to the symbolic meaning attached to them, considered in relation to the understanding or perceptions of them. Certain words were adopted in categorising while discussing fashion brands. The words were used as 'codes' in communication with brands and wearers 'labelled' or discriminated against (relevant to Blummer 1969 and Elliot and Leonard 2004). This can build on a greater understanding on the symbolic meanings attached to brands and their use as 'social tools' as fashion brands are categorised in terms of 'value' and 'power'. A process which pre-exists, results in the 'coding', categorisation and placement of fashion brands in specific categories depending on various factors.

Coding and categorising appeared to be inter-related, with 'codes' acting as labels of specific symbolic meanings attached to brands, assisting the brands' placement in specific categories. This is commonly done in relation to the brands' suitability to individuals of a specific socioeconomic status and categorisation is carried out by using the same criteria, supporting studies such as Laroche et al. (1986). Fashion brands are seen to be used in order to project (via their symbolic meanings), supporting their role as social tools.

The participants displayed two types of projection: intentional, through which they attempt to show something to others (regardless of it being reflective of current socioeconomic status) and reflective, which enables an understanding of the wearers' socioeconomic status. These findings can relate to Goffman's (1959) views on stereotyping against individuals due to their appearance and dress style to depend on different social situations. Goffman's notion of 'performers', 'moulded and modified to fit into the understanding and expectations of society' (Goffman 1959: 44) can also relate to the shared understanding of fashion brands and their wearers in terms of 'suitability' of self-presentation by occasions by wearing specific brands.

The 'codes' fundamentally represent a brand's unique symbolic meaning, how these meanings are shared, and their use as a key tool in effective communication in social interaction related to Mead's (1934) theory of projection. The findings can strengthen the symbolic interactionist approach in regards to how individuals understand themselves, others and objects (namely fashion brands) through interaction and the creation of symbolisms through language. Fashion brand 'coding' proposes the importance of language as a means of non-verbal 
communication and the shared reality within the coding process, suggests a need in labelling both fashion brands and their wearer in explicit terms.

Certain fashion brands were attached to certain meaning which others were not, which supports the idea of a categorisation process of fashion brands and wearers. Most significantly, the relation of the findings to symbolic interactionism are discovered, displayed in the attachment of symbolisms to fashion brands lending support to the use of the methodology and methods chosen.

\section{Formation of Viewpoints and Opinions}

The attachment of symbolic meanings to fashion brands leads to a creation of 'codes' acting as a 'labelling' system. This is demonstrated in how Greek women need to label fashion brands and their wearers, in order to make sense of, and position them within their social group. The Labels which act as 'codes', enable efficient communication through shared non-verbal language and use of the same words and context.

The meanings, labels and 'codes' are then used to categorise brands, acting as a component in forming views and opinions towards fashion brands and their wearer which can be related to symbolic interactionist theory of fashion acting as language (Blumer 1969) through which Greek women communicate non-verbally. Additionally, it is vividly demonstrated how symbolic interactionism (as a framework) assists in gaining a wider understanding of the interaction process between consumers and fashion brands in the way labels are attached to fashion brands. Brand differentiation and categorisation are indicators of how Greek women distinguish between fashion brands and label them.

This process occurs in various ways involving a more complex process, including many determinants when categorising and 'coding' due to the meanings attached which result from a complex thinking process, influenced by social interaction and the stimulus. The process exists in the way fashion brands are perceived (of high quality or not) and is also a result of a mutual and common shared symbolic meaning attached to fashion brands.

Categorisation mainly concerns factors such as price, intention to project quality, prestige and suitability to socioeconomic status and profession (e.g. a lawyer needs to dress smartly) relating to Goffman's (1959: 40) identical example. These findings are suggested to build on the idea of dressing 'accordingly' depending on the social situation. Furthermore, categorisation depends on the brands worn, as through them, wearers can be understood, identified, perceived and described. Greek women 'read' both the fashion brands and the wearers (as proposed by Elliot and Leonard 2004 and Kamenidou et al. 2007).

The categorisation process appears to exist due to the stimulus and influences as they impact individuals in various ways. The influences are responsible for individuals' perceptions of fashion brands, contributing to the formation of symbolic meanings of brands and wearers. This is followed by a brand categorisation placement through labelling and coding resulting to the use of fashion brands as projection tools. This displays how brands are used to project either intentionally or reflectively by Greek women. 


\section{Outcome: Mind-Sets towards Fashion Brands}

This 'stage' is the outcome of the process shown in Figure 2 offering greater knowledge on the overall mentality of Greek women towards foreign fashion brands and the way it is formed. It is a result of the previous 'stages', which are the general views and opinions of Greek women and the shared reality that exists.

A socially-created culture is existent around foreign fashion brands, displayed in the similar mind-set towards them with frequent references to what peers think, suggesting the contribution of social interaction in forming socially shared views. A specific culture is created where a certain mind-set and attitude towards fashion brands exists and the relationships created between individuals and brands, relevant to consumerism and the meanings attached to fashion brands by consumers. Hedonic and symbolic brand consumptions is apparent with 'brand' referring to expensive, known and luxury fashion brands. An understanding of fashion brand meaning is shared related to brand community research (e.g.: Schembri 2009) regarding the building of social and cultural relationships. This is mostly seen relevant in the culture created by Greek women, as it is suggested the culture around fashion brands inevitably affects brand consumption.

Lastly, this 'stage' builds on the Kamenidou et al. (2007) findings in regards to the greater understanding of Greek women in terms of why and how they perceive and feel about foreign fashion brands.

\section{Conclusion}

Overall, the value of the research contributes towards a better understanding of the Greek female consumer in regards to the symbolic meanings she attaches to foreign fashion brands and their wearers, created mostly through social interaction. This is displayed for instance, in how 'brand' is used to refer to expensive, known and luxury fashion items with specific symbolic meanings attached to certain fashion brands. This demonstrates the role of non-verbal language, as brands act as social tools and a means for intentional projection as well as a reflection of the wearer's actual state.

More specifically, the research offers an opportunity to see how the female Greek consumer 'reads' foreign fashion brands through the stimulus and the process they go through in forming a mentality towards them (Figure 2).

Practitioners can benefit as the research also displays how a sociological approach, such as symbolic interactionism, can assist brand research in gathering 'valuable' information via 'thick description'. This can reinforce the more effective way consumers are approached with acknowledgement of consumers needing to be treated more like the complex beings they are than a passive audience open to compliance.

Moreover, the development of clearer insights into the Greek market which, although apparent to be attracted to luxury brands, has not so far been particularly studied in relation to the overall mentality towards fashion brands. The research has offered a greater understanding of the female Greek consumer and how she 
'reads', understands and decodes brands and more significantly, the discovery of an existent shared mind-set or mentality towards foreign fashion brands is understood (Figure 2).

The better understanding of the Greek female consumer's general mentality towards fashion brands and how they are understood (Figure 2), can offer a more effective and improved brand identity strategy in brand building and promotion and inform practitioners in various dimensions in how print advertisements are 'read'. Such knowledge can contribute to a greater understanding of this neglected market as it appears particularly significant in promotional practises and strategic planning.

Key contributions to knowledge are emphasised in relation to how the socioeconomic status and the projection of self in relation to status emerged as a key underpinning factor in fashion consumption. Further, the print images within advertisements emerged as a stimulus which may add to, rather than drive brand awareness, knowledge and perceptions where the 'social' dimension of theories such as self-congruity theory (Sirgy 1986, Jamal and Goode 2001) might be further researched. The wider social values and norms which emerged as a significant influence on the brand communication process and fashion advertising can also contribute to greater knowledge in relation to consumer use and meaning attachment of fashion brands beyond utilitarian purposes as fashion brands serve social situations to matter to the individual's social group.

The specific and common words and terms used and the symbolic meanings attached to fashion brands, are a form of non-verbal communication, through which fashion brands are understood. Fashion brands are associated to wealthy women, of a certain socioeconomic status and even when negative feelings were displayed, a consensus in views was present. Counterfeit products were generally perceived to be of inferior quality to original ones while their wearers were commonly seen as 'fake' and pretentious, attempting to appear something that is unreflective of their socio-economic status.

Greek women's relationship to fashion magazines relates to social factors and social interaction, making further contribution on fashion brand and fashion brand perception research of Greek women. Advertising is perceived to set standards and was displayed to influence purchasing decisions significantly. Further, fashion brand advertisements were seen make Greek women conscious of their bodies with weight being a key determinant for dress style, purchasing decisions and perception of self-image. This provides a greater understanding on how print fashion images are 'read' building on existing research on the effects of images in fashion advertising as participants compared themselves to the models. 


\section{References}

Auty S, Elliot R (1998) Fashion involvement, self- monitoring and the meaning of brands. Journal of Product and Brand Management 7(2): 109-123. Available at https://www. emeraldinsight.com/doi/abs/10.1108/10610429810216874.

Benzies KM, Allen MN (2001) Symbolic interactionism as a theoretical perspective for multiple method research. Journal of Advanced Nursing 33(4): 541-547. Available at: https://onlinelibrary.wiley.com/doi/abs/10.1046/j.1365-2648.2001.01680.x.

Bhat S, Reddy SK (1998) Symbolic and functional positioning of brands. Journal of Consumer Marketing 15(1): 32-43. Available at https://emeraldinsight.com/doi/abs/ 10.1108/07363769810202664.

Blumer H (1969) Fashion: from class differentiation to collective selection. Sociological Quarterly 10(3): 275-291. Available at https://onlinelibrary.wiley. com/doi/abs/10. 1111/j.1533-8525.1969.tb01292.x.

Callero PL (2003) The sociology of self. Annual Review of Sociology 29: 115-133. Available at https://www.annualreviews.org/doi/abs/10.1146/annurev.soc.29.010202. 100057.

Cianfore B, Bennett G, Siders R, Tsuji Y (2006) Virtual advertising and brand awareness. International Journal of Sport Management and Marketing 1(4): 289-310.

Dean D, Arroyo-Gamez RE, Punjaisri K, Pich C (2016) Internal brand co-creation: The experiential brand meaning cycle in higher education. Journal of Business Research 69(8): 3041-3048. Available at https://www.sciencedirect.com/science/article/abs/ pii/S0148296316000321?via\%3Dihub.

Debicka M (2000) Advertising-the art of manipulation. Cultural determinants in effectiveness of advertising, Polish and American cases. In LV Ryan, M Eisend, P Schuchert-Güler (2006) Explaining counterfeit purchases: A review and preview. Academy of Marketing Science Review 12(6): 1-25. Available at https://www.research gate.net/profile/Martin_Eisend/publication/252248476_Explaining_Counterfeit_Purc hases_A_Review_and_Preview/links/0a85e5395b8b8297a9000000/Explaining-Cou nterfeit-Purchases-A-Review-and-Preview.pdf.

Dion D, Borraz S (2017) Managing Status: How Luxury Brands Shape Class Subjectivities in the Service Encounter. Journal of Marketing: 81(5): 67-85. DOI= https://doi.org/ 10.1509/jm.15.0291.

Elliott R, Leonard C (2004) Peer pressure and poverty: Exploring fashion brands and consumption symbolism among children of the 'British poor. Journal of Consumer Behaviour 3(4): 347-359. DOI= https://doi.org/10.1002/cb.

Elliot R, Wattanasuwan K (1998) Brands as symbolic resources for the construction of identity. International Journal of Advertising 17(2): 131-144. Available at https:// www.tandfonline.com/doi/abs/10.1080/02650487.1998.11104712.

Feinberg RA, Mataro L, Burroughs WJ (1992) Clothing and social identity. Clothing and Textile Research Journal 18(1): 18-23. Available at http://journals.sagepub.com/doi/ abs/10.1177/0887302X9201100103.

Fennis BM, Pruyn ATH (2007) You are what you wear: Brand personality influences on consumer impression formation. Journal of Business Research 60(6): 634-639. Available at https://www.sciencedirect.com/science/article/abs/pii/S0148296306002 293.

Fine GA (1993) The sad demise, mysterious disappearance and glorious triumph of symbolic interactionism. Annual Review of Sociology 19: 61-87. Available at https:// www.annualreviews.org/doi/10.1146/annurev.so.19.080193.000425.

Goffman E (1959) The presentation of self in everyday life. NY: Anchor. 
Handberg C, Thorne S, Midtgaaard J, Nielsen CV,Lomborg K (2015) Revisiting symbolic interactionism as a theoretical framework beyond the grounded theory tradition. Qualitative Health Research 25(28): 1023-1032. Available at https://journals.Sage pub.com/doi/abs/10.1177/1049732314554231? journalCode=qhra.

Hatzithomas L, Boutsouki C, Zotos Y (2009) The effects of culture and product type on the use of humor in Greek TV advertising: An application of Speck's humorous message taxonomy, Journal of Current Issues and Research in Advertising 31(1): 4361. Available at https://www.tandfonline.com/doi/abs/10.1080/10641734.2009.10 505256.

Heckler SE, Keller KL, Houston MJ, Avery J (2014) Building brand knowledge structures: Elaboration and interference effects on the processing of sequentially advertised brand benefit claims. Journal of Marketing Communications 20(3): 176-196. Available at https://www.tandfonline.com/doi/abs/10.1080/17544750.2012.660766? src= recsys\&journalCode=rjmc20.

Hume M, Mills M (2013) Uncovering Victoria's Secret. Exploring women's luxury perceptions of intimate apparel and purchasing behavior. Journal of Fashion Marketing and Management 17(4): 460-485. Available at https://www.emeraldinsig ht.com/doi/abs/10.1108/JFMM-03-2013-0020.

Husic M, Cicic M (2009) Luxury consumption factors. Journal of Fashion Marketing and Management 13(2): 231-245. Available at https://emeraldinsight.com/doi/abs/10.11 08/13612020910957734?journalCode=jfmm.

Jeon YH (2004) The application of grounded theory and symbolic interactionism. Scandinavian Journal of Caring Sciences 18(3): 249-256. Available at https://online library.wiley.com/doi/abs/10.1111/j.1471-6712.2004.00287.x.

Jamal A, Goode MMK (2001) Consumers and brands: a study of the impact of self-image congruence on brands preference and satisfaction. Marketing Intelligence and Planning 19(7): 482-492. DOI= https://doi.org/10.1108/0263450011040 8286.

Jiang P (2004) The role of brand name in customization decisions: a search vs experience perspective. Journal of Product \& Brand Management 13(2): 73-83.

Jussim L (1991) Social perception and social reality: A reflection-Construction model. Psychological Review 98(1): 54-73. Available at https://eric.ed.gov/?id=EJ494107.

Kamenidou I, Mylonakis J, Nikolouli K (2007) An exploratory study on the reasons for purchasing imported high fashion apparels. The case of Greece. Journal of Fashion Marketing and Management 11(1): 148-160. DOI= https://doi.org/10.1108/136120 20710734463.

Karanika K, Hogg MK (2010) The interrelationship between desired and undesired selves and consumption: The case of Greek female consumers' experiences. Journal of Marketing Management 26(11-12): 1091-1111. DOI= https://doi.org/10.1080/0267 257X.2010.508979.

Klink RR, Althaide GA (2012) Creating brand personality with brand names. Marketing Letters 23(1): 109-117. DOI= https://doi.org/10.1007/s11002-011-9140-7.

Laroche M, Rosenblatt JA, Manning T (1986) Services used and factors considered important in selecting a bank: an investigation across diverse demographic segments'. International Journal of Bank Marketing 4(1): 35-55. DOI=http://dx.doi.org/10.11 08/eb010771.

Lee DH (1990) Symbolic interactionism: some implications for consumer self-concept and product symbolism research. Advances in Consumer Research 17: 386-393. Available at http://acrwebsite.org/volumes/7037/volumes/v17/NA-17.

Martin MC, Peters CO (2005) Exploring adolescent girls' identification of beauty types through consumer collages, Journal of Fashion Marketing and Management 9(4): 
391-406. Available at https://www.emeraldinsight.com/doi/ abs/10.1108/136120205 10620777.

McCracken GD, Roth VJ (1989) Does clothing have a code? Empirical findings and theoretical implications in the study of clothing as a means of communication. International Journal of Research in Marketing 6(1) 13-33. DOI= https://doi.org/10. 1016/0167-8116(89)90044-X.

Mead H (1934) Mind, Self and Society. Chicago: University of Chicago Press.

Meenaghan T (1995) The role of advertising in brand image development. Journal of Product and Brand Management, 4(4): 23-34. DOI= https://doi.org/10.1108/10610 429510097672.

Millan E, Reynolds J (2014) Self-construals, symbolic and hedonic preferences, and actual purchase behavior. Journal of Retailing and Consumer Services 21(4): 550-560. Available at https://pdfs.semanticscholar.org/282a/c7ccaab 32ee0c0cf1440e348 fdf1c 7251564.pdf.

O' Cass A, Frost H (2002) Status brands: examining the effects of non-product-related brand associations on status and conspicuous consumption. Journal of Product \& Brand Management 11(2): 67-88. DOI= https://doi.org/10.1108/10610420210423 455.

Oliver C (2012) The relationship between symbolic interactionism and interpretive description. Qualitative Health Research 22(3): 409-415. DOI= https://www.ncbi. nlm.nih.gov/pubmed/21876207.

Perry P, Kyriakaki M (2014) The decision making process of luxury fashion retail buyers in Greece. Journal of Fashion Marketing and Management 18(1): 85-106. DOI= https://doi.org/10.1108/JFMM-06-2012-0030.

Petit TA, Zakon A (1962) Advertising and social values. Journal and Marketing 26(4): 15-17. DOI= https://www.jstor.org/stable/1248333.

Petrenko VV (2015) Fashion: The game on social meaning and the cynical strategy of consumption. Procedia- Social and Behavioural Sciences 200: 509-513. DOI=https:// doi.org/10.1016/j.sbspro.2015.08.010.

Piamphongsant T, Mandhachitara R (2008) Psychological antecedents of career women's fashion clothing conformity. Journal of Fashion Marketing and Management 12(4): 438-455. DOI= https://doi.org/10.1108/13612020810906119.

Rahman K (2013) 'Wow! It's Cool!': the meaning of coolness in marketing. Marketing Intelligence \& Planning 31(6): 630-638. DOI= https://doi.org/10.1108/MIP-09-20120094.

Schembri S (2009) Reframing brand experience. The experiential meaning of HarleyDavidson. Journal of Business Research 62(12): 1299-1310. DOI= https://doi.org/ 10.1108/13612020810906119.

Sirgy MJ (1986) Self-Congruity: Toward a Theory of Personality and Cybernetics. New York: Praeger Publishers.

Thomas DR (2006) A general inductive approach for analyzing qualitative evaluation data. American Journal of Evaluation 27(2): 237-246. DOI= https://doi.org/10.11 77\%2F1098214005283748.

Tynan C, Mckechnie S, Chhuon C (2009) Co-creating value for luxury brands. Journal of Business Research 63(11): 1156-1163. Available at https://www.sciencedirect.com/ science/article/abs/pii/S0148296309002793.

Thanh NND (2012) Relationship between brand awareness, perceived quality, trust, value, loyalty and brand equity: A case study of Vinamilk brand in Ho Chi Minh, Vietnam. $A U$-GSB e-journal 5(2): 93-100. Available at http://www.assumptionjournal.au. edu/index.php/AU-GSB/article/view/477. 
Valentine V (2003) Using semiotics to build powerful brands for children. Young Consumers 4(2): 9-16. https://edisciplinas.usp.br/pluginfile.php/3247411/modresour ce/content/1/Zakia_Nadin_1987_Semiotics\%20advertising\%20and\%20marketing.pdf.

Waide $\mathbf{J}$ (1987) The making of self and world in advertising. Journal of Business Ethics 6(2): 73-79.DOI= https://doi.org/10.1007/BF00382020.

Zhang B, Kim JH (2013) Luxury fashion consumption in China: factors affecting attitude and purchase intent. Journal of Retailing and Consumer Services 20(1): 68-79. https:// www.scirp.org/(S(czeh2tfqyw2orz553k1w0r45))/reference/ReferencesPapers.aspx?

ReferenceID $=2182525$. 



\title{
Climate Finance by Multinational Development Banks - with Special Attention to Europe
}

\author{
By Mária Bábosik
}

\begin{abstract}
The paper aims at highlighting the importance of climate protection in the world and in Europe due to climate change, as well as the role of multilateral development banks in climate finance. The topic has a current relevance as in 2017 President Donald Trump gave a notice to quit the Paris Climate Agreement accepted by all United Nations (UN) member states, amongst them by the members of the European Union (EU). The move of the United States (US) President was a shocking surprise worldwide and provoked heavy reactions - including the US. The paper gives an overview of the relationship between climate change, climate protection and climate finance. It sees climate change a threatening reality of today, affecting Europe as well. It considers climate protection necessary not only on country but also on regional and global level. Besides regulation and voluntary pledges, it attributes a crucial role to climate finance focusing on huge, long-term, high risk investments and projects to mitigate the effects and adapt to climate change. It mentions its sources, major directions and institutions, amongst them the multilateral development banks. It compares them with special attention to Europe exploring similarities and differences how climate finance is reflected in their policy, what resources they mobilize, what kind of projects they finance, what results they have achieved, what their plans are in this area and what reactions their activity provoke. Results show that multilateral development banks play a key role in climate finance. Due to differences in geographic, historic and economic circumstances and exposure to climate change they act on it differently. The paper helps to better understand the links between climate change, climate protection and climate finance and the role of the multilateral development banks in it in a comparative perspective.
\end{abstract}

Keywords: Climate Change, Climate Finance, Climate Protection, International Financial Institutions, Multilateral Development Banks.

\section{Introduction}

The purpose of the paper is to present the context of climate change, climate protection and climate finance, and to address the role played by Multilateral Development Banks (MDBs) in it. The topic is highly relevant as on June 1, 2017 US President Donald Trump gave a notice to quit the Paris Climate Agreement accepted by UN member states. In this epoch-making agreement, UN member states have committed themselves to limiting global warming to below 2 degrees Celsius by reducing emission of carbon dioxide. President Trump's decision sparked protests throughout the US and brought to life the "America's Pledge" initiative, to voluntarily comply with the Agreement and organize extensive campaigns to win the widest possible support. The US attitude is very important

\footnotetext{
*Senior Research Analyst, Central Bank of Hungary and PhD Student, University of Pécs, Hungary.
} 
not only because of the $\mathrm{CO} 2$ emission - as root cause of climate change - by the US itself, but the strong US influence on the international order and institutions.

The paper aims at finding answers to the following research questions: Can climate change be considered as a fact of today? Why has it become one of the key risk factors? Why is climate protection so important? What were the major steps made globally to protect the climate? How much investments are needed for climate protection? Who can provide them and in what form? What is the contribution of the Multilateral Development Banks to climate finance? What results have they achieved in this area and what could be improved? What kind of new questions did arise?

\section{Literature Review}

For this paper literature is reviewed in three different topics: climate change, climate finance and multilateral development banks. Each topic has many relevant publications, so without completeness only some of the most important literature is highlighted here.

Regarding climate change Andrew E. Dessler's (2012) book with the title of "Modern Climate Change" gives a very broad introduction defining climate change, explaining why it happens and what its effects are, and setting the fundamentals of the climate policy and actions. "Climate Change Denial: Heads in the Sand" by Haydn Washington and John Cook (2011) presents the standpoint of those who deny climate change with various arguments, reveals the interest behind them and uses scientific evidence to disprove them to realistically address the issue of climate change. Looking into the future Abishur Prakash (2016) in his book "Next Geopolitics" examines how new technologies will change geopolitics, amongst others the fight against climate change.

As for financing "Climate Finance: Theory and Practice" edited by Anil Markandya et al. (2017) gives a very good overview of the subject presenting the importance and debates on climate finance, providing theoretical and practical perspective to it and describing appraisal methods of investments. Regulatory and governance issues as well as market mechanisms are discussed in great details in the book "Climate Finance: Regulatory and Funding Strategies for Climate Change and Global Development" edited by Richard B. Stewart, Benedict Kingsbury and Bryce Rudyk (2009). A broad policy and regulatory overview and an empirical analysis on how financial institutions tackle climate change are given by Megan Bowman (2015) in "Banking on Climate Change". With regard to possible necessary actions, the book by Graeme Maxton and Jorgen Randers (2016) "Reinventing Prosperity" elaborates feasible proposals to reduce unemployment, inequality and climate change.

As far as Multilateral Development Banks are concerned, the role of Washington politics in the creation of these international financial institutions is revealed in the book by Sarah Babb (2009) titled "Behind the Development Banks". "Owning Development" edited by Susan Park and Antje Vetterlein (2010) presents how policy norms emerged and how they have changed in the IMF and 
the World Bank. Four regional development banks (RDBs) are thoroughly analyzed and compared by Ruth Ben-Artzi (2016) in her book on "Regional Development Banks in Comparison". She concludes that RDBs play a vital role in poverty elimination in spite of their institutional limitations. Robert O'Brien, Anne Marie Goetz, Jan Aart Scholte and Marc Williams (2000) in their book with the title of "Contesting Global Governance" focus on the critics against the policies and activities of the MDBs and show how global social movement can influence multilateral economic institutions.

This list of reviewed publications represents only a fragment of the very rich literature on the subject and could easily be enlarged. However, the role of the climate issue and the influence of international financial institutions through climate financing on geopolitics is not well presented.

\section{Methodology}

Methodology used in this paper is literature review, statistical analysis, and documents analysis regarding international negotiations on climate change and the publications of the Multilateral Development Banks as well as using relevant conference materials. Notre Dame Country Index of the University of Notre Dame (France) is also included to measure vulnerability and readiness of countries against climate change. $\mathrm{CO} 2$ emission data is drawn from EDGAR's database.

\section{Findings}

\section{From Climate Change to Climate Finance}

\section{The Challenge of Climate Change}

"Climate change" means a change of climate which is attributed directly or indirectly to human activity that alters the composition of the global atmosphere and which is in addition to natural climate variability observed over comparable time periods; as defined by the United Nations (UN 1992). Others associate climate change directly with global warming: "Climate change is the catch-all term for the shift in worldwide weather phenomena associated with an increase in global average temperatures". Wired (2018) widely used dictionaries underline the role of emission in defining climate change: "Changes in the world's weather, in particular the fact that it is believed to be getting warmer as a result of human activity increasing the level of carbon dioxide in the atmosphere." (Cambridge Dictionary n.d.) In my country a Hungarian curriculum quotes: "Climate change means the long-term and essential change of the Earth's climate and weather on local or global level. For example, changes in the temperature, the quantity and distribution of the rainwater, wind or the number of sunshine hours". (Tankönyvtár 2010) What explains climate change? Are there different opinions? What is the trend in climate change? 
Due to well-known explanations climate change is a consequence of the emission of greenhouse gases, mainly carbon dioxide (CO2), which is considered as the main reason of the increase in the average temperature of the Earth. Global warming may be fatal not only for the environment, but for the human civilization as well. Consequences can already be observed including melting ice cover and glaciers, higher sea level, slower ocean conveyor belt, altered flora, accelerated biodiversity loss, draught and heavy rainfalls, higher humidity, extreme weather events, etc. Unless we manage to limit the increase in temperature to less than 3.5 Celsius we will not survive, because food supply will be destroyed.

Not everybody is of this opinion. There is a wide range of climate sceptics, who have a different standpoint. "Trend sceptics" deny the fact of global warming and argue that climate changed even before. Others accept climate change as a fact but see nature being the cause of it. In contrast to them "Effect sceptics" see human activities as a cause but consider it being positive or neutral. Some are against regulation because of political-ideological considerations. "Science sceptics" question the validity of scientific research on climate change and argue that the models of the UN Intergovernmental Panel on Climate Change (IPCC) are not scientifically well grounded. They consider $\mathrm{CO} 2$ emission being only one of the factors influencing climate, and they oppose investing in emission reduction (Washington and Cook 2011).

One of the most well-known climate sceptics is Bjorn Lomborg, who assessed the actual impact of all climate promises made ahead of the Paris Climate Summit in 2015 and published shocking results. He concluded that even if every nation fulfilled every promise by 2030, and we assume that these promises could be extended for another 70 years until the end of this century, the Paris promises would reduce temperature rises by just 0.17 Celsius by 2100 . But this would cost us some USD 2-3 trillion over the next 25 years (Lomborg 2015).

Climate sceptics - though they are in minority and criticise the standpoint of the climate savers - are supported by lobbies and put considerable pressure on the public opinion as well as on the decision makers, well demonstrated by the attitude of the US President.

Nevertheless, during the past decade climate-related risks have increased tremendously. The World Economic Forum (WEF) assessed failure of climate change mitigation and adaptation the most important global risk factor (WEF 2016). Two years later the WEF stated, that "This trend has continued this year, with all five risks in the environmental category being ranked higher than average for both likelihood and impact over a 10-year horizon" (WEF 2018). The five risks mentioned above are as follows: Extreme weather events, Natural disasters, Failure of climate change mitigation and adaptation, Man-made environmental disasters, Biodiversity loss and ecosystem collapse.

\section{Vulnerability and Readiness to React on Climate Change}

Global warming affects the Earth everywhere but to a different extent. Due to different natural and social conditions some countries are more vulnerable to climate change impacts than others, and some countries are more prepared to cope 
with the challenge of climate change than the rest. Where are the hot spots, and which are the countries that are least ready to withstand the pressure of climate change? And where are the strongholds, countries that are least vulnerable and most ready to adapt? Which countries could improve their situation and which countries failed to do it?

To answer these questions, the ND-GAIN Global Adaptation Index of the University of Notre Dame's Environmental Initiative (France) can be used. It is a free and open source data. The index looks at two key dimensions. The first is "vulnerability" - a country's exposure, sensitivity and capacity to adapt to the negative effects of climate change. It considers six life-supporting sectors: food, water, health, ecosystem service, human habitat, and infrastructure. The second dimension is "readiness" - a country's ability to leverage investments and convert them to adaptation actions. It considers three components: economic, governance and social readiness (ND-GAIN Country Index).

As measured by the index, the top 10 most vulnerable countries in 2016 were Niger, Somalia, Chad, Micronesia, the Solomon Islands, Guinea-Bissau, Sudan, Liberia, Mali and Eritrea - all are developing countries with low GDP per capita in Africa and Asia. At the same time the top 10 least vulnerable countries were Switzerland, Norway, Luxemburg, Germany, Australia, Canada, France, UK, Sweden and Spain - all with a high GDP per capita, many of them are in Europe.

Again, top 10 countries least ready to adapt to climate change are low income countries of Africa and Asia with one exception: Somalia, Eritrea, Central African Republic, Chad, Democratic Republic of Congo, Democratic People's Republic of Korea, Libya, Zimbabwe, Venezuela and Haiti. Not surprisingly the top 10 countries most ready to adopt are high income countries: Singapore, New Zealand, Norway, Denmark, Finland, Sweden, Austria, Republic of Korea, Iceland and Switzerland - seven of them are European.

It draws attention to a major global problem as a World Bank's statement puts it: "Low income countries tend to be more vulnerable, and less equipped to invest against, extreme climate impacts". (World Bank Pubs 2018) Figure 1 below presents the position of the countries by their overall ability to withstand climate effects as measured by the ND-GAIN Country Index for 2016 combining vulnerability and readiness. The darker the country on the map is, the more resistant it is.

As far as Europe is concerned, the "Old Continent" is also affected by climate change although the situation in this respect is much more favourable in Europe than in Africa or Asia. Within Europe the most endangered territories are the sea coasts and some regions of Central Europe. The Scandinavian and some Western European countries are the most prepared to cope with climate change effects, while the Southern and Eastern part of the continent is less resistant. 
Figure 1. Resistance of Countries against Climate Effects as Measured by the NDGAIN Country Index (2016)

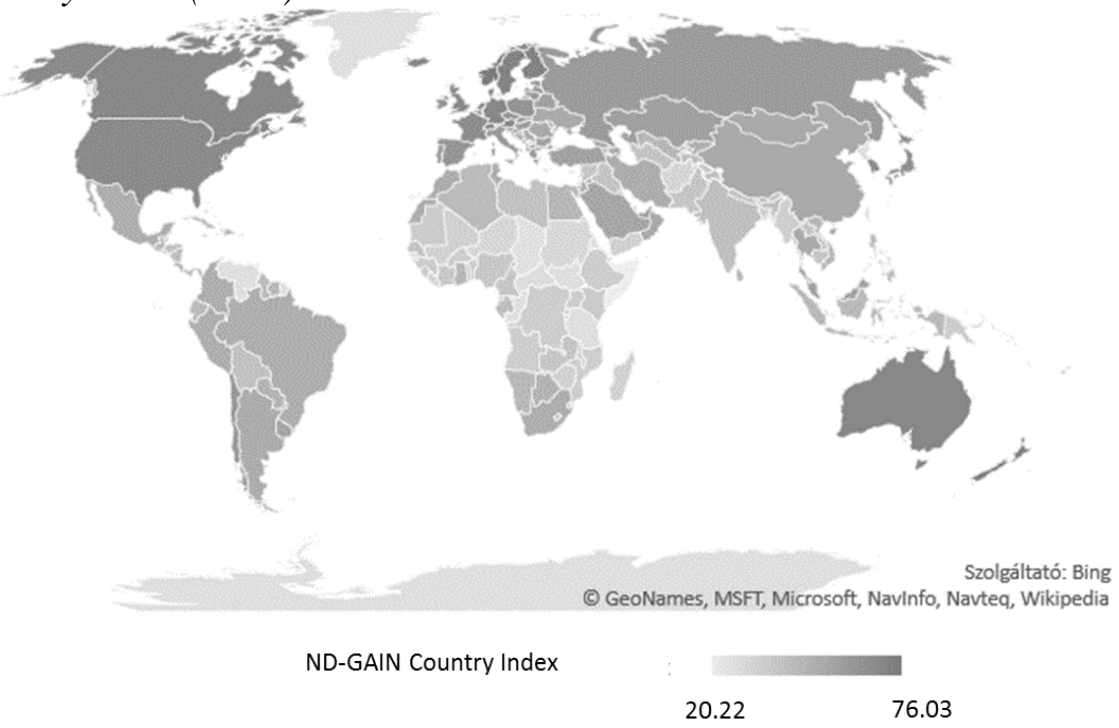

Source: Author's own map using data from ND Country Index, https://ntrda.me/2ATM9E4 [Accessed 19.11.2017].

During the past 15 years Europe made considerable efforts to improve resilience. 23 out of the 39 countries in Europe succeeded improving their overall ND-GAIN Country Index score from 2000 to 2016. Half of them belong to the group of high GDP per capita countries, one third of them to the upper middle and 3 countries to the lower middle GDP per capita group. The scores of the rest of the countries were either maintained or slightly declining but with less than one point on the scale.

Figure 2 below presents the ND-GAIN Country Index of the European countries in 2000 and 2016.

Figure 2. ND-GAIN Country Index of the European Countries in 2000 and 2016

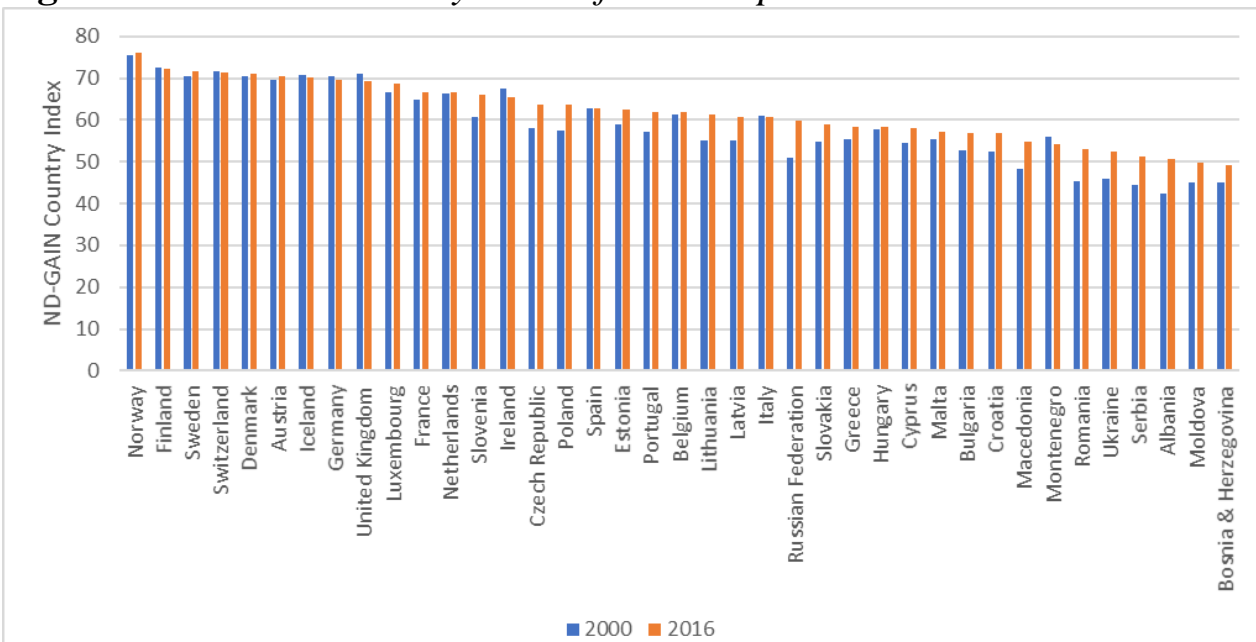

Source: Author's own chart using data from ND-GAIN Country Index https://ntrda.me/2QE7B9V [Accessed: 19.11.2017]. 


\section{The Root Cause: CO2 Emission}

As $\mathrm{CO} 2$ emission is considered the root-cause of climate change due to human activity on the Earth, which has increased considerably during the past twenty-five years and reached a level that endangers the climate. Figure 3 below shows the increase of the total $\mathrm{CO} 2$ emission by all countries of the world between 1990 and 2015 measured in kton.

Figure 3. Total CO2 Emission of all Countries 1990-2015 (kton)

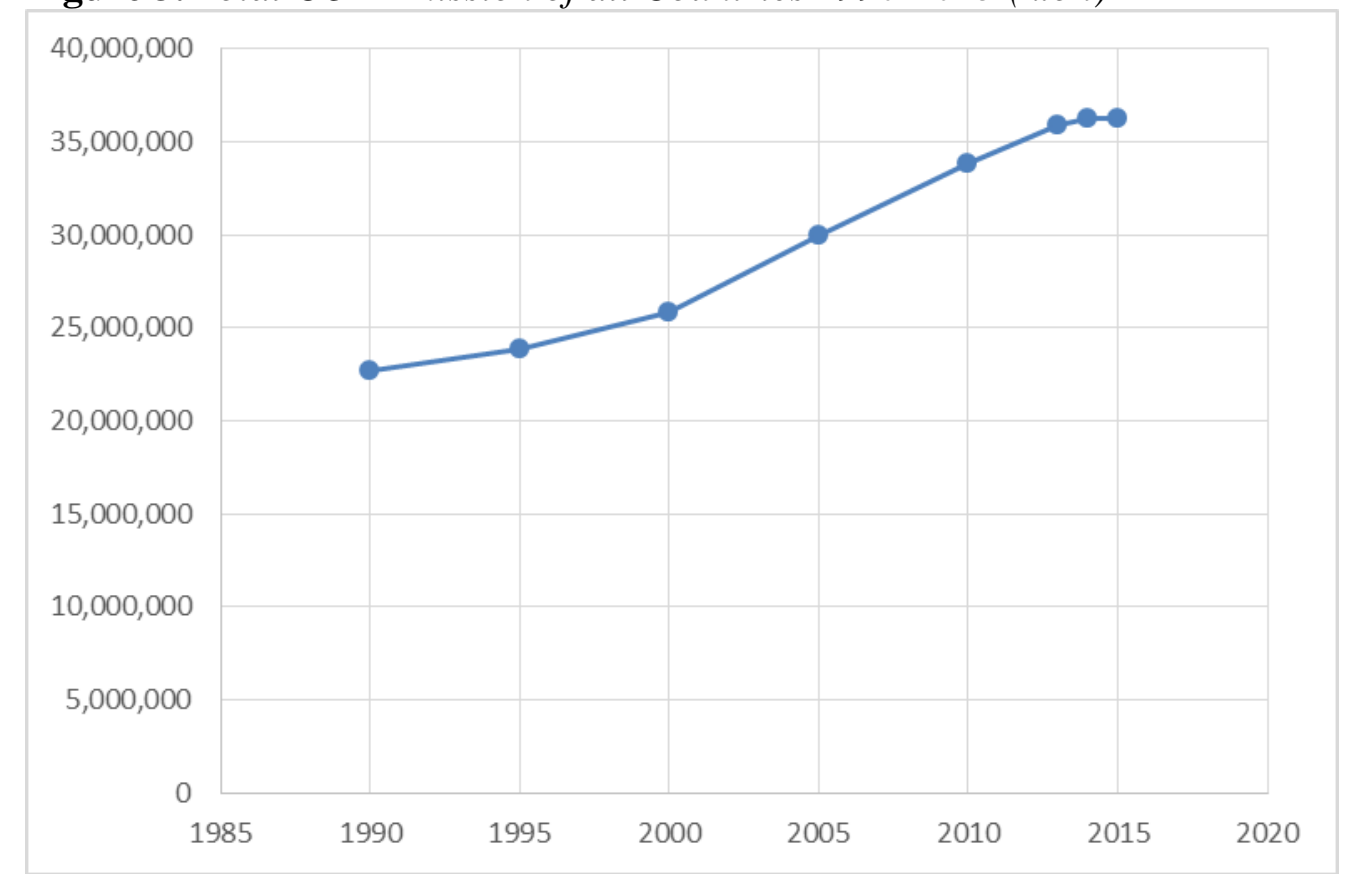

Source: Author's own chart using data from EDGAR (2017).

In 2015 the world produced over 35,633 million of tonnes of carbon dioxide, which means a sharp increase of nearly 60 percent between 1990 and 2015 . Emission is highly concentrated to the industrialized counties, as the top 20 emitters are accountable for 79 percent of it.

China is far more the largest emitter country producing 10,642 million of tons of $\mathrm{CO} 2$ with an enormous increase (354 percent) in the past twenty-five years representing 29 percent of the global $\mathrm{CO} 2$ emission. The USA is the second largest emitter with 5,114 million of tons but with "only" a 3 percent increase over the same period, representing $14 \%$ of the total emission. Other large emitter countries are India, Russia, Japan (all above 1,000 million of tons) with a share of 3-7 percent of the total emission. While there was a sharp increase in emission of CO2 in India (369 percent) and a moderate one in Japan (8 percent), emission by Russia decreased considerably during the past 25 years (29 percent). Table 1 below presents the top 20 global CO2 emitter countries and their emission in 2015, the increase of their emission from 1990 to 2015 and their share in the total emission of the world in 2015. 
Table 1. Top 20 Global CO2 Emitter Countries 1990-2015

\begin{tabular}{|l|c|c|c|c|}
\hline Country & $\mathbf{1 9 9 0}$ & $\mathbf{2 0 1 5}$ & $\begin{array}{c}\text { Increase } \\
\text { from 1990 to } \\
\mathbf{2 0 1 5}\end{array}$ & $\begin{array}{c}\text { Share in the } \\
\text { total } \\
\text { emission in } \\
\mathbf{2 0 1 5}\end{array}$ \\
\hline \hline Unit & kton CO2 & kton CO2 & $\mathbf{\%}$ & $\mathbf{\%}$ \\
\hline World Total & $22,452,432$ & $35,633,093$ & $159 \%$ & $100.0 \%$ \\
EU-28 & $4,334,975$ & $3,424,778$ & $79 \%$ & $9.6 \%$ \\
\hline China & $2,305,425$ & $10,461,742$ & $454 \%$ & $29.4 \%$ \\
USA & $4,955,641$ & $5,114,424$ & $103 \%$ & $14.4 \%$ \\
India & 655.462 & $2,419,637$ & $369 \%$ & $6.8 \%$ \\
Russia & $2,379,433$ & $1,698,007$ & $71 \%$ & $4.8 \%$ \\
Japan & $1,158,222$ & $1,254,800$ & $108 \%$ & $3.5 \%$ \\
Germany & $1,003,149$ & 765,923 & $76 \%$ & $2.1 \%$ \\
Canada & 554,684 & 682,765 & $123 \%$ & $1.9 \%$ \\
Iran & 201,720 & 628,611 & $312 \%$ & $1.8 \%$ \\
Korea & 268,057 & 601,322 & $224 \%$ & $1.7 \%$ \\
Saudi Arabia & 167,929 & 512,351 & $305 \%$ & $1.4 \%$ \\
Indonesia & 159,852 & 498,098 & $312 \%$ & $1.4 \%$ \\
Brazil & 215,804 & 492,986 & $228 \%$ & $1.4 \%$ \\
Mexico & 289,350 & 450,999 & $156 \%$ & $1.3 \%$ \\
Australia & 276,218 & 419,088 & $152 \%$ & $1.2 \%$ \\
United Kingdom & 575,834 & 392,946 & $68 \%$ & $1.1 \%$ \\
South Africa & 268,333 & 392,467 & $146 \%$ & $1.1 \%$ \\
Italy & 423,297 & 355,143 & $84 \%$ & $1.0 \%$ \\
Turkey & 149,477 & 349,756 & $234 \%$ & $1.0 \%$ \\
France & 376,700 & 324,691 & $86 \%$ & $0.9 \%$ \\
Poland & 358,700 & 288,938 & $81 \%$ & $0.8 \%$ \\
\hline Total of Top 20 countries & $16,743,287$ & $28,104,698$ & $168 \%$ & $78.9 \%$ \\
\hline Sourc: A & & &
\end{tabular}

Source: Author's own table using data from EDGAR (2017).

With regard to Europe, the EU-28 is the third largest emitter of the world with 3,424 million of tons of $\mathrm{CO} 2$ providing nearly 10 percent of the global emission. It is important to note, that contrary to China and the US, the EU-28 succeeded to cut emission by 21 percent between 1990 and 2015 - due not only to the economic crisis but to its considerable effort to "green the economy".

Within Europe, Germany is far more the largest CO2 emitter in the EU-28, followed by the United Kingdom, Italy, France, Poland and Spain. These large emitter countries of Europe succeeded to decrease emission by 14-32 percent between 1990 and 2015, except for Spain, where CO2 emission has increased by 15 percent during the same period. These six countries together, account for 70 percent of the total $\mathrm{CO} 2$ emission of the EU. Figure 4 below presents how $\mathrm{CO} 2$ emission has changed in the EU-28 member-states between 1990 and 2015. 
Figure 4. CO2 Emission by the Current Member-States of the European Union $1990-2015$

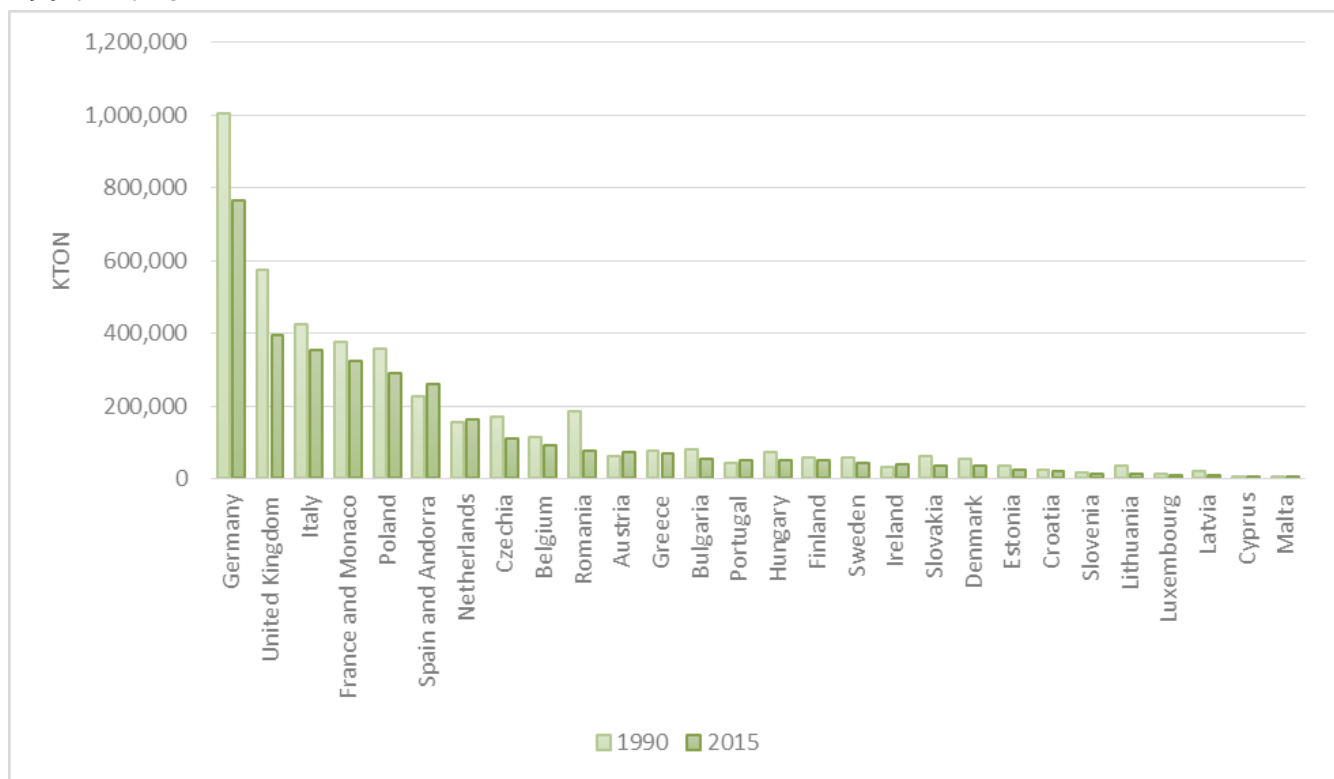

Source: Author's own chart using data from EDGAR (2017).

$\underline{\text { The Need for Climate Protection and its Directions }}$

Actions against climate change are called climate protection. By the 1980s it turned out that action against climate change is not possible at the level of individual countries, it requires global action. This led to the adoption of the United Nations Framework Convention on Climate Change (UNFCCC) adopted in 1992 at the Rio Earth Summit and to the Conference of Parties (COP) held each year. Based on the UNFCCC and after many rounds of negotiations the Paris Climate Agreement was signed in 2015, which is the most extensive international cooperation in the fight against climate change. "Combating Climate Change and its Effects" is also included in the UN "Sustainable Development Goals" adopted in 2015 (Goal 13: Climate Action, UN 2015).

The two main directions of climate protection are mitigation and adaptation. The UN International Panel on Climate Change (IPCC) defines climate mitigation as: "An anthropogenic intervention to reduce the sources or enhance the sinks of greenhouse gases." Climate adaptation refers to the ability of a system to adjust to climate change (including climate variability and extremes) to moderate potential damage, to take advantage of opportunities, or to cope with the consequences. The IPCC defines adaptation as the "adjustment in natural or human systems in response to actual or expected climatic stimuli or their effects, which moderates harm or exploits beneficial opportunities" (UN 1992). Of these two directions, mitigation is the dominant, adaptation gets still less attention. 


\section{$\underline{\text { Financing Climate Actions }}$}

The key question of climate protection is climate finance. Climate finance is part of the environmental finance and partly overlaps with green finance. It is a heavily contested term. From a climate justice perspective, it refers to the transfer of public resources from North to South to cover the costs of dealing with the long-term impacts of climate change. This money, a key component of climate debt, should also be provided to help Southern countries to pursue low-emissions paths without repeating the unsustainable reliance on fossil-fuels that was central to the industrialization of Northern countries. Other definitions are broader and refer to all financial flows relating to climate mitigation and adaptation (Reyes 2012). They include aid, private and equity investments, in case they are related to climate protection.

Estimated global total climate finance by 'Carbon Brief'- a UK-based website covering the latest developments in climate science, climate policy and energy policy - amounted to USD 340-650 billion in 2014. Developed countries transferred USD 40-175 billion to developing countries, out of which USD 35-50 billion was coming from public and USD 5-125 billion from private sources (Yeo 2015). Public climate finance is constantly increasing. From the annual USD 35 billion in 2011-12 it increased to USD 42 billion in 2013-14, and it will reach USD 67 billion by 2020 (ODI 2016). This is getting closer to the USD 100 billion pledge of the Paris Climate Agreement, but still there is a gap. More than half of this amount is bilateral financing, 40 percent is provided by MDBs, some percentage is financed through multilateral climate funds, part of which is managed also by MDBs, mainly by the World Bank.

The institutional structure of climate finance is rather complex and includes many actors (Nakhooda et al. 2015). Contributors are the developed donor countries, the European Union and some subnational organizations. They create dedicated climate finance funds and initiatives and establish bilateral and multilateral institutions, including MDBs. Bilateral institutions generally work with implementing agencies to execute their projects. Multilateral institutions use both market and non-market mechanisms to meet their climate goals. Market mechanisms - created by the Kyoto Protocol - are International Emissions Trading, Clean Development Mechanism and Joint Implementation. Non-market mechanisms is a broad basket, it can be anything provided it is not market-based, for instance cooperation on climate policy, fiscal measures, such as putting a price on carbon or applying taxes to discourage emissions. Recipients are the beneficiary developing countries. They usually work with regional and national implementing agencies and funds. Figure 5 below shows the model of institutional structure of climate finance. 
Figure 5. Model of Institutional Structure of Climate Finance

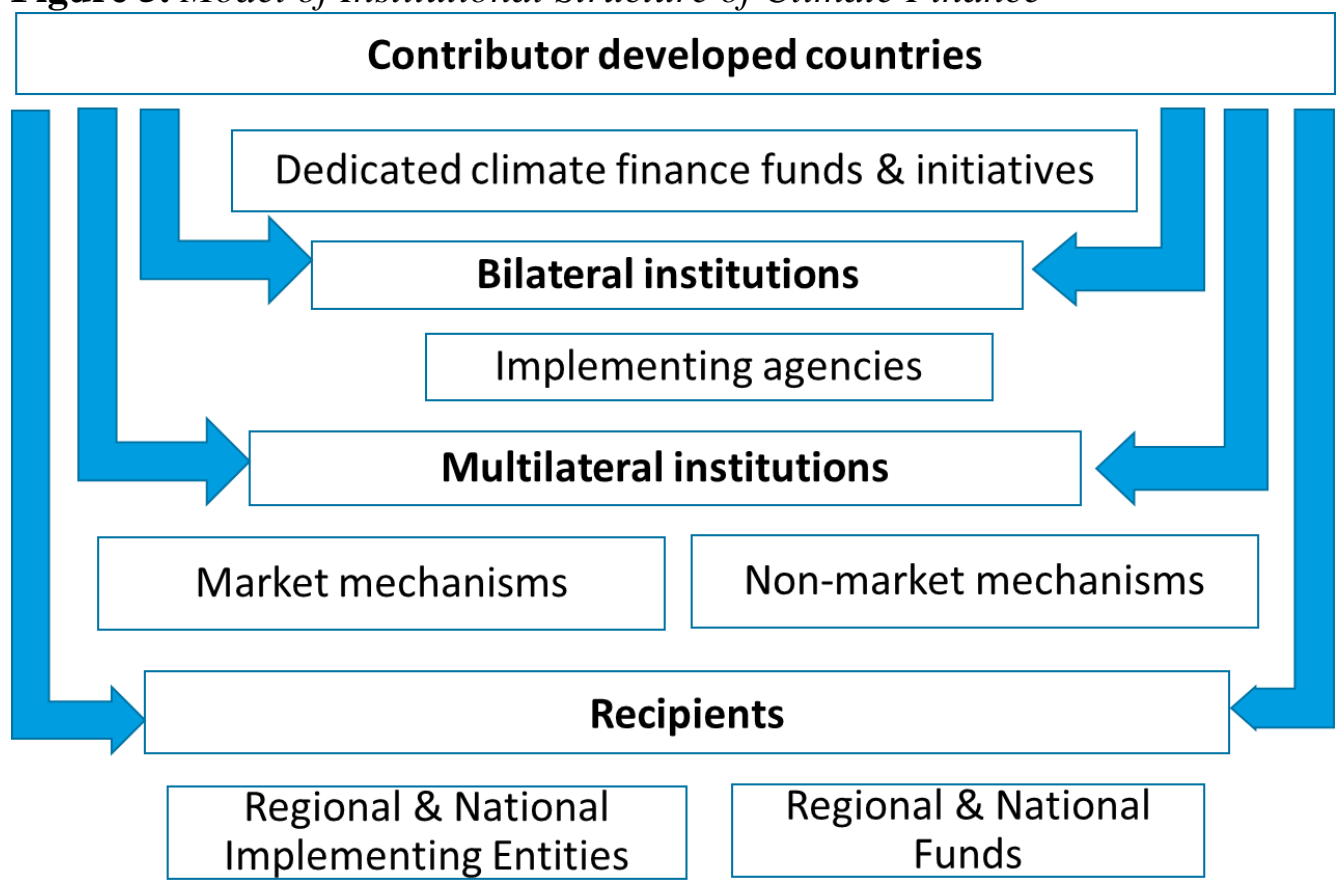

Source: Author's.

\section{The Role of Multilateral Development Banks in Climate Finance}

$\underline{\text { Multilateral Development Banks as Key International Financial Institutions }}$

Multilateral Development Banks (MDBs) are International Financial Institutions (IFIs). They are key members of the Bretton Woods financial system established after the World War II by sovereign states to foster reconstruction and development. They are important financial intermediators providing finance for long-term and risky investments which are not attractive enough for the private sector but badly needed for development, such as infrastructure, economic and social environment etc. They focus on the developing and the transition countries providing loans and guarantees, technical advice and make equity investments. They are owned by their shareholders and the decision-making is based on the shareholder's votes. This way the big donor countries can exercise heavy influence on the decisions which raises issues in the time of global power shift to a multipolar world and when recipient countries want to have a stronger voice (Babb 2009).

The largest and globally operating MDB is the World Bank (WB), which serves as a model for the regional development banks: the African (AfDB), Asian (ADB) and Inter-American Development Bank (IDB), the European Bank for Reconstruction and Development (EBRD) and the bank of the European Union, the European Investment Bank (EIB).

These institutions are only one group of the most important players in global climate finance and can satisfy only a part of the development needs. Their role is unique, they cooperate with other public and private finance institutions to 
mobilize as much resources as possible through the best use of opportunities and risk sharing. In addition, they are extremely important in the development and dissemination of norms (Park and Vetterlein 2010).

However, MDBs and their activities are also heavily criticized. On the one hand, the influence of the US in their governance and decision-making is said to be problematic, which is a consequence of their ownership structure. On the other hand, their caution and risk aversion make it difficult to finance projects of those who are in the greatest need. As MDBs are regularly rated by large international credit rating agencies, and their position on the capital markets is determined by their rating, they only provide loans to creditworthy borrowers and under strict conditions, which does not necessarily coincide with development needs. Criticism is also concerned with their bureaucracy, sluggishness and inflexibility, which makes it difficult and time-consuming to dynamically implement projects in the fast-paced world (Ben-Artzi 2016).

As MDBs are key international financial institutions, it is important to learn if they are committed to financing climate actions? Is climate finance a priority area in their strategy? What is the share of climate finance in their activities?

\section{$\underline{\text { Multilateral Development Banks' Commitment to Climate Finance }}$}

MDBs are active in climate finance. They set strategies and action plans for financing climate actions. They declared their commitment to the Paris Climate Agreement in 2015 and play an important role in delivering the annual USD 100 billion climate finance commitment of the developed countries.

Under the term climate finance, MDBs understand the use of financial resources for development activities devoted to mitigating and/or adapting climate change impacts in the developing and emerging countries. For accounting purposes, they have developed and use a common methodology based on the list of activities that can be linked to low carbon emissions (MDB Methodology 2015).

\section{Climate Change Strategies of the Multilateral Development Banks}

All MDBs have strategic documents guiding their activities in climate finance. These documents were elaborated during the past ten years, mainly following the Paris Climate Agreement signed in 2015.

The African Development Bank (AfDB) developed its "Strategy on Climate Risk Management and Adaptation" (CRMA) in 2009 (AfDB 2009). It calls for increased support for capacity building of African countries to tackle climate change risks. It also ensures that all investments financed by the Bank are "climate-proof", meaning that they are designed, installed, implemented and managed to reduce to a minimal level the adverse effects of climate change, with the most cost-effective ratio as possible. Based on this strategy a "Climate Change Action Plan" (CCAP) was prepared for the period of 2011-2015 as well (AfDB 2011). 
The Asian Development Bank (ADB) published its priorities for climate action in 2010 in a document titled "Addressing Climate Change in Asia and the Pacific: Priorities for Action". It aims at helping the region to be more resilient to the adverse impacts of climate change and follow a low-carbon path for economic growth and poverty reduction (ADB, 2010). In 2017 a "Climate Change Operational Framework" was developed for the period between 2017 and 2030 determining "Enhanced Actions for Low Greenhouse Gas Emissions and ClimateResilient Development" (ADB 2017).

The Inter-American Development Bank (IDB) issued its "Integrated Strategy for Climate Change Adaptation and Mitigation, and Sustainable and Renewable Energy" in 2011 (IDB 2011). Its objective was to contribute to low carbon development and address key vulnerabilities to the consequences of climate change in Latin-America.

The European Bank for Reconstruction and Development (EBRD) announced its overall "Green Economy Transition" (GET) approach in 2015. It states that with sustainable investments EBRD helps to mitigate and/or build resilience to the effects of climate change and other forms of environmental degradation (EBRD 2015). EBRD also introduced green economy aspects into the project evaluation criteria.

The European Investment Bank (EIB) adopted its "Climate Strategy" also in 2015, mobilising finance for the transition to a low-carbon and climate-resilient economy. It defines three strategic action areas: reinforcing the impact of EIB climate financing, increasing resilience to climate change, and further integrating climate change considerations across all EIB's standards, methods and processes. Within each of these areas operational initiatives are also launched (EIB 2015).

The World Bank Group (WBG)'s "Climate Change Action Plan 2016-2020" was published in 2016. It sets ambitious targets for 2020 in high-impact areas, including clean energy, green transport, climate-smart agriculture, and urban resilience, as well as in mobilizing the private sector to expand climate investments in developing countries and lays out concrete actions to help countries deliver on their contributions to global targets (World Bank, IFC, MIGA 2016).

These strategies demonstrate, that MDBs have elaborated climate finance strategy, developed action plans and are dedicated to follow up their climaterelated financing against their strategy.

\section{Financing Climate Actions by Multilateral Development Banks}

Financing climate actions has become an important direction in the activities of the MDBs. They spend over USD 35 billion annually on climate finance, 80 percent of which is for mitigation, and 20 percent for adaptation. Additionally, they provide approximately USD 50 billion co-financing per year with other international financiers and private investors. Between 2011 and 2017 their cumulative climate finance investment amounted nearly to USD 200 billion. The overwhelm-ming majority of climate finance ( 97 percent) is made from own, the rest is from external resources. They are provided by bilateral donors or the climate funds managed also by the MDBs. 
Loans represent 80 percent of climate finance of the MDBs. Aid, guarantees, budget support, capital investments and other assets have only 1-6 percent share but these are extremely important to mobilize the private sector for co-financing.

The focus areas of the climate actions are rather narrow. Most of the projects finance renewable energy and energy efficiency.

The main beneficiary of climate actions of the MDBs is the public sector of the recipient countries. Public sector accounts for two-third of climate finance from the MDBs' own sources, and three quarters of the external sources, being a much smaller amount. AfDB finances only the public sector, while EBRD provides more financing for the private than for the public sector.

Regarding geographical targeting, 20 percent of MDBs' climate finance is directed to non-EU Europe and Central Asia, 19 percent to South Asia, 15 percent to Latin America and the Caribbean, 14 percent to East Asia, 13 percent to $11 \mathrm{EU}$ countries, 9 percent to the Middle East and North Africa, and another 9 percent to the sub-Saharan region. Least developed countries receive 15 percent of climate finance and small island states another 2 percent. As climate finance is mainly used for mitigation, it is expected to bring the most benefit in the major polluting countries.

Climate finance represents 20-30 percent in the investment portfolio of MDBs in general. EBRD is the only exception, where the share of climate finance in the total investments is much higher, amounting to 38 percent (MDBs 2017).

Climate investments of the MDBs have fundamental impact on many people's lives. For example, "Renewable energy projects representing 10 gigawatts of generation capacity, and 10 new operations that when in place will improve the climate resilience of over 50 million people" - said John Roome, Senior Director for Climate Change of World Bank Group (WBG 2017). This way, MDBs are key to upscale climate protection in the region where they operate.

These figures show that MDBs have a prominent role in climate finance, which became even more important after the Paris Climate Agreement. Each MDB has set ambitious targets for rapidly expanding climate finance till 2020 and is enhancing its activity in this field. It is proven by the fact that they managed to increase the share of climate finance in their activity by 5-10 percent from 2016 to 2017. Table 2 below presents MDBs' climate finance commitment for 2020.

Nevertheless, critics are also voiced regarding the climate activities of the MDBs. Civil Society Organizations (CSOs), that have a global or regional reach closely watch these investments, report on their observations and act if needed. They managed to become a major stakeholder group with whom the MDBs are obliged to cooperate. Therefore, all MDBs have developed a platform to work with the CSOs, have regular consultations with them, invite them for their Annual Meetings, consider and react to their opinion, findings and actions. 
Table 2. MDBs' Commitment to Climate Finance

\begin{tabular}{|c|c|}
\hline & 2020 Climate Finance Target \\
\hline ADB & $\begin{array}{l}\text { To double climate finance to USD } 6 \text { billion per annum, USD } 4 \text { billion for } \\
\text { mitigation and USD } 2 \text { billion for adaptation (up from USD } 3 \text { billion in 2015) }\end{array}$ \\
\hline AfDB & $\begin{array}{l}\text { To triple climate finance to } 40 \text { percent of the annual investments, ca. USD } 5 \\
\text { billion (up from } 26 \text { percent on average between 2011-2014) }\end{array}$ \\
\hline EBRD & $\begin{array}{l}40 \text { percent of annual investments for green finance (composed of climate } \\
\text { finance and finance for projects with a possible environmental impact) (up } \\
\text { from } 25 \text { percent on average between 2010-2014) }\end{array}$ \\
\hline EIB & 35 percent of annual lending, ca. EUR 2 billion per year ( 25 percent in 2015 ) \\
\hline IDBG & $\begin{array}{l}\text { To double climate finance to } 30 \text { percent of approved loans, an average of } \\
\text { USD } 4 \text { billion a year, and climate risk assessment, identification of } \\
\text { opportunities and measures to improve resistance and mitigate the effects of } \\
\text { climate change (up from } 14 \text { percent on average between 2012-2014) }\end{array}$ \\
\hline WBG & $\begin{array}{l}\text { To increase the amount of climate finance by one third to USD } 16 \text { billion } \\
\text { annually, and its share in the annual commitment to } 28 \text { percent. WBG wants } \\
\text { to maintain the current level of co-financing, which would increase climate } \\
\text { finance by another USD } 13 \text { billion a year. The combined value of direct and } \\
\text { co-financing would thus reach USD } 29 \text { billion a year. (up from } 21 \text { percent in } \\
\text { 2015) }\end{array}$ \\
\hline
\end{tabular}

Source: Author's own table using information from MDBs (2015) and Cuntz et al. (2017).

For example, the Arab NGO Network for Development (ANND) is focusing on the involvement of EIB and EBRD in the Arab Region, one of the most affected areas by climate change according to the UN Intergovernmental Panel on Climate Change (IPCC). In its paper on climate change ANND shows, that in spite the share of climate finance is relatively high in the total investment of both EIB and EBRD (22 and 15 percent respectively in 2013), the Arab region benefits only with 2 percent of it, which is a very low share compared to other regions (ANND 2017).

Referring to an analysis done by the Bankwatch, ANND warns that many EIB projects benefit the European companies the most and not the local communities. Energy projects ensure oil to European counties rather that increase energy efficiency locally. ANND also criticizes that EIB does not consider carbon footprint of the projects to express the merit of the project and does not pay enough attention to $\mathrm{CO} 2$ emission.

ANND shows, that in the climate financing activities of EBRD the share of the Southern and Eastern Mediterranean region (SEMED), - where the Arab countries belong to - was as small as 0.7 percent only between 2006 and 2013 . Less than one quarter of the energy projects is financing renewable energy, the rest, - more than three quarters of the projects - are dedicated to fossil fuels using the argument of energy security and efficiency. Environmental categorization of the projects is also problematic. Miscategorization misleads when calculating with the environmental impact of the projects and turns the attention away from possible environmental degradation.

ANND gives some recommendations, too. EIB and EBRD should imply with the decarbonization target by 2050 and stop to support coal, observe environmental 
and social standards, ensure that the green economy concept is not merely a rhetoric, promote the transfer and dissemination of clean and environmentally sound technologies, finance energy efficiency and ensure that privatization related to water, energy, roads etc. consider these sectors as basic rights of people living in that region and projects should not prohibit people from enjoying their rights. ANND is not the only critical voice to be heard. Other CSOs express similar concerns in all geographies regarding climate actions of MDBs, too.

To further foster climate finance MDBs need to take seriously these critics and recommendations, enlarge the scope of their activities and improve efficiency. To enlarge the scope new MDBs can be established, sources for climate finance can be increased, private capital can be mobilized and co-financing can be done with the private sector, risk sharing facilities can be provided by partial credit guarantees, financial innovations can be introduced like green bonds, cat bonds, green credit lines, insurance products etc., environmental and social assessment can be included in all projects. Other ways to enlarge the scope can be raising awareness, sharing knowledge, building up capacity and knowhow in risk assessment, helping to create bankable and environmentally sustainable projects. To increase efficiency project design, management and coordination could be improved, technical and financial experts could be involved, multiple barriers should be tackled, initial interventions could be scaled up and expanded, specific interventions could be replicated in different locations, and scaling up and reproduction could be mixed. These tools and solutions can be combined and taylor-made for the specific needs, once the MDBs keep their promises to stay committed to help the developing and emerging countries to cope with the challenge of climate change.

\section{Results}

The results of the above analysis show, that

- Climate change has become a reality of today and is one of the top risk factors endangering the Earth. $\mathrm{CO} 2$ emission is the main cause of climate change. Industrialized developed countries are the major emitters.

- Climate change affects all countries, though to a different extent. The most affected countries are low income developing countries in Africa and Asia, accounting for only a small part of global emission. They need financial resources for climate mitigation and adaptation.

- Climate protection is in the interest of the whole world to ensure proper conditions for the survival of mankind. International agreements have been concluded and signed by nearly every country in the world defining targets, actions and measures.

- Climate protection requires long-term and risky investments. Developed countries invest in climate finance also through the MDBs. MDBs have strong commitment to climate mitigation and adaptation, set strategies, provide loans and assistance for the recipient developing and emerging 
countries. They can meet part of the climate finance needs only but make effort to increase their contribution.

- To best utilize the potential of the MDBs' for climate finance they should enlarge the scope of their activities, improve efficiency and instead of favouring the interest of the donor countries, their climate-related projects should serve the interest of the local communities and people at first.

\section{Discussion}

The fight against climate change is in the interest of the entire world. Its success or failure will influence international power relations of the future, and vice versa, international power relations today outline what is possible to achieve and how in the field of climate protection. This way climate finance shapes geopolitics and it is being shaped by geopolitics at the same time. Therefore, power relations, interest of the stake-holders, long-term effects of the projects as well as ethical questions of justice and inequalities could be further discussed. The debate on development versus growth cannot be avoided, either. As all these questions are far reaching and complex, an interdisciplinary approach would be essential.

\section{Conclusions}

Climate change has highlighted the need for climate protection including international agreements, voluntary commitments, and investments for mitigation and adaptation which requires tremendous additional financing. Multilateral Development Banks play an important role to provide considerable funding. They account for about 40 percent of the total climate finance, while climate finance represents about 25-35 percent in their investments. Their role is extremely important not only due to the financing they provide but because of the norms, standards and expectations they create and implement. They are committed to include climate finance into their priorities and increase climate investments. This way they are key to upscale climate protection in their region and globally and fight against climate change. To meet these stretching targets, MDBs need to enlarge the scope, increase efficiency as well as listen to and act on well-based critics.

However, three major questions are remaining. Firstly, how will the US quit from the Paris Climate Agreement influence climate finance of the MDBs as the US has a considerable influence on them? Secondly, how will Brexit affect climate finance of EBRD and EIB? Thirdly, what will these changes mean for climate finance globally? To answer these questions further research would be essential. 


\section{Acknowledgements}

The author expresses special thanks to the University of Pécs, Doctoral School of Earth Studies and The Pallas Athéne Foundations for the grant provided for the participation on the $5^{\text {th }}$ Annual International Conference on Social Sciences organized by ATINER (Athens, 30-31 July 2018).

\section{References}

ADB (2010) Addressing Climate Change in Asia and the Pacific: Priorities for Action. Retrieved from https://bit.ly/2Q6SPsE. [Accessed 10 June 2018].

ADB (2017) Climate Change Operational Framework 2017-2030. Retrieved from https:// bit.ly/2eI6bHj. [Accessed 10 June 2018].

AfDB (2009) Strategy on Climate Risk Management and Adaptation (CRMA). Retrieved from https://bit.ly/2BNqyil. [Accessed 10 June 2018].

AfDB (2011) Climate Change Action Plan 2011-2015 (CCAP). Retrieved from https:// bit. \#ly/2k6mf6j [Accessed 10 June 2018].

ANND (2017) Series of analysis on European Financial Institutions engagement in the Arab Region. Paper \#2, European Investment Bank and European Bank for Reconstruction and Development and Climate Change. Retrieved from https://bit.ly/2BNP Pst. [Accessed 01 September 2018].

Babb S (2009) Behind the development banks. Chicago: University of Chicago Press.

Ben-Artzi R (2016) Regional Development Banks in Comparison. Cambridge: Cambridge University Press.

Bowman M (2015) Banking on Climate Change: How Finance Actors and Transnational Regulatory Regimes are Responding. Kluwer Law International.

Climate Change (n.d.) In Cambridge Dictionary. Retrieved form https://bit.ly/2QwCahB [Accessed 20 June 2018].

Cuntz C, Afanador A, Klein N, Barrera F, Sharma R (2017) Connecting multilateral climate finance to mitigation projects, Mitigation Momentum. ECOFYS, 13.

Dessler A (2012) Modern Climate Change, 239. New York, USA: Cambridge University Press.

EBRD (2015) Green Economy Transition Approach. Retrieved from https://bit.ly/2RvSJ Yr. [Accessed 10 June 2018].

EDGAR (2017) Emissions Database for Global Atmosphere Research: Global Fossil CO2 Emissions from 1990 to 2016 (EDGARv4.3.2_FT2016 dataset). Retrieved from https://bit.ly/2jfhZCE. [Accessed 20 September 2018].

EIB (2015) Climate Strategy. Retrieved from https://bit.ly/1W7HYGi [Accessed 10 June 2018].

IDB (2011) Integrated Strategy for Climate Change Adaptation and Mitigation, and Sustainable and Renewable Energy, 2011. Retrieved from https://bit.ly/2EaS23A. [Accessed 10 June 2018].

Lomborg B (2015) Impact of Current Climate Proposals. Retrieved from https://bit.ly/2z ErLXq. [Accessed 06 May 2018].

Markandya A, Galarraga I, Dirk Rübbelke D (Eds) (2017) Climate Finance: Theory and Practice. World Scientific Series on the Economics of Climate Change: (2), World Scientific.

Maxton G, Randers J (2016) Reinventing Prosperity. Vancouver BC, Canada: Greystone Books Ltd., David Suzuki Institute. 
MDBs (2015) 2015 Joint Report on Multilateral Development Banks' Climate Finance. 7. Retrieved from https://bit.ly/2rhGxyM. [Accessed 20 May 2017].

MDBs (2016) 2016 Biennial Assessment and Overview of Climate Finance Flows. United Nations Framework Convention on Climate Change, 6. Retrieved from https://bit.ly/ 2BOFj4j. [Accessed 20 May 2017].

MDBs (2017) 2017 Joint Report on Multilateral Development Banks' Climate Finance. Retrieved from https://bit.ly/2KWGRfH [Accessed 20 June 2018].

MDB Methodology (2015) MDB Methodology for Tracking Climate Adaptation. 2015 Joint Report on Multilateral Development Banks' Climate Finance. 2016, 8-9. Retrieved from https://bit.ly/2DZUbOV [Accessed 20 May 2017].

Nakhooda S, Watson C, Schalatek L (2015) The Global Climate Finance Architecture. Overseas Development Institute, London, UK - Heinrich Böll Stiftung North America, Washington, US, 3. Retrieved from https://bit.ly/2KQeIXt [Accessed 10 June 2016].

ND-GAIN Country Index (n.d.) Retrieved from https://ntrda.me/2J1WErL. [Accessed 20 September 2017].

O’Brien R, Goetz AM, Scholte JA, Williams M (2000) Contesting Global Governance. Cambridge Studies in International Relations: 71, Cambridge University Press, Cambridge, United Kingdom, 260.

ODI (2016) 10 things to know about climate finance in 2016. Overseas Development Institute, London - Heinrich Böll Stiftung North America, Washington, 1. Retrieved from https://bit.ly/2fUfPtc. [Accessed 20 May 2017].

Park S, Vetterlein A (2010) Owning Development - Creating Policy Norms in the IMF and the World Bank, 287. Cambridge, New York: Cambridge University Press.

Prakash A (2016) Next Geopolitics: The Future of World Affairs (Technology) Volume One, 186.

Reyes O (2012) A Glossary of Climate Finance Terms. Institute for Policy Studies, 9. Washington, USA. Retrieved from https://bit.ly/2KQfq75. [Accessed 15 July 2016].

Stewart RB, Kingsbury B, Rudyk B (Eds) (2009) Climate Finance: Regulatory and Funding Strategies for Climate Change and Global Development, New York and London: New York University Press.

Tankönyvtár (2010) A klímaváltozás fogalma és értelmezése. [The definition and interpretation of climate change]. Retrieved from https://bit.ly/2E8hOpn [Accessed 18 June 2017].

UN (1992) United Nations Framework Convention on Climate Change (UNFCCC). United Nations, 7. Retrieved from https://bit.ly/1oNZ0PZ. [Accessed 15 May 2017].

UN (2015) Sustainable Development Goals. United Nations. Retrieved from https://bit.ly/ 1mZqbqP [Assessed 15 May 2017].

Washington H, Cook J (2011) Climate Change Denial: Heads in the Sand, 192. New York, USA: Earthscan from Routledge, Abingdon.

WBG (2017) WBG Press release: MDBs Increase 2016 Financing to Tackle Climate Challenge. Retrieved from https://bit.ly/2KOiBMo [Accessed 15 May 2018].

WEF (2016) The Global Risk Report 2016. Geneva: World Economic Forum. Retrieved from https://bit.ly/1RRzt37. [Accessed 20 May 2018].

WEF (2018) The Global Risk Report 2018, 6. Geneva: World Economic Forum. Retrieved from https://bit.ly/2DVJWLn. [Accessed 20 June 2018].

Wired (2018) What is Climate Change? The Definition, Causes and Effects. Retrieved from https://bit.ly/2uuksQk. [Accessed 20 June 2018].

World Bank, IFC, MIGA (2016) World Bank Group Climate Change Action Plan 20162020. Washington, DC: World Bank. Retrieved from https://bit.ly/2DWQc5y. [Accessed 10 June 2018]. 
World Bank Pubs (2018, 11 June) Low-income countries tend to be more vulnerable to, and less equipped to invest against extreme, climate impacts [Tweet]. Retrieved from https://bit.ly/2rgSh4R. [Accessed 10 September 2018].

Yeo S (2015) Climate finance: Funding a low-carbon global economy. Carbon Brief 16.07.2015. Retrieved from https://bit.ly/2PglipA [Accessed 10 June 2016]. 